Evaluation of the Non-Transient Hydrologic Source Term from the CAMBRIC Underground Nuclear Test in Frenchman Flat, Nevada Test Site

A. F. B. Tompson, R. M. Maxwell, S. F. Carle, M. Zavarin, G. A. Pawloski, D. E. Shumaker

November 18, 2005 
This document was prepared as an account of work sponsored by an agency of the United States Government. Neither the United States Government nor the University of California nor any of their employees, makes any warranty, express or implied, or assumes any legal liability or responsibility for the accuracy, completeness, or usefulness of any information, apparatus, product, or process disclosed, or represents that its use would not infringe privately owned rights. Reference herein to any specific commercial product, process, or service by trade name, trademark, manufacturer, or otherwise, does not necessarily constitute or imply its endorsement, recommendation, or favoring by the United States Government or the University of California. The views and opinions of authors expressed herein do not necessarily state or reflect those of the United States Government or the University of California, and shall not be used for advertising or product endorsement purposes.

This work was performed under the auspices of the U.S. Department of Energy by University of California, Lawrence Livermore National Laboratory under Contract W-7405-Eng-48. 


\title{
Evaluation of the Non-Transient Hydrologic Source Term from the CAMBric Underground Nuclear Test in Frenchman Flat, Nevada Test Site
}

\author{
A. F. B. Tompson, R. M. Maxwell, S. F. Carle, M. Zavarin, \\ G. A. Pawloski, and D. E. Shumaker ${ }^{1}$ \\ Atmospheric, Earth, and Energy Department \\ ${ }^{1}$ Center for Applied Scientific Computing \\ Lawrence Livermore National Laboratory \\ August 5, 2005
}




\section{TABLE OF CONTENTS}

1. BACKGROUND

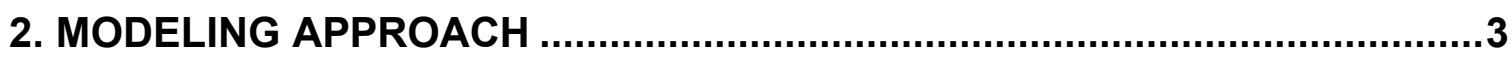

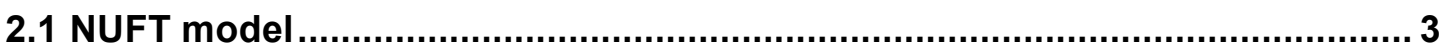

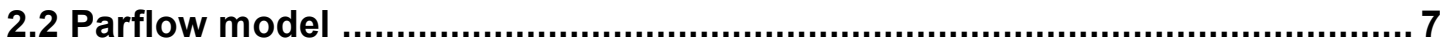

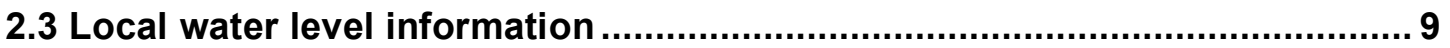

2.4 Physical configuration of the source term region ....................................... 10

2.5 Radionuclide selection and inventory ……………….............................. 10

2.5 Steady state transport model ................................................................. 12

3. STEADY STATE FLOW AND TRANSPORT MODEL RESULTS .................14

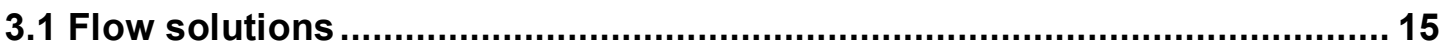

3.2 Transport solutions ..................................................................................... 17

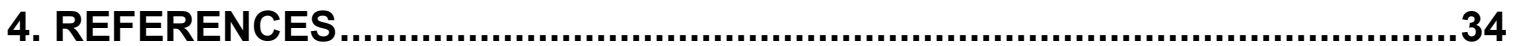

APPENDIX A: PHYSICAL MEDIUM PROPERTIES AND SPECIFICATIONS

USED IN THE STEADY STATE FLOW MODEL …......................................36

APPENDIX B: STOCHASTIC PROPERTIES USED IN THE PARFLOW

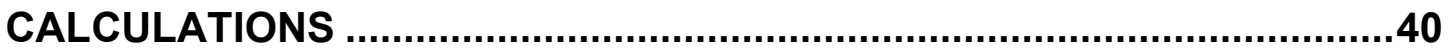

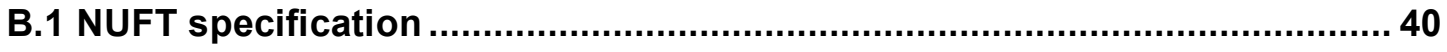

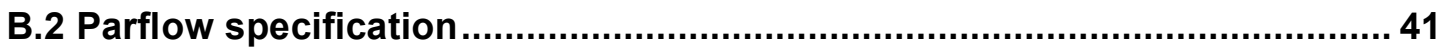

APPENDIX C: RADIONUCLIDE INVENTORY DATA USED IN THE STEADY

STATE SOURCE TERM MODEL..............................................................

APPENDIX D: THE GLASS MODEL .............................................................

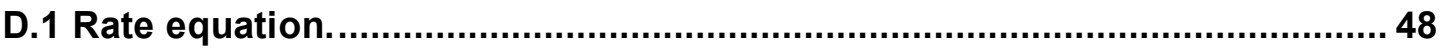

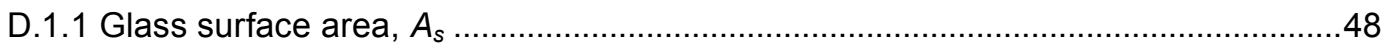

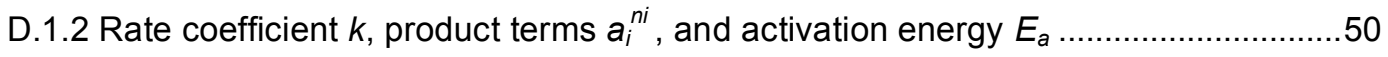

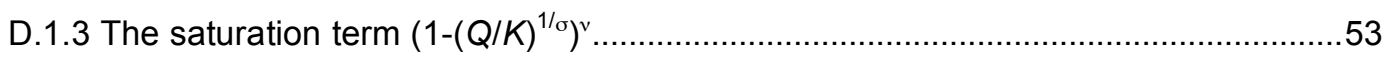

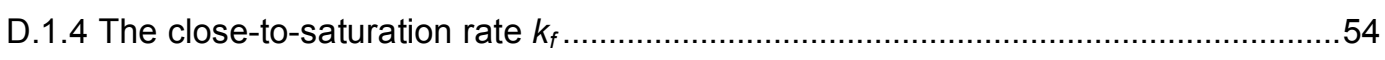


D.2. Implementation of glass dissolution model.......................................... 54

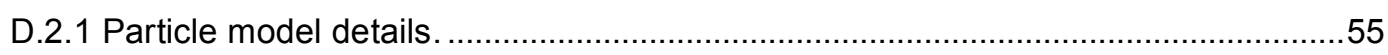

APPENDIX E: THE RADIONUCLIDE RETARDATION MODEL.......................60 


\section{Background}

Hydrologic Source Term (HST) calculations completed in 1998 at the CAMBRIC underground nuclear test site were LLNL's first attempt to simulate a hydrologic source term at the NTS by linking groundwater flow and transport modeling with geochemical modeling (Tompson et al., 1999). Significant effort was applied to develop a framework that modeled in detail the flow regime and captured all appropriate chemical processes that occurred over time. However, portions of the calculations were simplified because of data limitations and a perceived need for generalization of the results. For example,

1. Transient effects arising from a 16 years of pumping at the site for a radionuclide migration study were not incorporated.

2. Radionuclide fluxes across the water table, as derived from infiltration from a ditch to which pumping effluent was discharged, were not addressed

3. Hydrothermal effects arising from residual heat of the test were not considered.

4. Background data on the ambient groundwater flow direction were uncertain and not represented.

5. Unclassified information on the Radiologic Source Term (RST) inventory, as tabulated recently by Bowen et al. (2001), was unavailable; instead, only a limited set of derived data were available (see Tompson et al., 1999).

6. Only a small number of radionuclides and geochemical reactions were incorporated in the work.

7. Data and interpretation of the RNM-2S multiple well aquifer test (MWAT) were not available.

As a result, the current Transient CAMBRIC Hydrologic Source Term project was initiated as part of a broader Phase 2 Frenchman Flat CAU flow and transport modeling effort. The source term will be calculated under two scenarios:

1. A more specific representation of the transient flow and radionuclide release behavior at the site, reflecting the influence of the background hydraulic gradient, residual test heat, pumping experiment, and ditch recharge, and taking into account improved data sources and modeling approaches acquired or developed since the previous work (as in Pawloski et al., 2001, at the CHESHIRE site). This will be referred to as the transient CAMBRIC source term.

2. A generic release model made under steady-state flow conditions, in the absence of any transient effect, at the same site with the same RST for use in the development of simple release models at the other nine underground test sites in the Frenchman Flat CAU. This will be referred to as the steady state (non-transient) source term. 
The purpose of this report is to summarize the results of our steady state source term simulations. Additional details pertaining to these results, the transient model results, and the overall strategy, rationale, and assumptions used in the models will be documented in a separate report. 


\section{Modeling Approach}

Both the steady state and transient source term simulations are being carried out using the NUFT and Parflow groundwater flow models, coupled with a combination of streamline and/or particle-based transport models. Both flow models are being developed in the same overall physical modeling domain (Figures 1 and 2). The rectilinear geometry of the domain is rotated approximately $\mathrm{N} 41^{\circ} \mathrm{W}$ such that its longer edge is roughly parallel with the CAMBRIC ditch.

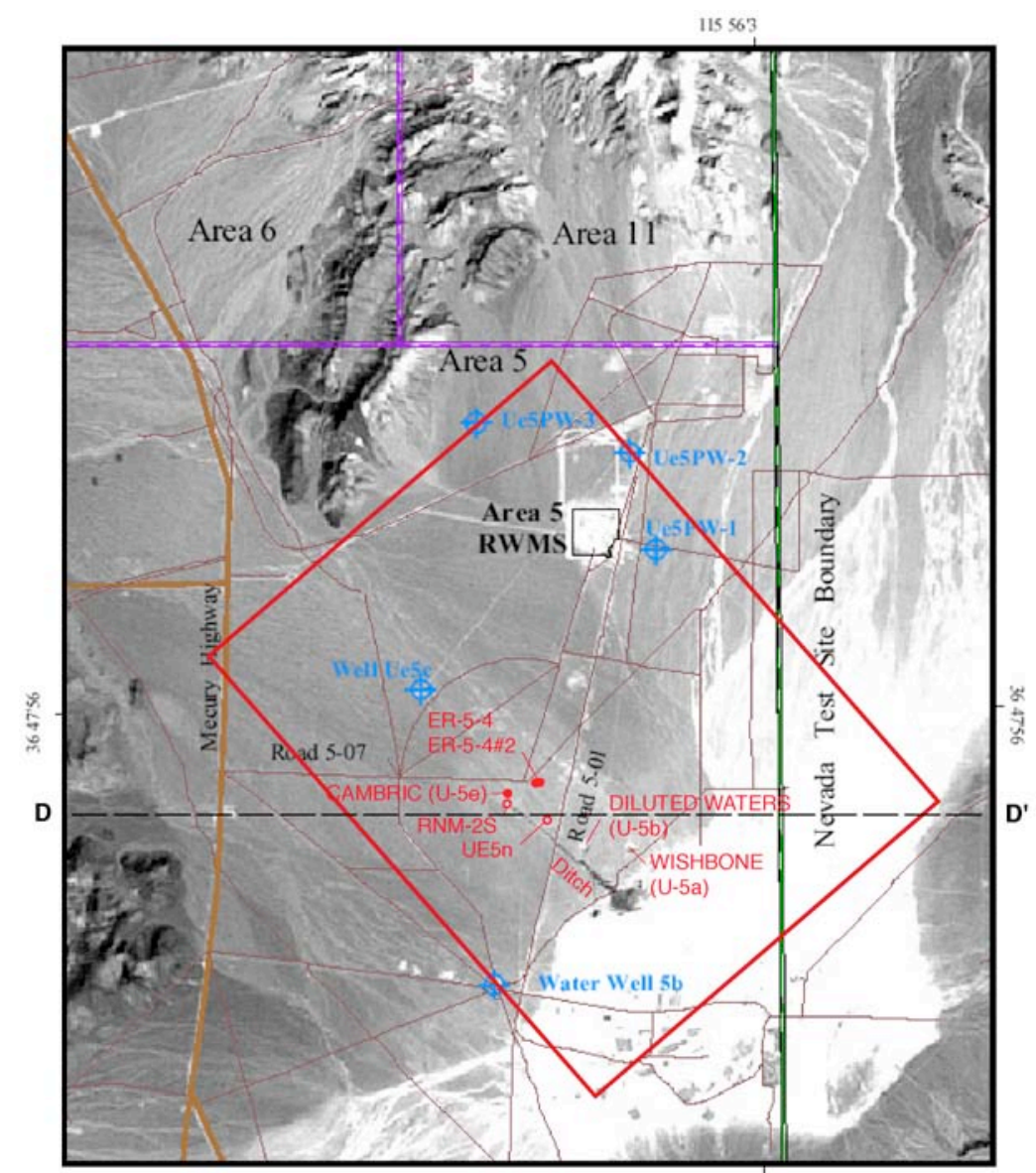

Figure 1: Plan view of the model domain for the NUFT and Parflow models.

\subsection{NUFT model}

The NUFT model was primarily used in the transient simulations to study early (0 to 10y) transient flow behavior under the effects of residual test heat. This model was also used, initially, to develop a calibrated model of the recent RNM-2S multi-well aquifer test (MWAT), conducted in 2003 (Stoller-Navarro, 2004a). As such, the results of this calibration study provide a means to improve the conceptualization and 
parameterization of alluvial materials in the vicinity of CAMBRIC for use in both the transient and steady state simulations.

The model domain was extended some distance away from the CAMBRIC site largely to remove boundary influences on drawdown behavior from the pumping test, and also as a means to specify observed head conditions at wells UE-5PW-2 and WW-5b. The vertical extent of the domain ranges from sea level to the ground surface. To accommodate the large size of the domain, the finest spatial resolution in the numerical grids of both NUFT and Parflow were restricted primarily to the alluvial zones surrounding the test cavity, pump test area, and effluent ditch (Figures 1 and 2), with telescoping grid resolution to the horizontal and deeper extremities of the domain.

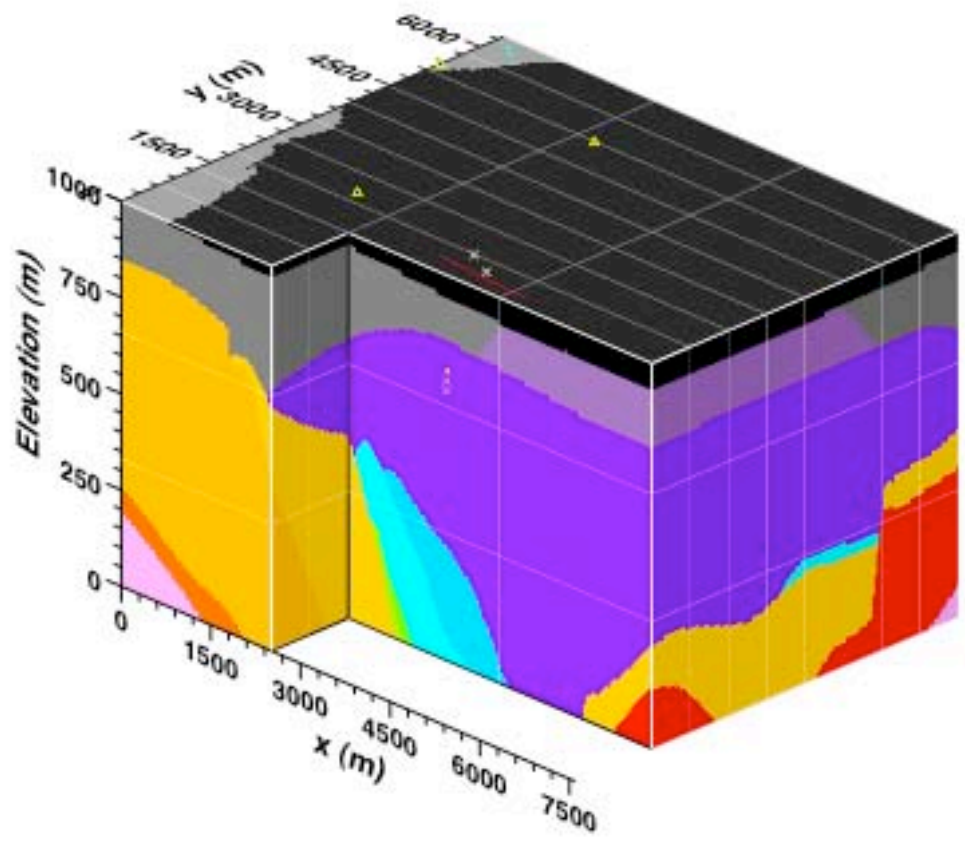

Figure 2: Flow units within the Parflow model domain as determined from the most recent hydrostratigraphic framework model for Frenchman Flat. Underlying the CAMBRIC ditch (red line segment), black corresponds to air (above ground surface); gray (L) and light purple (R) to units AA3 and PCU2T, respectively; purple to unit AA2; light blues to units AA1 and OAA1; and, on the left, yellow, orange, and pink to units LTCU, VCU, and LCA, respectively. The CAMBRIC test cavity is shown hidden (behind the exposed face) in unit AA2 $(X=3492 \mathrm{~m}, Y=1967 \mathrm{~m}, \mathrm{Z}=662 \mathrm{~m}$, ASL).

Two levels of detail were used to describe the geologic structure employed in the NUFT model. The innermost is a zoned (layered) configuration built into the AA2, AA1, and OAA1 alluvium units in the near-field around CAMBRIC, as represented in Figure $3 a$. Beyond the layered zones, the model extends to the boundaries shown in Figure 2 using a 
series of approximate buffer zones, largely unrelated to the hydrostratigraphic framework (HSU) model, with assigned gross physical properties. The alluvial layers, or hydrofacies, are similar those employed in the previous CAMBRIC HST model, yet have been refined in terms of their numbers and locations using the recent lithologic and mineralogic models developed by Warren et al. (2002) and Carle et al. (2002) based primarily on data from ER-5-4. Additional, isolated zones in the AA2 unit are used to represent the cavity, chimney, and compressed (or crush) and other altered zones of CAMBric (i.e., Appendix A), as well as a long and narrow gravel pack surrounding pumping well RNM-2S. Constant, effective-scale hydraulic properties (permeability, porosity) are assigned to each zone or layer (Table A2), as well as in each HSU unit outside of the layered units. The intrinsic grain density is considered to be $2.6 \mathrm{~g} / \mathrm{cm}^{3}$ in all layers; bulk densities may be calculated using the associated porosities.

The hydraulic properties assigned to the layered configuration produced good calibration to the RNM-2S Multi-Well Aquifer Test (MWAT). Simulated drawdown was matched simultaneously for data from observation wells RNM-1, RNM-2, and ER-5-4 ("piezometer" and "upper" screened interval) and the pumping well RNM-2S. Estimated layer permeabilities, porosities, and water contents are consistent with observed permeability variation with depth, lithologic descriptions, and other geophysical data (Ramspott and McArthur 1977; Warren et al., 2002; Stoller-Navarro, 2004a; StollerNavarro, 2004b). The layer permeabilities are also consistent with other bulk estimates based on MWAT interpretation assuming 1-D radial flow (Stoller-Navarro 2004a) or 3-D homogeneous alluvium (USGS, 2004). Additionally, the NUFT model accounts for the unusual gravel pack height in the pumping well RNM-2S, which extends to over $100 \mathrm{~m}$ above the well screen to the top of the saturated zone. This vertically extensive gravel pack likely creates a conduit between the RNM-2S pump intake and higher-permeability alluvium above the CAMBRIC working point and below the water table. Inclusion of this feature was critical for calibrating the model to the MWAT data.

Simulations of the RNM-2S multiple aquifer test were not sensitive to the hydraulic properties assigned to the altered zones (Table A2), with the exception of the compressed zone (CZ). Cavity (CAV) and melt glass zone (MG) permeabilites were based on pumping response analysis in well RNM-1 (Hoffman et al., 1977). Chimney zone permeabilities (CHM1, CHM2, and CHM3) were based on the parent alluvium horizontal permeability values (AL3, AL2b, and AL2a, respectively) with an added assumption of isotropy due to collapse. Pumping response analysis by Hoffman et al. (1977) indicates that compressed (or "crush") zone (CZ) permeability may be very low. Current model calibrations made to tritium breakthrough measurements at RNM-2S (obtained from the CAMBRIC radionuclide migration experiment) were found to be very sensitive to compressed zone (CZ) permeability. Both NUFT and Parflow non-reactive transport calibration simulations indicate that compressed zone $(\mathrm{CZ})$ permeability is significantly lower than the parent alluvium. 


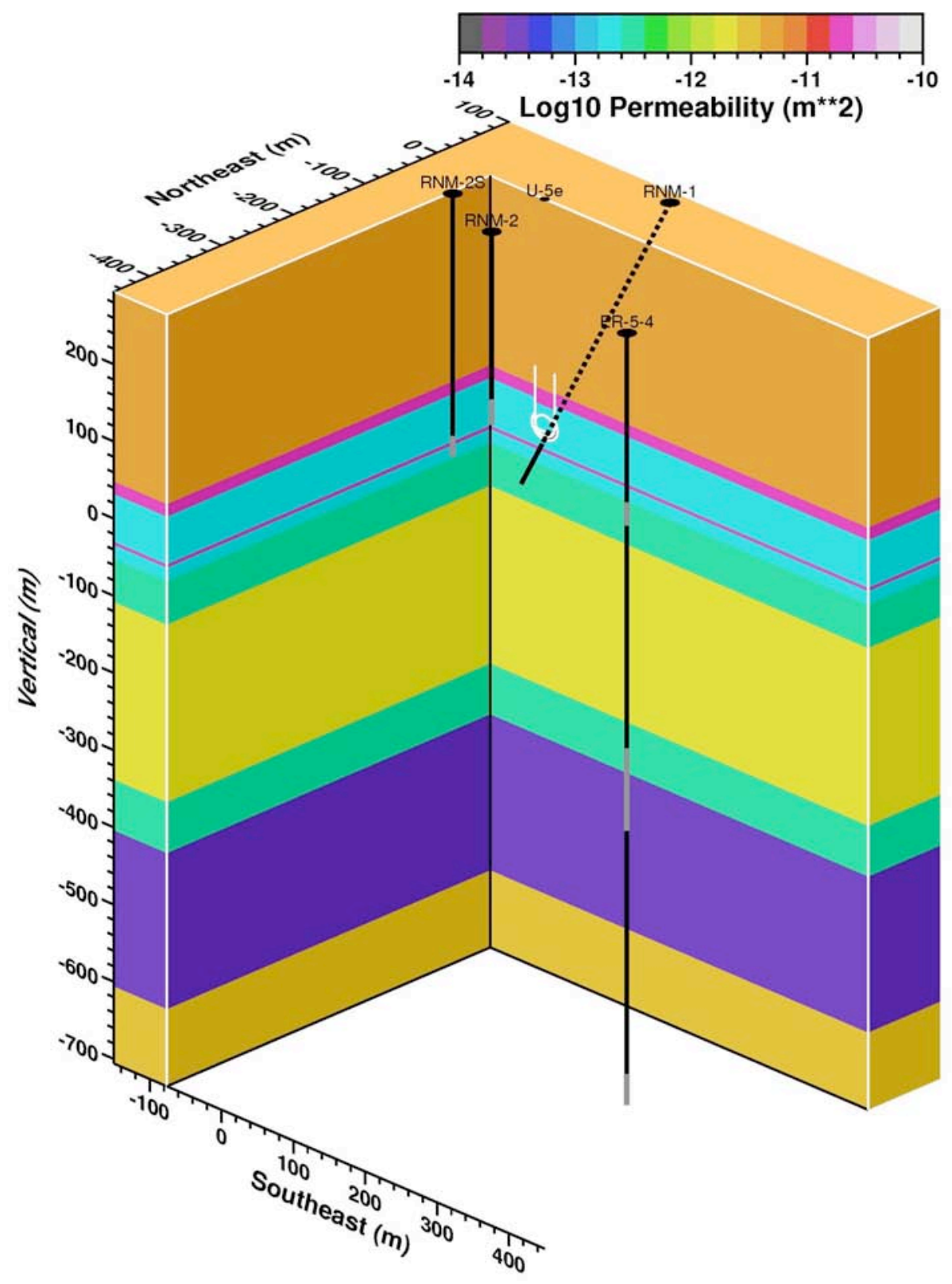

Figure 3a: Close up view of layered alluvium conceptualization (10 layers) developed in units AA2, AA1, and OAA1 for the NUFT model, based on the NUFT MWAT analysis. NUFT spatial coordinates are relative to CAMBRIC working point. Test cavity and altered zones are shown in middle. 


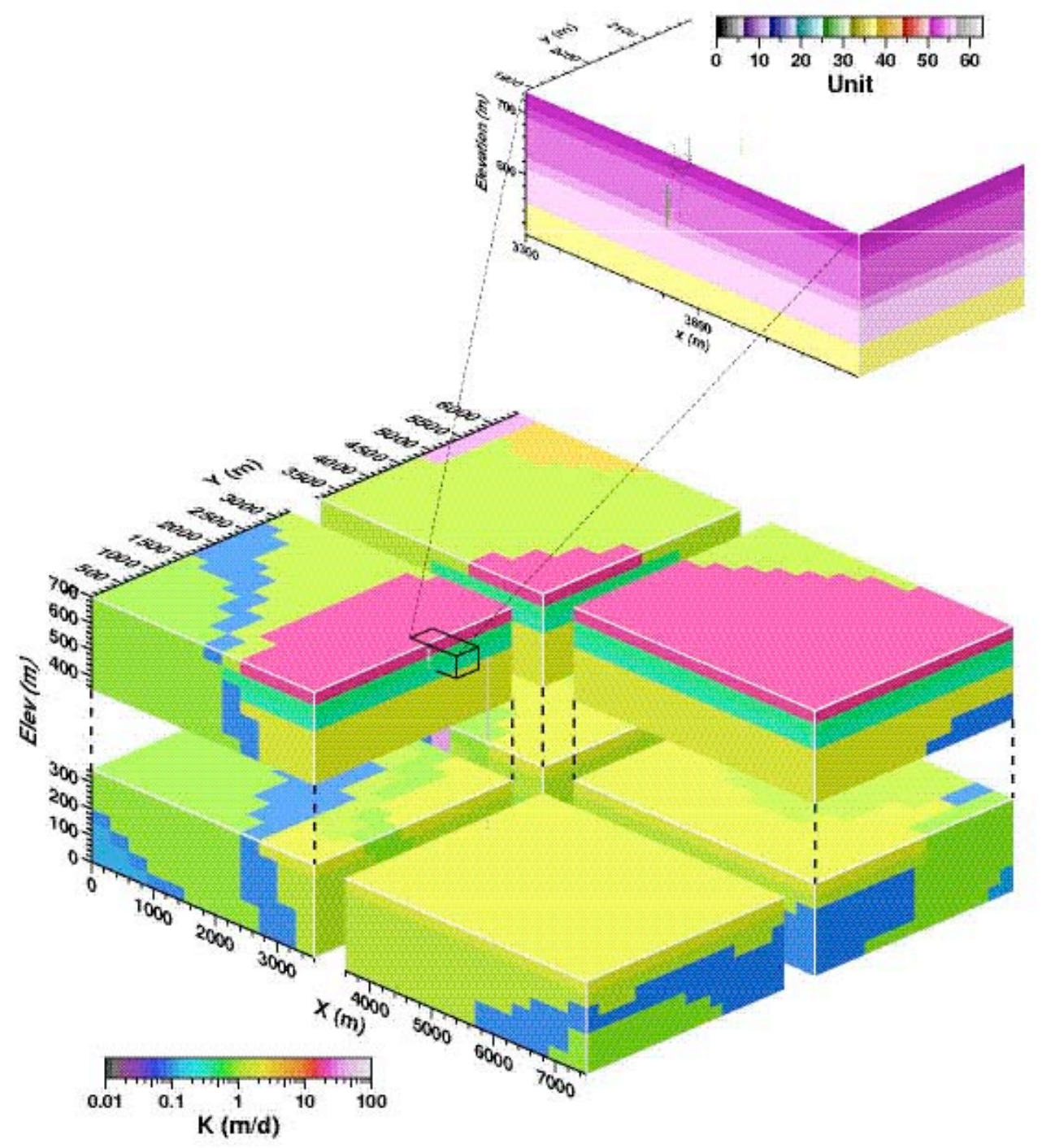

Figure 3b: Close-up view of layered alluvium conceptualization (10 layers, upper right) developed in units AA2, AA1, and OAA1 for the Parflow model, and the broader extent of the Parflow model (lower left, with hydraulic conductivities shown). The CAMBRIC test cavity and altered zones are shown in the foreground of the close-up section, where the top represents the water table.

\subsection{Parflow model}

The Parflow model is used in the transient simulations to study later time (10-1000y) isothermal flow behavior under pumping and ditch recharge conditions and in the steady 
state simulations to provide a steady flow field (isothermal, no pumping, no ditch recharge) for the entire 1000-y transport model simulation period. In the latter configuration, the water table is used as upper boundary of the model, where a no-flow condition is specified; in the former, the upper boundary is the ground surface across which ditch recharge is applied. At larger times, beyond about 200 years, the transient portion of the Parflow solution beneath the water table essentially relaxes to the steady state Parflow solution, as all pumping and ditch recharge effects will have disappeared. The rationale for using two models (NUFT and Parflow) in the transient simulation approach is based upon the fact that finer spatial discretization can be used more extensively in the Parflow model (without thermal and gas phase modeling as in NUFT) to better resolve heterogeneity within the layers. As mentioned previously, the NUFT model focuses on evaluating initial transient effects from residual test heat, which are short lived $(\sim 10 \mathrm{y})$ relative to the 1000 -year timeframe of the transport simulations.

Three levels of detail have been used to describe the geologic structure employed in the Parflow model. The outermost is the most recent hydrostratigraphic (HSU) framework model, shown in Figures 2 and 3b, exactly as is being used to develop the Frenchman Flat CAU flow model. This roughly corresponds to the buffer zone approximations used in the NUFT model. In the central portion of the domain, a layered alluvium configuration is used, just as in the NUFT model (Figure 3b). Within the alluvial layers themselves, as well as most of the altered zones near the working point, a finer level of detail is used to represent small-scale heterogeneity in the geologic material properties. Here, a stochastic model of local heterogeneity in the hydraulic conductivity distribution is modeled using a Gaussian random field representation. This is similar to the approach used in the previous CAMBRIC HST calculations (Tompson et al., 1999). The parametric characteristics of the stochastic conductivity distribution specified in the extended, unaltered alluvial layers were chosen to be consistent with available information on alluvial heterogeneity (as in Tompson et al., 1999), and also ensure that the effective (scaled-up) conductivities associated with each distribution in each layer match their homogeneous counterparts developed in the NUFT MWAT calibration (Appendix B). The homogeneous layer conductivities developed in the NUFT calibration essentially represent effective scale properties for each alluvial layer. Some typical specifications are shown in Table A2. Note that the steady state Parflow model does not utilize those layers that exist above the water table since the water table is a no-flow boundary.

The parametric characteristics in the altered zones were based on the "effective values" obtained in the NUFT model, but were adjusted slightly (Table A1) to account for grid differences and to facilitate additional calibration of the model and subsequent transport simulations under transient pumping conditions. 


\subsection{Local water level information}

The most recent "contemporary" water level data (provided by Nicole DeNovio, personal communication) from wells in the model domain were used to drive and interpret various versions of the steady state NUFT and Parflow model simulations. As previously mentioned, the NUFT analysis of the 2003 MWAT was carefully performed to simultaneously reproduce observed transient drawdown and recovery profiles in RNM-1, RNM-2, RNM-2S and ER-5-4 (upper, lower).

Both the Parflow and NUFT models were developed to be consistent under steady state conditions (isothermal, no pumping) with an apparent NNE to NE hydraulic gradient between 0.0003 and 0.0013 (Stoller-Navarro, 2004a) in the RNM-2S, ER-5-4 (main) and UE5n well triangle (see Section 3.1 below). This is approximately consistent with recent water level data, although we recognize this gradient could have shifted historically due to slight water level fluctuations. Notably, the apparent NNE to NE hydraulic gradient is also consistent with the discovery of tritium identified at the $300 \mathrm{~m}$ depth in ER-5-4 during its construction (suggesting its possible migration from the CAMBRIC cavity area), even though this observation could itself be suspect due to detection limitations.

For the Parflow simulations, water level data at WW5b and Ue5PW2 were used as a starting point to specify constant head conditions along the SW and NE sides of the model domain. These head conditions were then varied to calibrate the Parflow model predictions of steady-state water level to observations in 5 wells: RNM-2S, RNM-2, UE-5n, ER-5-4, and ER-5-4piezometer. The calibration was stopped when the RMS error between observations and model predictions was less than $0.3 \mathrm{~m}$. Further discussion of these predictions along with the presentation of the results may be found in Section 3.1. No-flow conditions were used along the NW and SE sides and the bottom of the domain. For the NUFT simulations, the local hydraulic gradient near CAMBRIC was approximated without calibration to WW5b and Ue5PW2 because the NUFT model focuses on distances within a few hundred meters of CAMBRIC. No-flow conditions were used along the NW and SE sides and the bottom of the domain, except that a constant head and temperature boundary condition was added to the bottom to account for the vertical gradient of 0.0031 measured between well ER-5-4 upper and lower completion zones (Stoller Navarro, 2004a) and the geothermal gradient. In the steady state Parflow model, no-flow conditions were also specified at the (fixed) water table, whereas in transient simulations, more flexible conditions were used.

We recognize that these specifications are approximate, but the focus was to develop the most accurate results in the local CAMBRIC area, as opposed to an emphasis on the entire domain 


\subsection{Physical configuration of the source term region}

The physical configuration of the source term region used in both the transient and steady state models is shown in Figure A1 in Appendix A. We consider a spherical cavity (CAV) zone centered at $662 \mathrm{~m} \mathrm{ASL}$, a melt glass (MG) zone in the lower portion of the cavity, a compressed (or "crush", CZ) zone forming a shell outside of the cavity, and three portions of a collapsed chimney (CHM1, 2, 3) zone that correspond to collapsed alluvium. The portion of the compressed zone $(\mathrm{CZ})$ shell volume intersecting the chimney (CHM1) is called the pimento (PIM) region. It was assigned the physical properties of the CHM1 zone, yet populated with that portion of the radiologic inventory assigned to the exchange volume, which includes the entire $\mathrm{CZ}$ and cavity zones as described below.

The original interpretations of high intensity gamma-log surveys from drill back holes performed immediately after the CAMBRIC test suggest a cavity radius of $13.4 \mathrm{~m}$. This value was used in the current model specification, even though it differs from the $10.9 \mathrm{~m}$ value identified in the CAMBRIC migration study (Hoffman et al., 1977). Interpretations of post-test gamma surveys suggest an exchange volume radius of $18.1 \mathrm{~m}$, which is used as the radius of the compressed zone.

Based upon the $0.75 \mathrm{kt}$ yield of the test, we have estimated the mass of melt glass to be $5.25 \times 10^{5} \mathrm{~kg}$, with an intrinsic density of $2.5 \mathrm{~g} / \mathrm{cm}^{3}$. This is smaller than the mass estimated in the previous HST simulations because it is based on a smaller, 700-mt glass produced per kt-yield criterion. Based upon gamma log interpretations, the melt glass zone in the steady state and transient models was represented as a mixed glass/collapsed alluvium zone in the lower hemisphere of the cavity (Figure A1, Appendix A). This differs from previous models in which a confined zone of pure melt glass was considered. The solid glass volume fraction is determined by dividing the volume of the melt glass by the volume of the (discretized) melt glass zone, with the remaining volume fraction considered as collapsed alluvium and porosity (details are provided in Appendices A and B).

In the steady state model, components of the initial RST were partitioned into solid melt glass in the melt glass (MG) zone and into groundwater in the cavity (CAV), compressed (CZ), and MG zones. As mentioned above, this specifically includes the portion of the chimney (CHM1) zone overlapping the $\mathrm{CZ}$, similar to previous efforts (e.g., Pawloski et al., 2001). The porosities of the zones comprising the source term region are listed in Appendix A.

\subsection{Radionuclide selection and inventory}

The radionuclide inventory used for the steady state source term simulations is based upon the unclassified radiologic source term (RST) data for Frenchman Flat tabulated in the report of Bowen et al. (2001). Specifically, an average RST was developed by 
dividing the reported Frenchman Flat inventoriea by the number of underground tests (10) conducted there. A total of 36 radionuclides distributed in 13 unique classes are considered, and they have been selected using the criteria developed in the previous CHESHIRE HST report (Pawloski et al., 2001; see also Appendix C). Additional or differing inventory data appearing in Hoffman (1977) or the previous HST report are not considered in the steady state simulations, but could be considered through mathematical superposition of the existing results.

It is important to recognize that the data of Bowen et al. (2001), as tabulated, are decay corrected to September 23, 1992. In the steady state model, the Bowen et al. inventories were decay corrected to coincide with time zero for CAMBRIC, May 14, 1965. This is necessary to achieve an appropriate RST mass balance as a function of time. This decay correction was particularly important for the decay chain ${ }^{241} \mathrm{Pu} \rightarrow{ }^{241} \mathrm{Am} \rightarrow{ }^{237} \mathrm{~Np}$ since it results in substantially lower initial ${ }^{241} \mathrm{Am}$ mass than reported in Bowen et al. (2001) at the CAMBRIC $t_{0}$ (Figure 4).

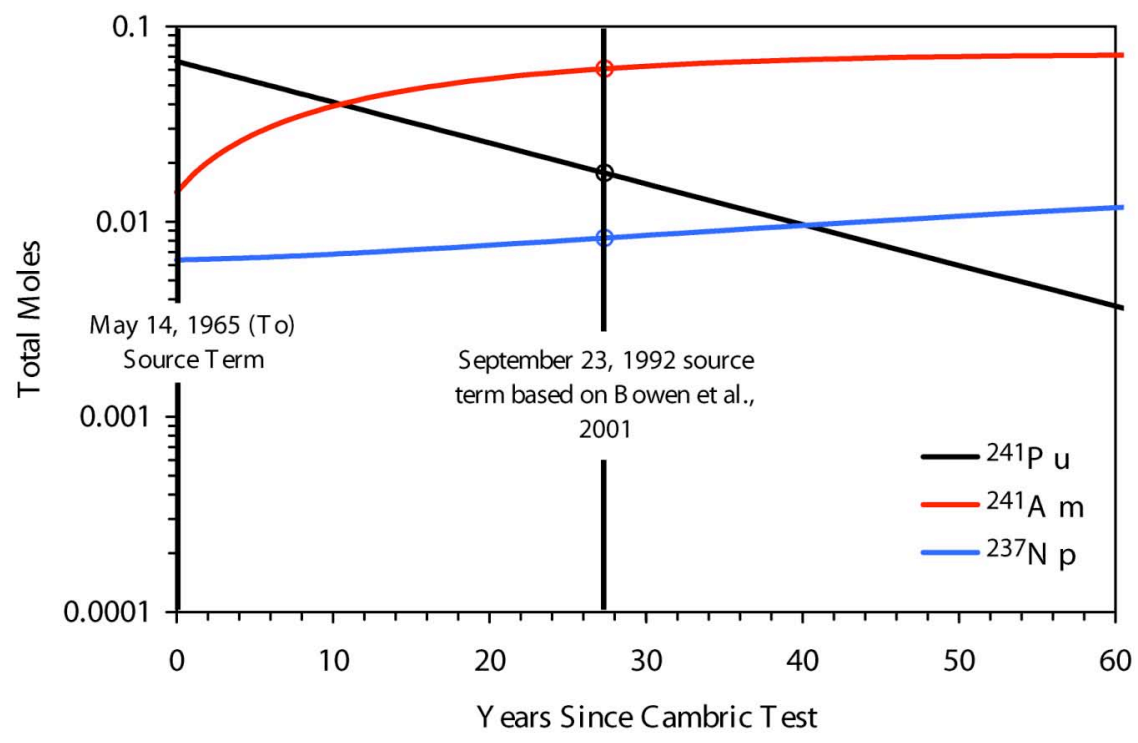

Figure 4: Decay correction of Bowen et al. (2001) RST to CAMBRIC $t_{0}$ for the ${ }^{241} \mathrm{Pu} \rightarrow{ }^{241} \mathrm{Am} \rightarrow{ }^{237} \mathrm{~Np}$ decay chain. 


\subsection{Steady state transport model}

Transport simulations in the steady state model were developed from a particlebased transport model (Pawloski et al., 2001). Initial aqueous and glass-bound radionuclide concentrations were developed as described in Appendix C.

Although the steady state simulations are based upon an isothermal flow model, the temperature-dependent melt glass release functions were determined from a nonisothermal temperature history derived from the corresponding NUFT simulation developed for the transient source term model. Because of the sensitivity of dissolution to temperature, we felt it was a more representative way to describe the melt glass release function at all test sites in Frenchman Flat. Additional details of the melt glass release function are provided in Appendix D, and a separate table of the temperature history used in this model is also available.

In the particle model, surface complexation and ion exchange reactions between radionuclides and reactive minerals in the AA2 alluvium HSU are treated with a spatially variable sorption or partitioning model (Pawloski et al., 2001). As such, specification of the spatial distribution of reactive minerals is equivalent to specification of the spatial distribution of effective partitioning $(\mathrm{Kd})$ coefficients for each radionuclide class. Recent analyses of reactive minerals in the Frenchman Flat alluvium (Carle et al., 2002) have been used to estimate the magnitude and spatial distribution of partitioning coefficients in the AA2 alluvium pertinent to many of the reactive radionuclides considered in this study. (As in the past, the lack of sufficient sorption data for particular radionuclide and mineral pairs will prevent their being considered as reactive in this analysis). Contrary to the reactive models used in the original CAMBRIC HST simulations, Kd distributions were more spatially uniform in their distribution. Specifically, mean values were specified in each alluvial layer (e.g., Table E2) along with a spatially uncorrelated fluctuation based upon the standard deviation of the observation variability. It was not possible in the new analyses to identify significant spatial correlation of reactive mineral (or $\mathrm{Kd}$ ) variability, even though variation across the alluvial layers was observed (and used to distinguish the layers in the first place). Additional details of these analyses and the coefficients used are presented in Appendix E. Colloidal-facilitated transport is not considered significant at CAMBRIC and is not represented in the steady state model. 


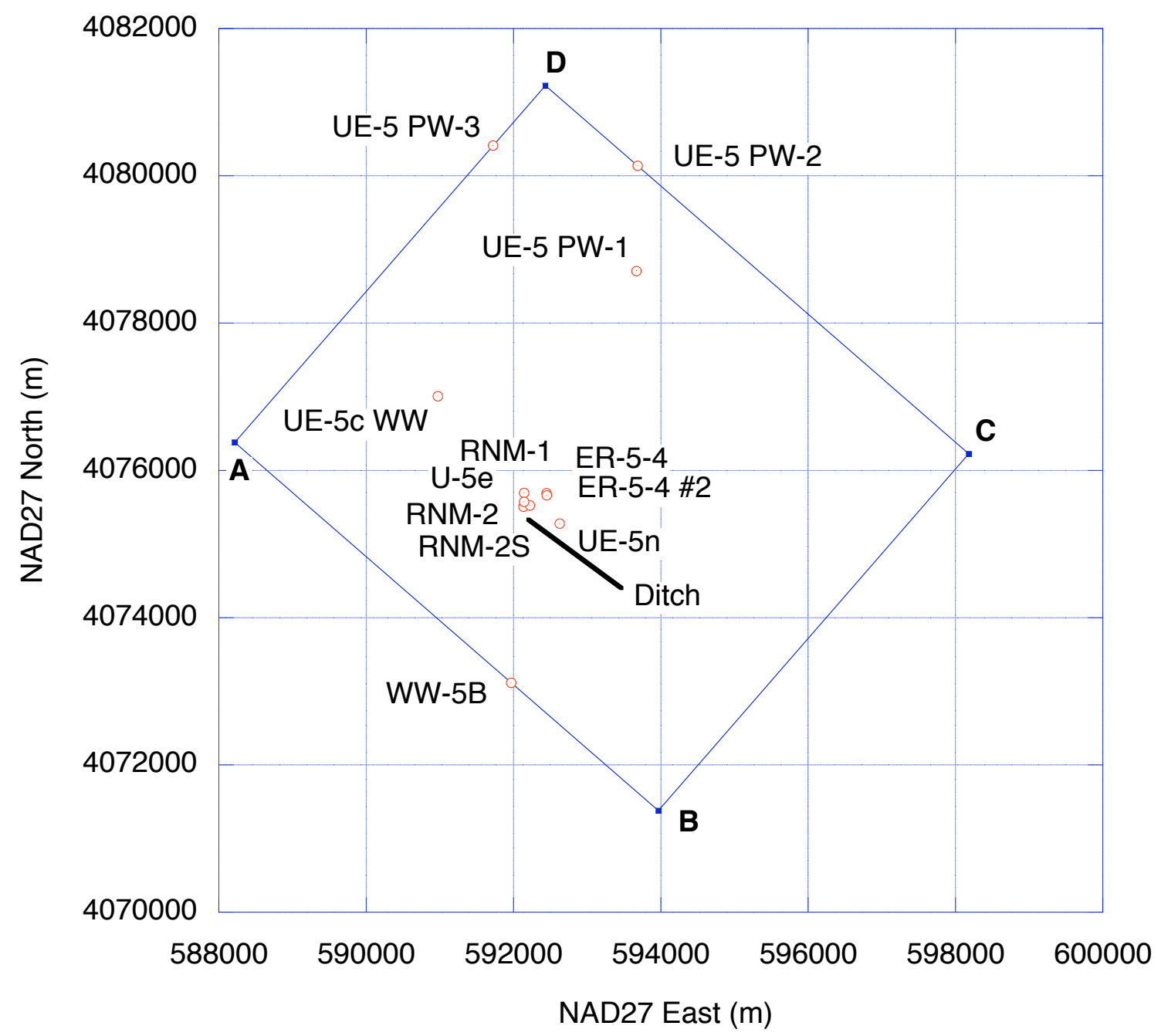

Figure 5. Plan view of the model domain showing the ditch and relevant wells and boreholes. 


\section{Steady State Flow and Transport Model Results}

Figures 5 and 7 show plan views of the model domain at two levels of detail. The ABCD corners can be compared with Figure 1 . The steady state Parflow model utilized a transformed coordinate system, rotated $\mathrm{N} 41^{\circ} \mathrm{W}$, and translated so that point " $\mathrm{A}$ " is the $\mathrm{X}, \mathrm{Y}$ origin and segment $\mathrm{AB}$ corresponds to the translated $\mathrm{X}$ axis (the coordinates shown in Figures 2 and 3 pertain to the translated system). A total of 50 geostatistical realizations of the hydraulic conductivity and effective partitioning $(\mathrm{Kd})$ coefficient distributions were developed for the domain, as described above and in Appendices A and $\mathrm{D}$. Note that heterogeneous property values were also specified in the altered zone hydrofacies surrounding the CAMBRIC working point.

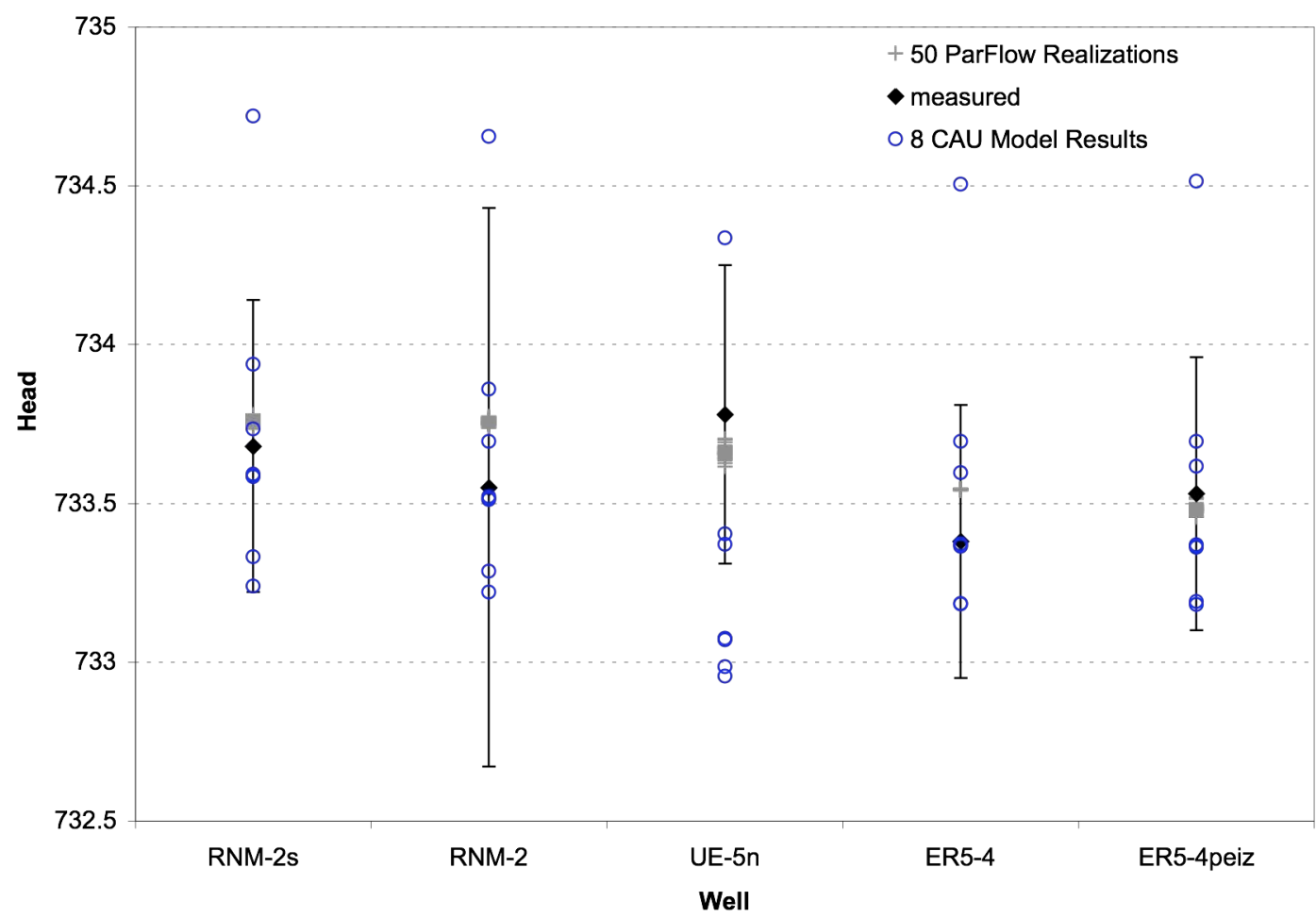

Figure 6. Simulated head ranges from the Parflow model and larger scale CAU model at wells UE-5n, RNM-2S, RNM-2, UE-5n, and ER-5-4 (upper, and piezometer), as compared with measured (contemporary) values. Note the extent of variability in the measured values. 


\subsection{Flow solutions}

A total of 50 flow solutions were obtained from the Parflow model, one for each realization, and each corresponding to the boundary conditions described earlier. Specified constant head values along the AB and CD boundaries (Figure 5) were adjusted slightly, within cited measurement uncertainties, as a means to calibrate the simulated heads in wells UE-5n, RNM-2S, and ER-5-4 upper (as identified at the open interval locations) to their measured (contemporary) values (Figure 6). A single homogeneous model (using the effective conductivities shown in Appendix A) produces similar results. Also shown in Figure 6 are head solutions obtained from eight calibrated Frenchman Flat CAU flow model runs, conducted at a larger scale (Nicole Denovio, Stoller-Navarro, personal communication). Note that, in general, the 50 Parflow solutions are more closely clustered than the CAU solutions or the well measurement variabilities. The CAU model results are more variable than the Parflow counterparts because they reflect differences in model scale, boundary conditions applied, and the underlying hydrogeologic framework model used. Uncertainty in the well observations themselves is due, in part, to transient fluctuations and measurement errors.

In Figure 7, a close-up view of the model domain is shown. Attached to well U-5e is an arrow pointing in the "observed" direction of flow, as determined from the hydraulic gradient apparent in the mean (contemporary) water level data in 3 wells: UE-5n, RNM2S, and ER-5-4 upper. In addition, a range of analogous water flow directions is shown, as determined from the simulated water levels in the same 3 wells from the 50 Parflow flow realizations (green), the eight CAU model results (blue), and 400 random head observations falling within the measured uncertainties or ranges indicated in Figure 6 (gray).

The directions of flow predicted by Parflow are generally perpendicular to the ditch, parallel with the rotated $\mathrm{Y}$-axis and the AD boundary segment in Figure 5, and further to the northeast of the (mean) observed gradient. Their apparent magnitudes (0.0006 to $0.0008)$ are generally smaller than the observed measured magnitude (0.001). These differences are evident in the figure by the relative (scaled) distance between the green dots and the U-5e well location. Notably, they do lie within the cloud of random directions that reflect uncertainty in the measured water level data in UE-5n, RNM-2S, and ER-5-4 upper. The directions of flow predicted by the CAU simulations, on the other hand, generally point to the east-southeast and lie on the periphery of the same cloud of random directions. These discrepancies are likely the result of the difference in scale between the CAU and HST models, as well as the generally low magnitude gradient that is present. 


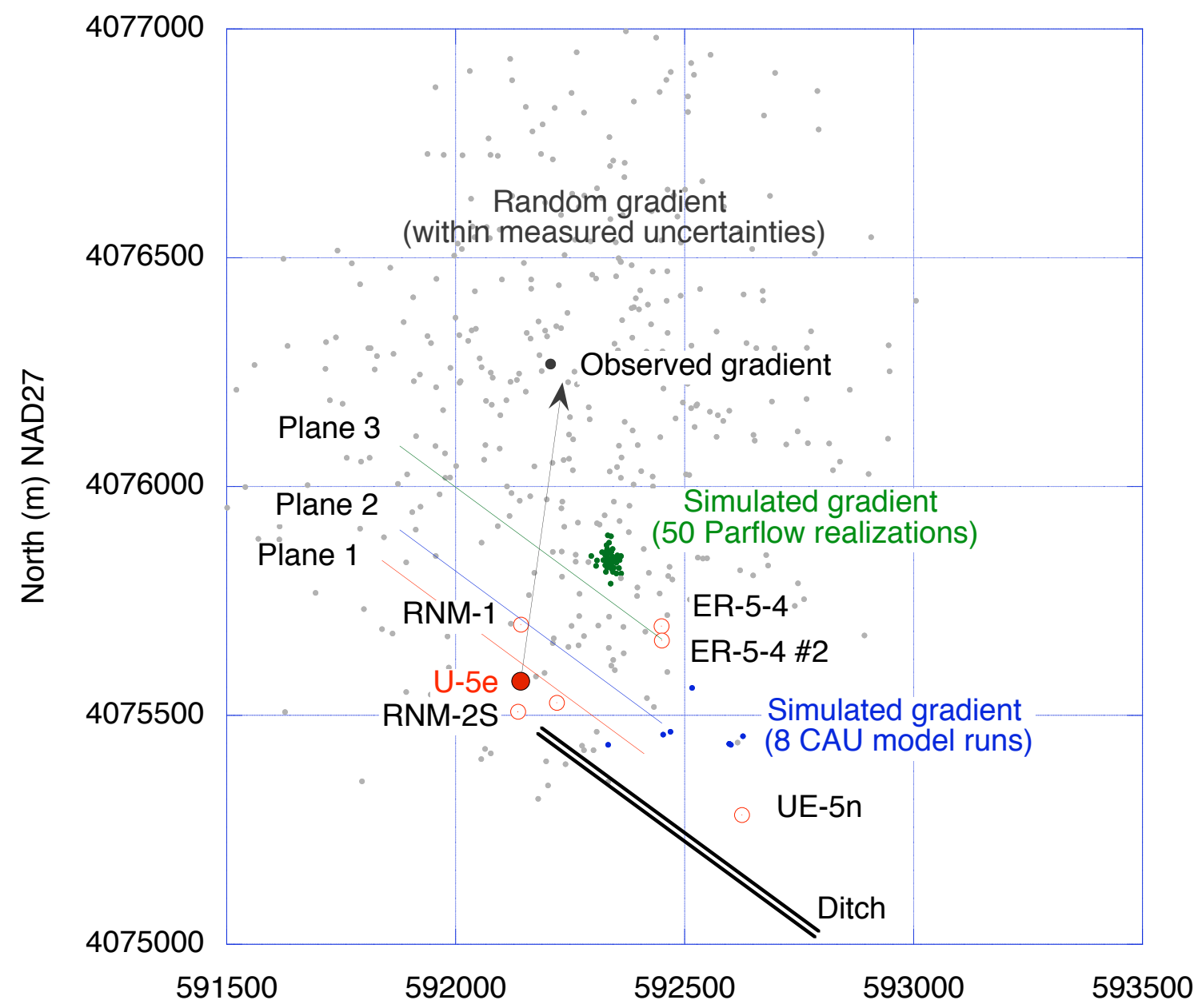

East (m) NAD27

Figure 7. Close-up view of the model domain showing the ditch, relevant wells, and locations of three breakthrough planes. Approximate flow directions away from U-5e, as based upon water levels in UE-5n, RNM-2S, and ER-5-4 upper, are shown as computed from the mean observations (black), the 50 Parflow realizations (green), the $8 \mathrm{CAU}$ model runs (blue) and a series of 400 random head observations falling within the measured uncertainties or ranges indicated in Figure 6 (gray). 


\subsection{Transport solutions}

Three parallel breakthrough planes were identified (Figure 7) across which radionuclide fluxes would be computed for all radionuclide classes in all 50 flow model realizations. The planes are vertical and parallel to the ditch and the $\mathrm{AB}$ side of the domain (Figure 1) and cross through (or close to) wells RNM-2, RNM-1, and ER-5-4 \#2. They are, respectively, 16, 93, and $269 \mathrm{~m}$ away from U-5e.

Mean breakthrough fluxes (as averaged over all 50 realizations) for all radionuclides are shown in Figures 8-11, expressed either in mol/y or $\mathrm{Ci} / \mathrm{y}$. Separate data tables reflecting the mean, $5^{\text {th }}, 50^{\text {th }}$, and $95^{\text {th }}$ percentile distribution of breakthrough results are also available. Note that a mean breakthrough will over-represent dispersive behavior that may be observed in single-replicate simulations. Radioactive decay (corrected to 1992) is included in these results.

Figures 12-16 show several selected two- and three-dimensional snapshots of the tracer and total uranium plumes (with no decay correction) moving away from the cavity. These represent more clearly the nature of plume evolution and/or retention in the lower permeability cavity in addition to the local flow conditions resulting from geologic heterogeneity downgradient of the cavity system. It is also clear how the plumes move in the apparent direction(s) of flow indicated in Figure 7. 

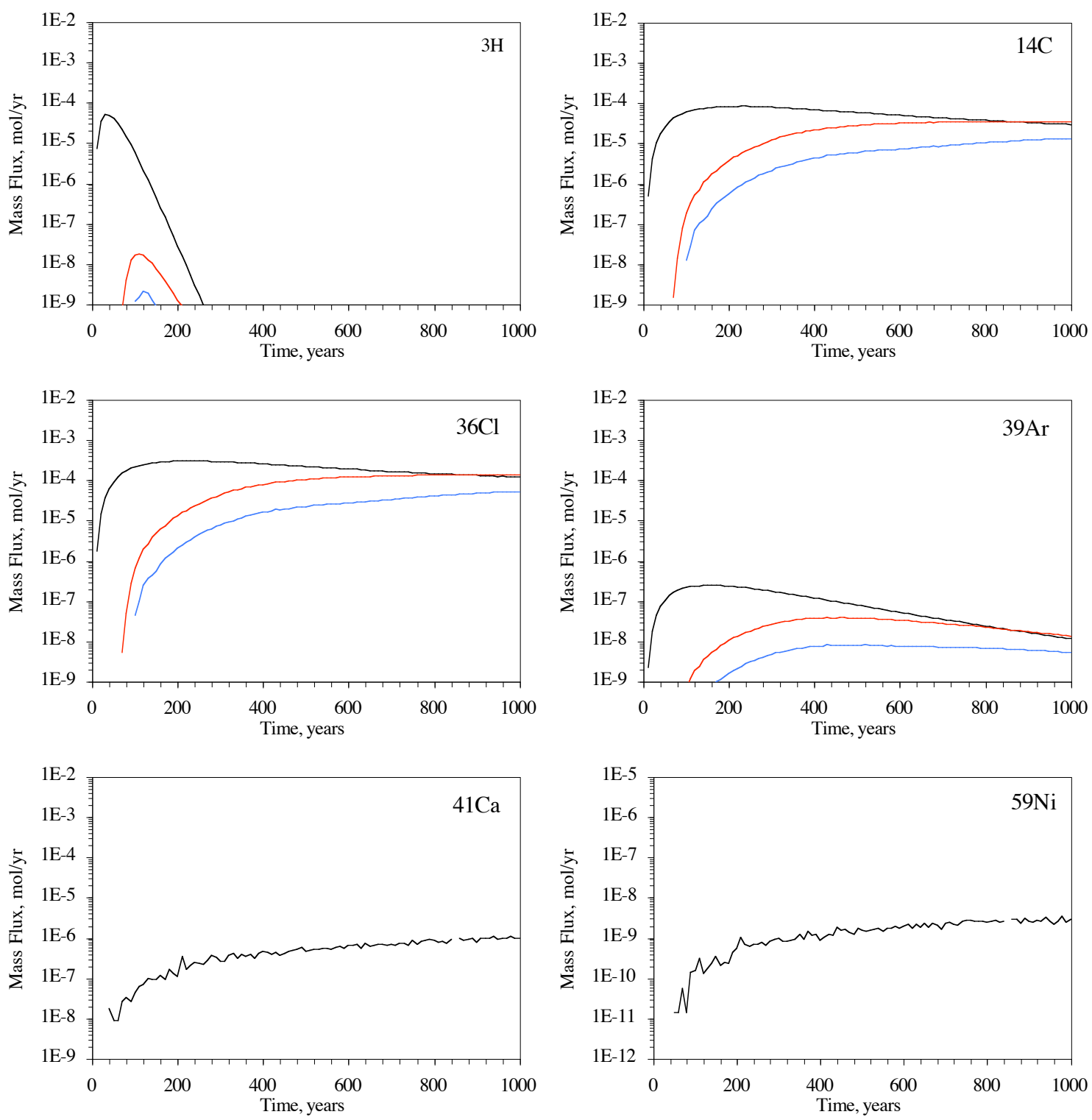

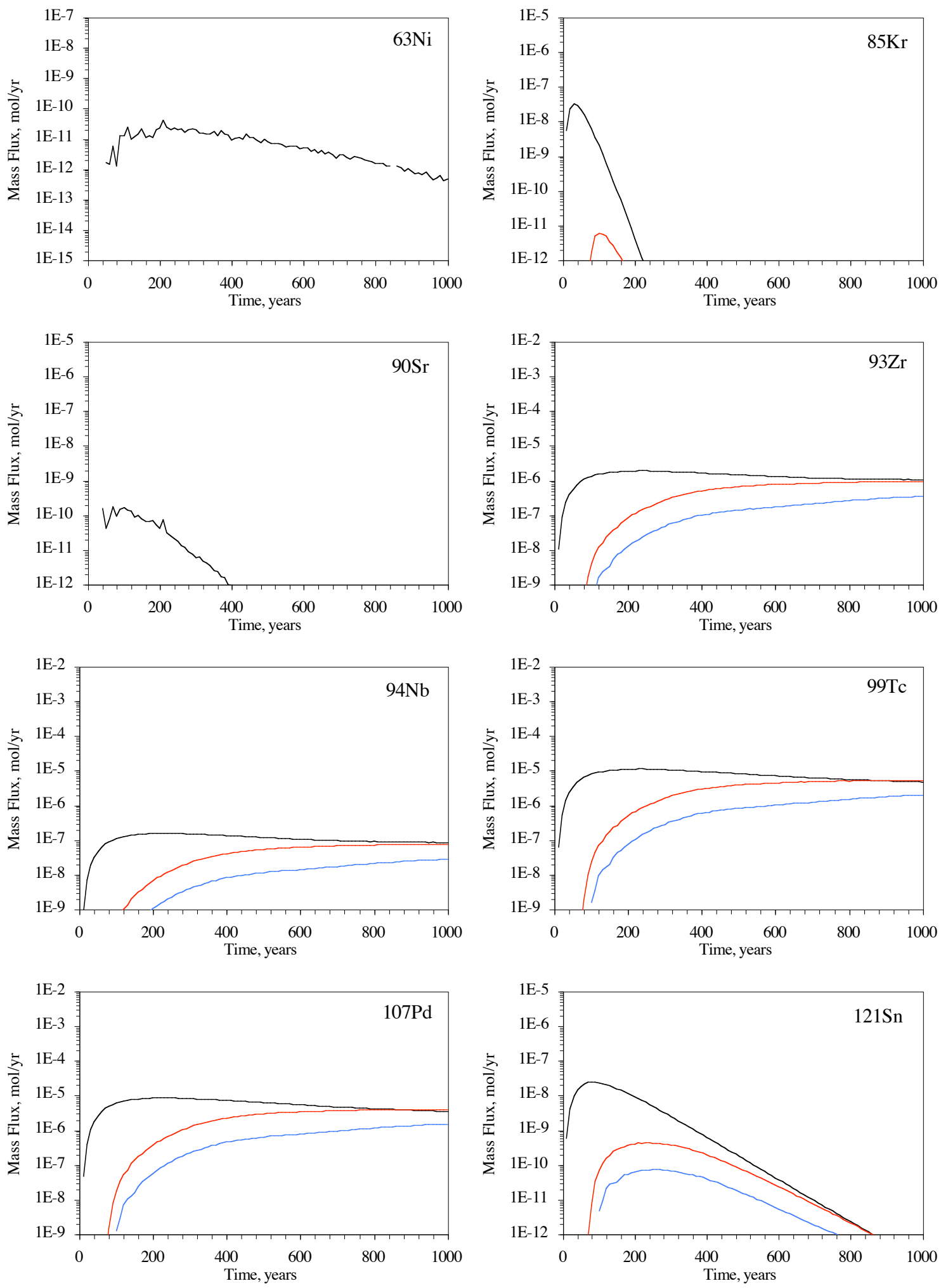

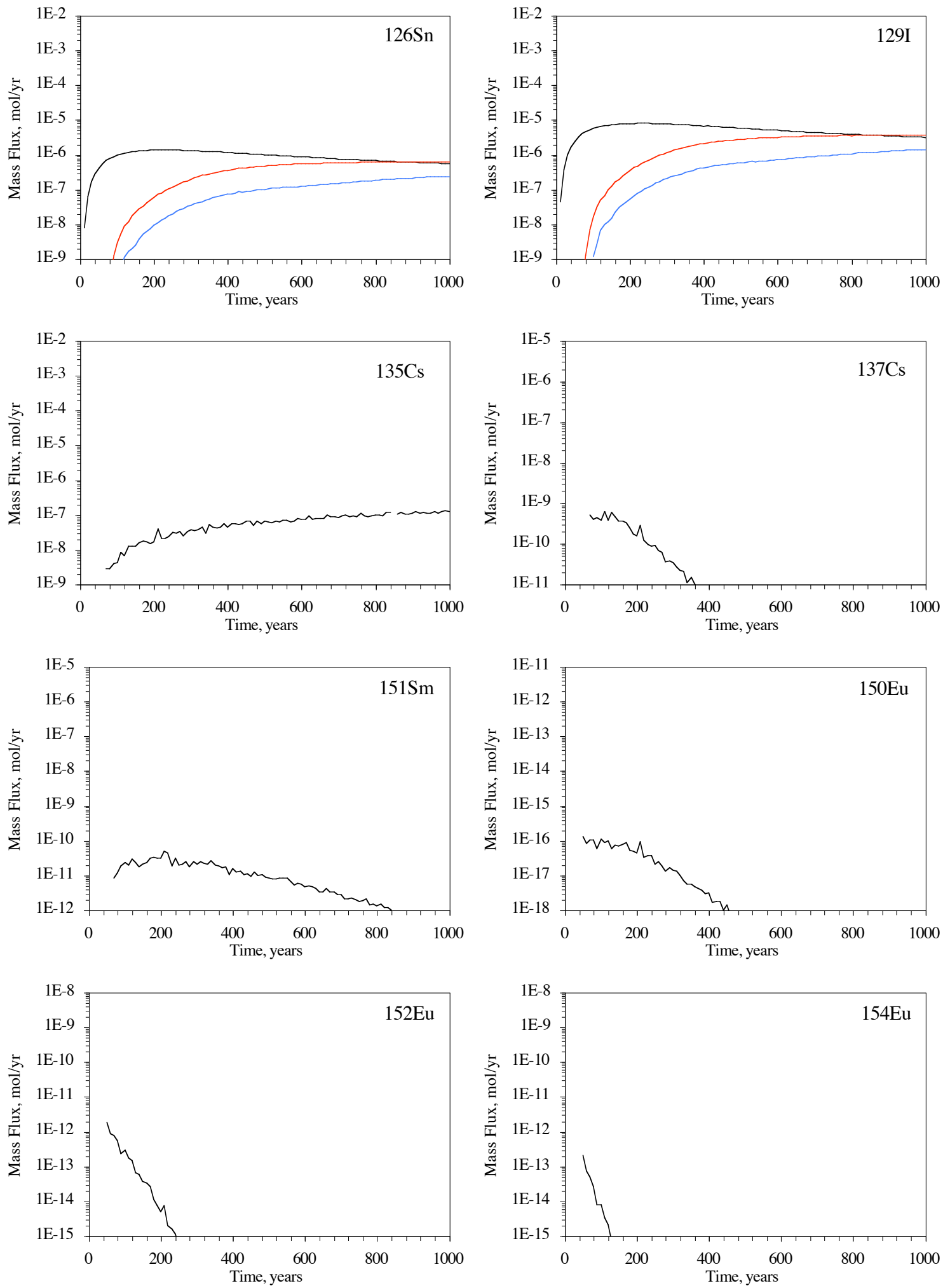

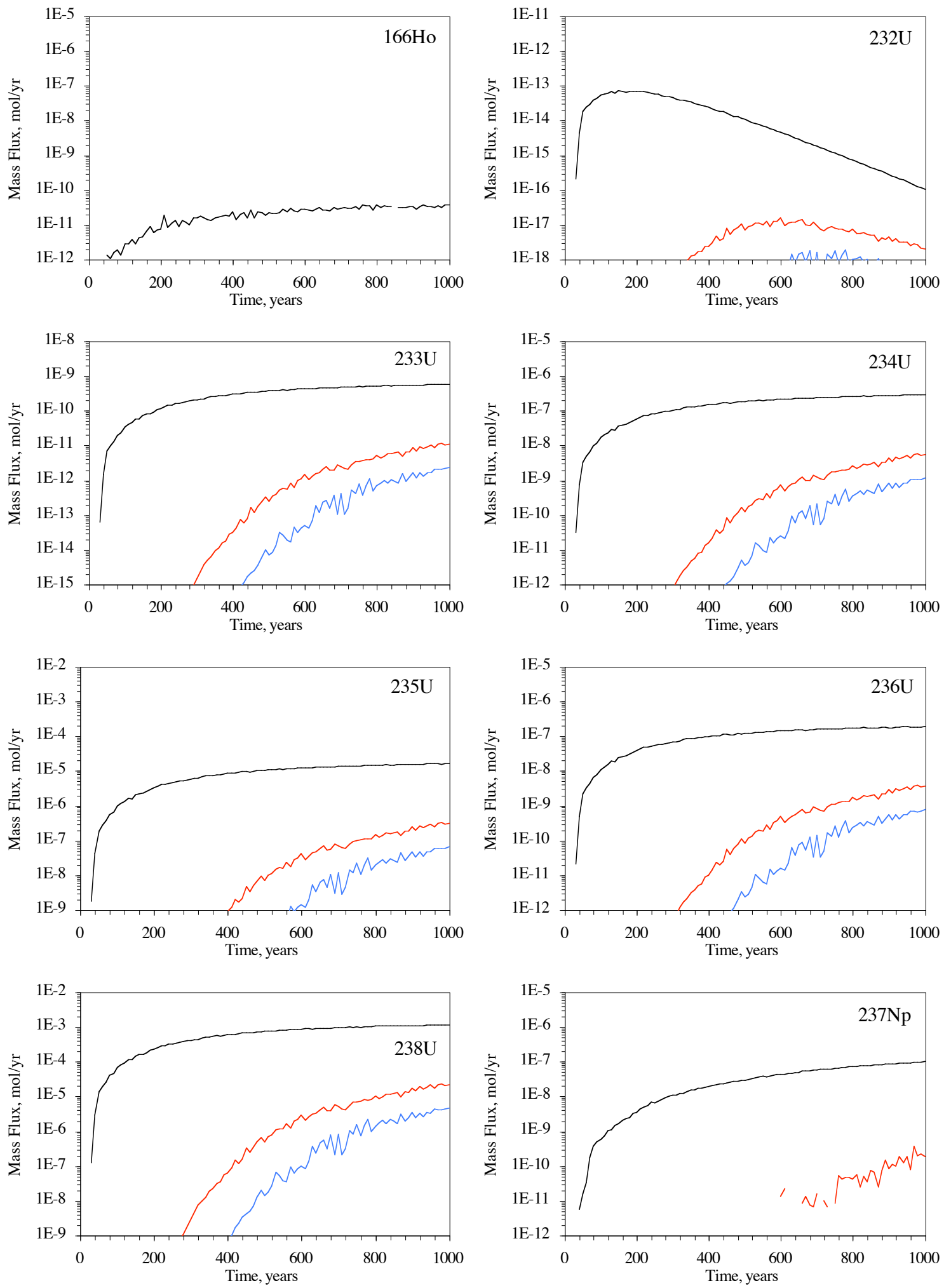

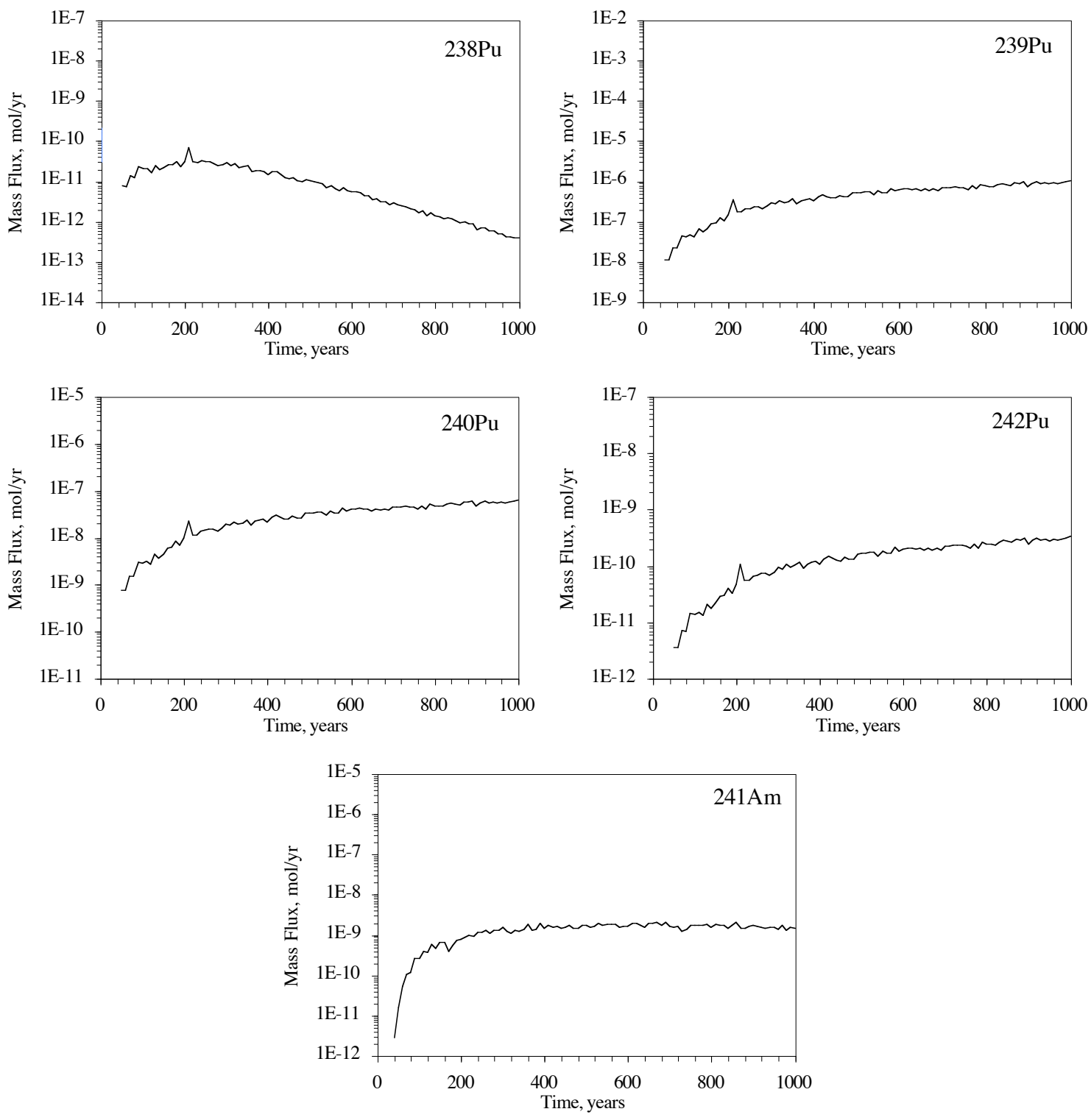

Figure 8. Mean breakthrough flux profiles $(\mathrm{mol} / \mathrm{y})$ at the three downstream boundaries (black $=1$, red $=2$, blue $=3$; Fig. 7 ) as determined for all radionuclides included in the steady-state model. Decay since $t_{0}$ included. Note that ${ }^{241} \mathrm{Am}$ was not predicted to reach any of the breakthrough planes over the 1000-year simulation time frame. 

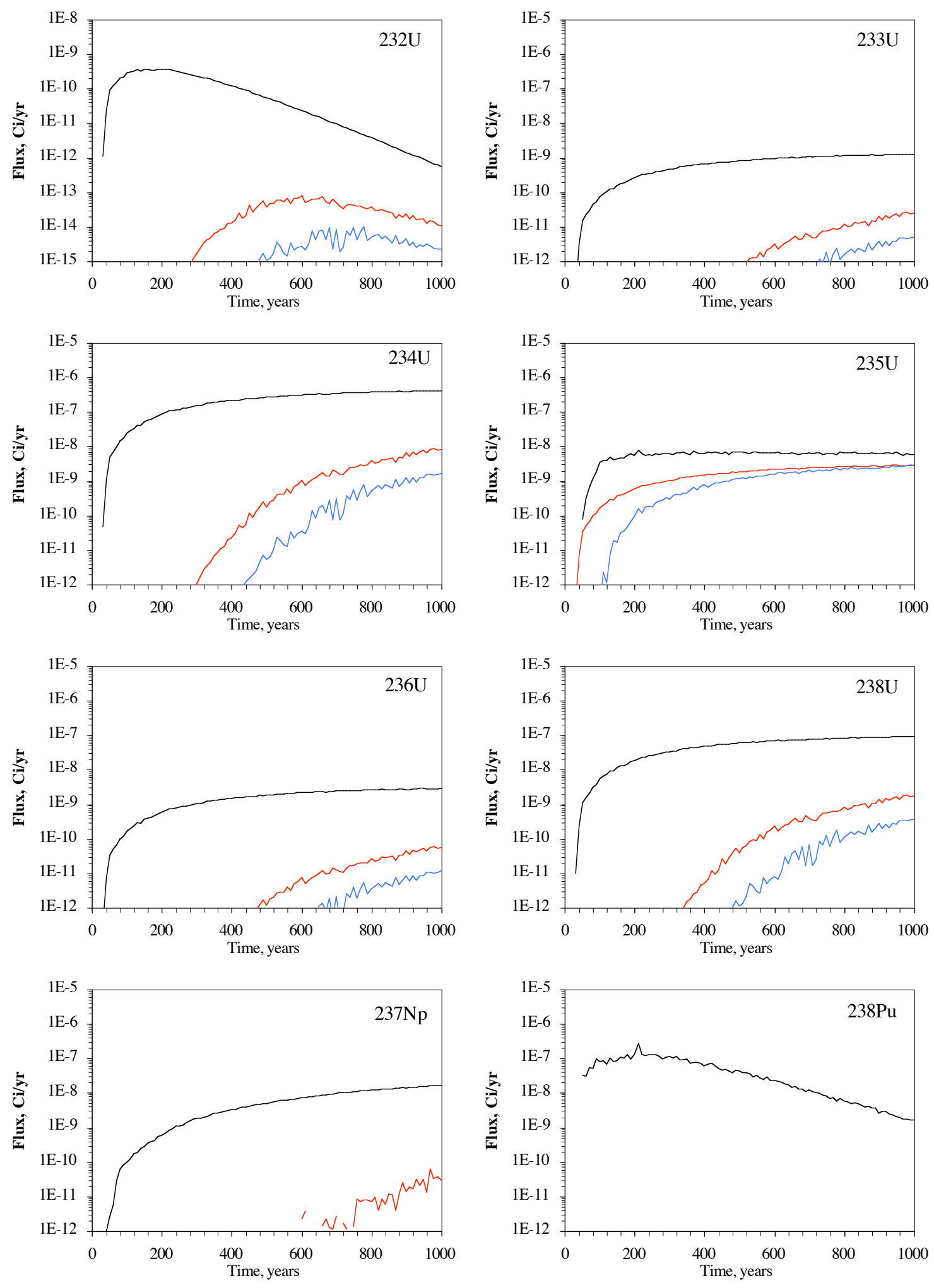

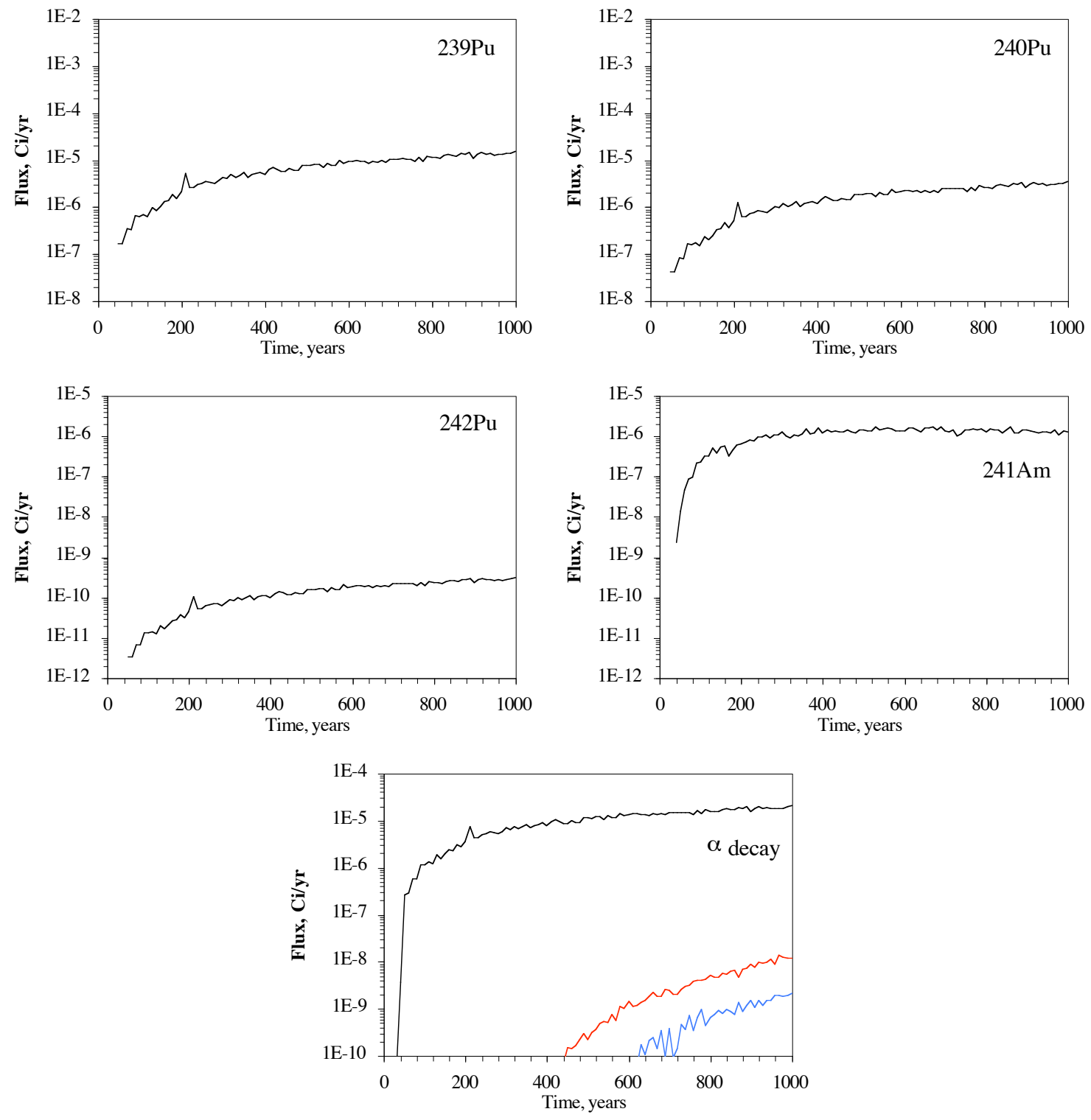

Figure 9. Mean breakthrough profiles $(\mathrm{Ci} / \mathrm{y})$ at the three downstream boundaries (black $=1$, red $=2$, blue $=3$; Fig. 7 ) as determined for all alpha-decaying radionuclides (and total alpha) included in the steady-state model. Decay since $t_{0}$ included. Note that ${ }^{241} \mathrm{Am}$ was not predicted to reach any of the breakthrough planes over the 1000-year simulation time frame. 

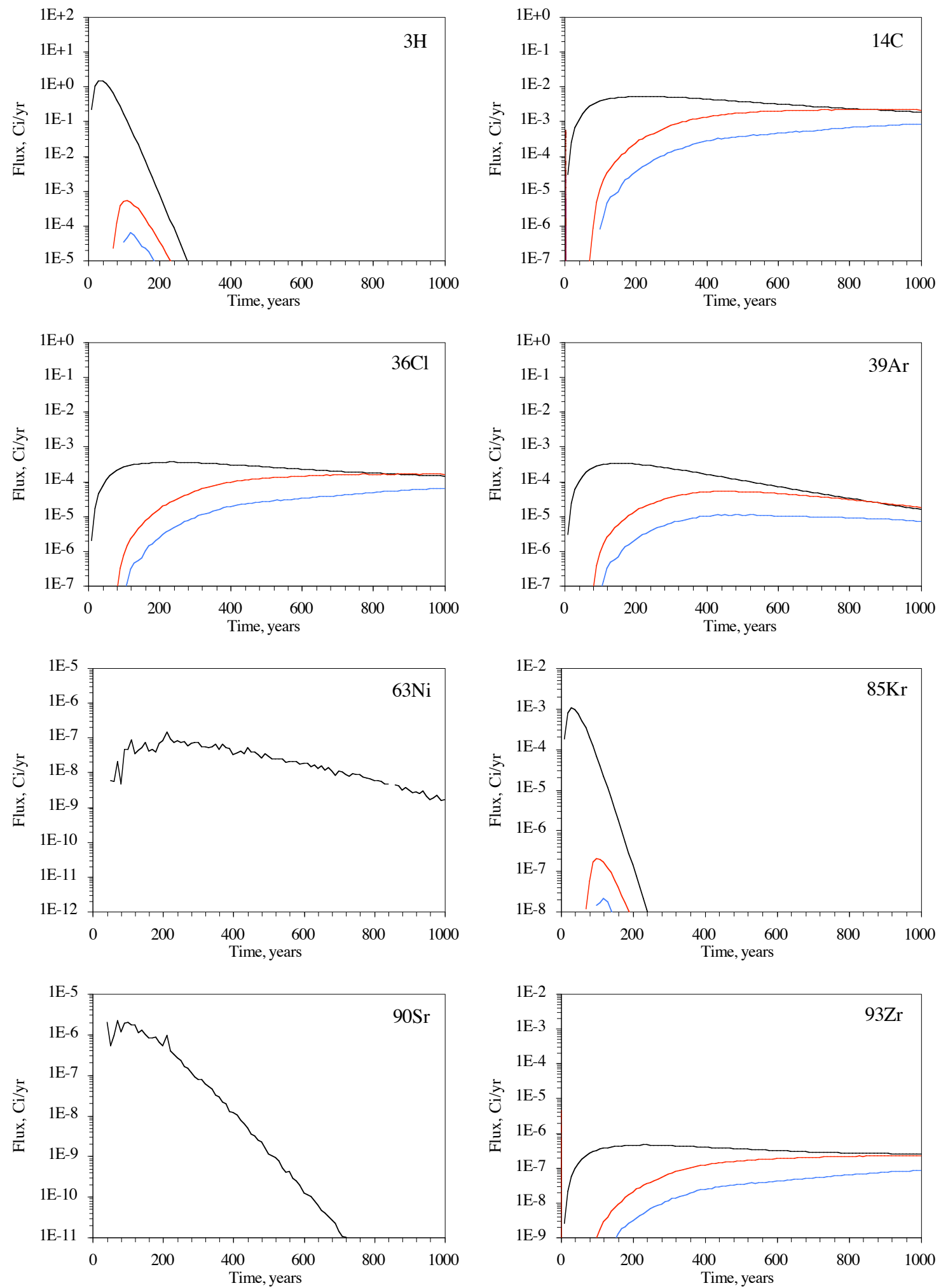

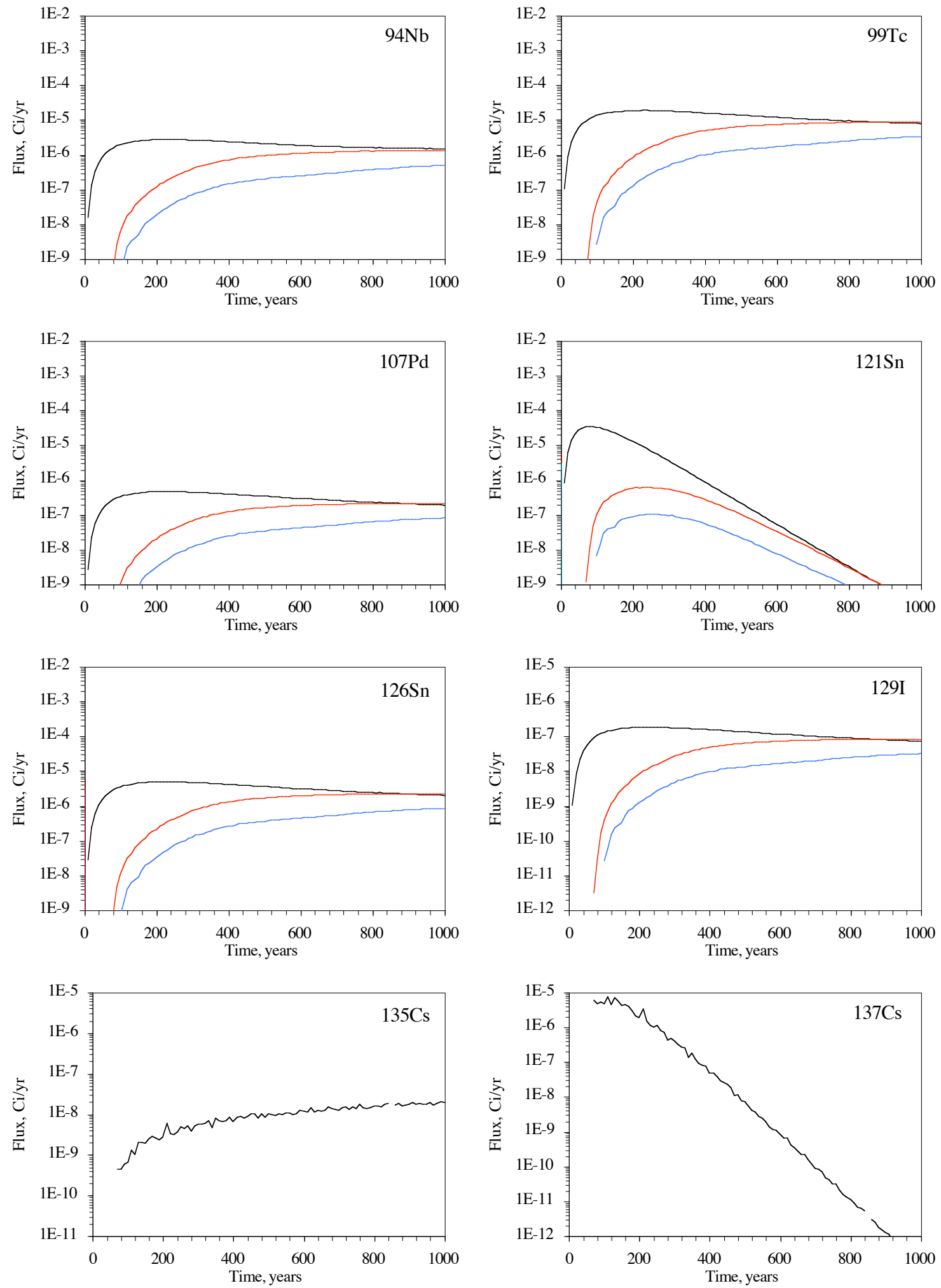

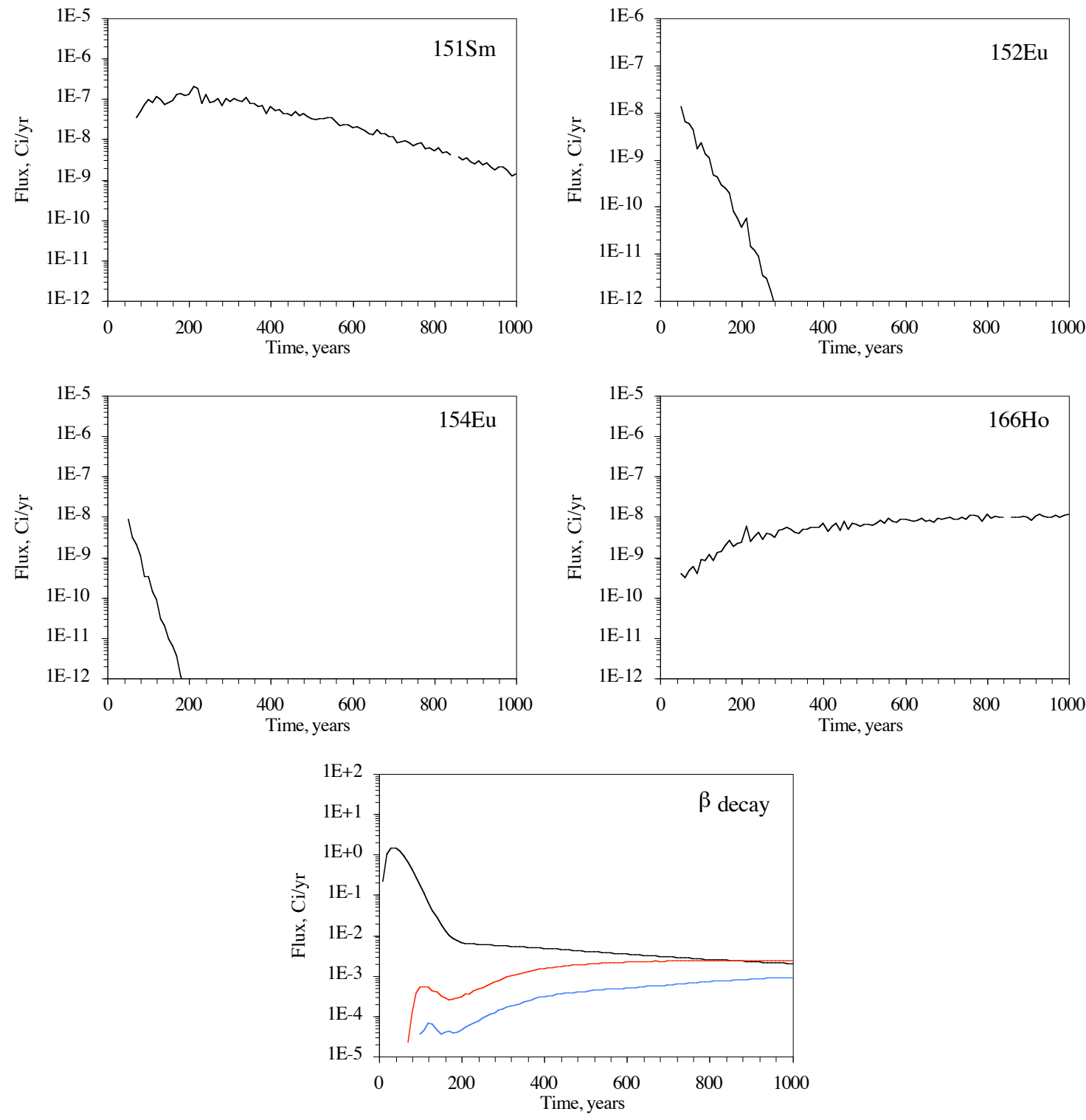

Figure 10. Mean breakthrough profiles $(\mathrm{Ci} / \mathrm{y})$ at the three downstream boundaries (black $=1$, red $=2$, blue $=3$; Fig. 7) as determined for all beta-decaying radionuclides (and total beta) included in the steady-state model. Decay since $t_{0}$ included. Note that ${ }^{241} \mathrm{Pu}$ was not predicted to reach any of the breakthrough planes over the 1000-year simulation time frame. 

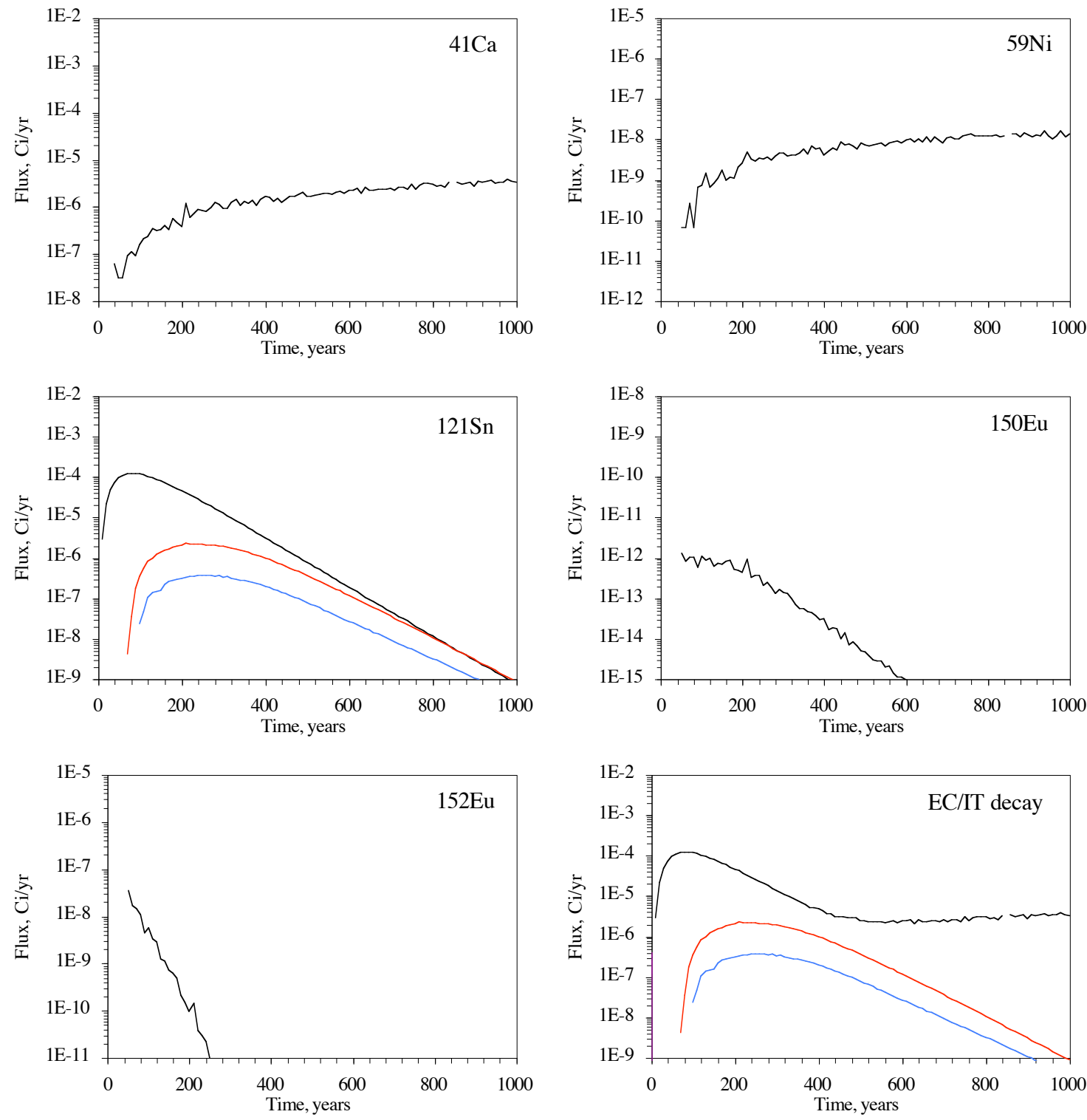

Figure 11. Mean breakthrough profiles $(\mathrm{Ci} / \mathrm{y})$ at the three downstream boundaries (black $=1$, red $=2$, blue $=3$; Fig. 7) as determined for all EC/IT-decaying radionuclides (and total EC/IT) included in the steady-state model. Decay since $\mathrm{t}_{0}$ included. Note that ${ }^{41} \mathrm{Ca},{ }^{150} \mathrm{Eu}$, and ${ }^{152} \mathrm{Eu}$ were not predicted to reach any of the breakthrough planes over the 1000-year simulation time frame. 


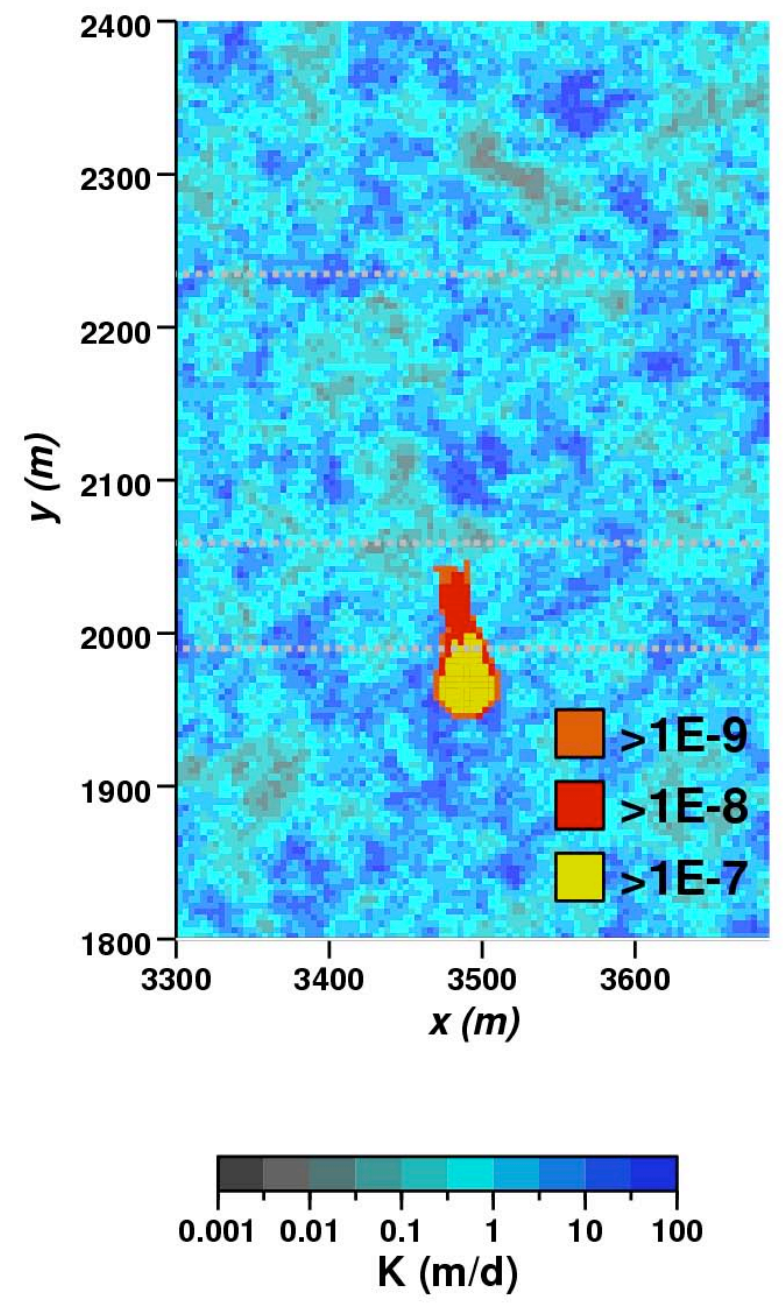

Figure 12.Tracer initially distributed in the exchange volume, Realization 5 , at $t=$ 100 years. Aqueous concentrations in moles/L. Background hydraulic conductivity distribution at water table as indicated. 


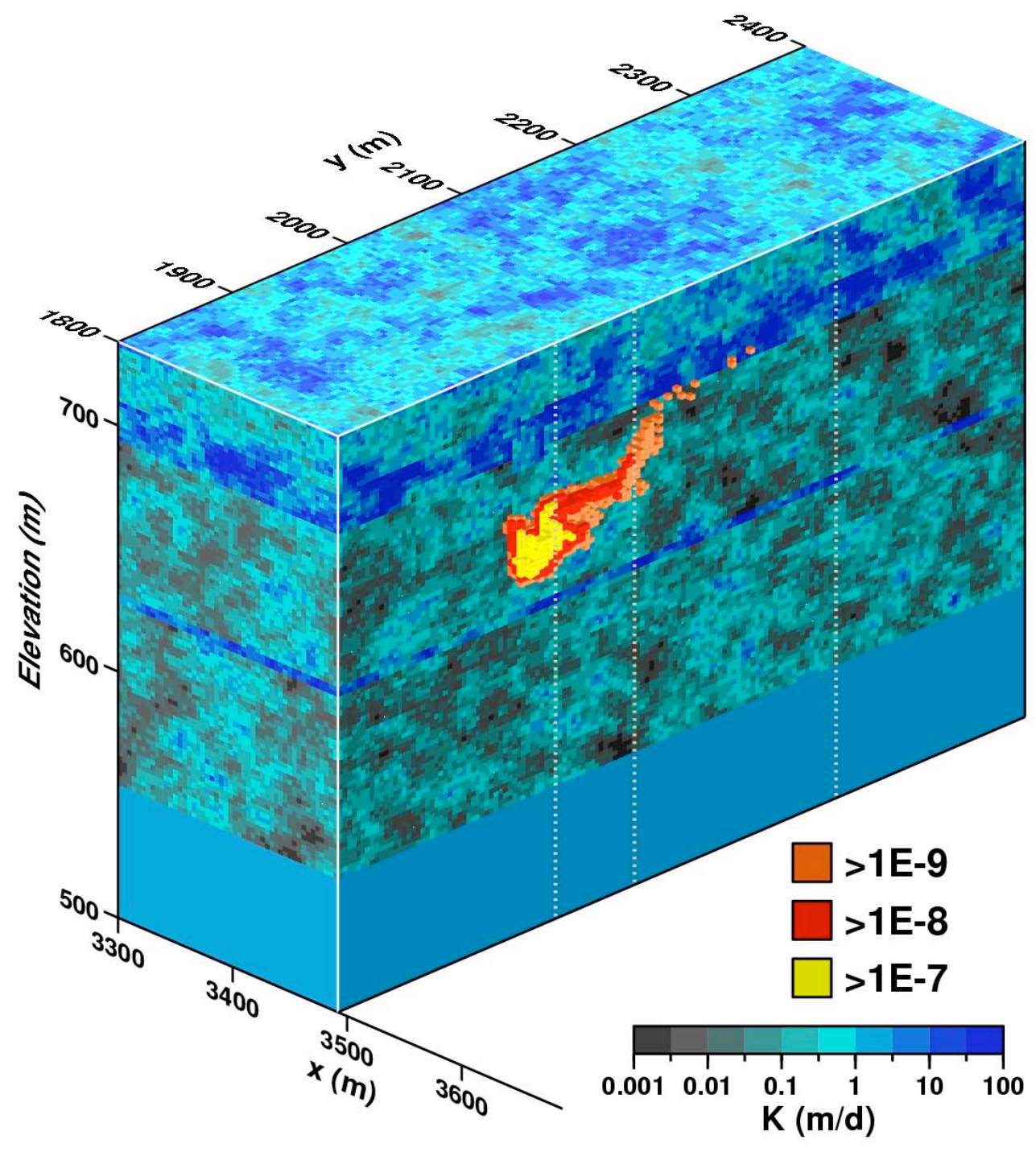

Figure 13. Tracer initially distributed in the exchange volume, realization 25 , at $t=$ 500 years. Aqueous concentrations in moles/L. Background hydraulic conductivity distribution as indicated. 


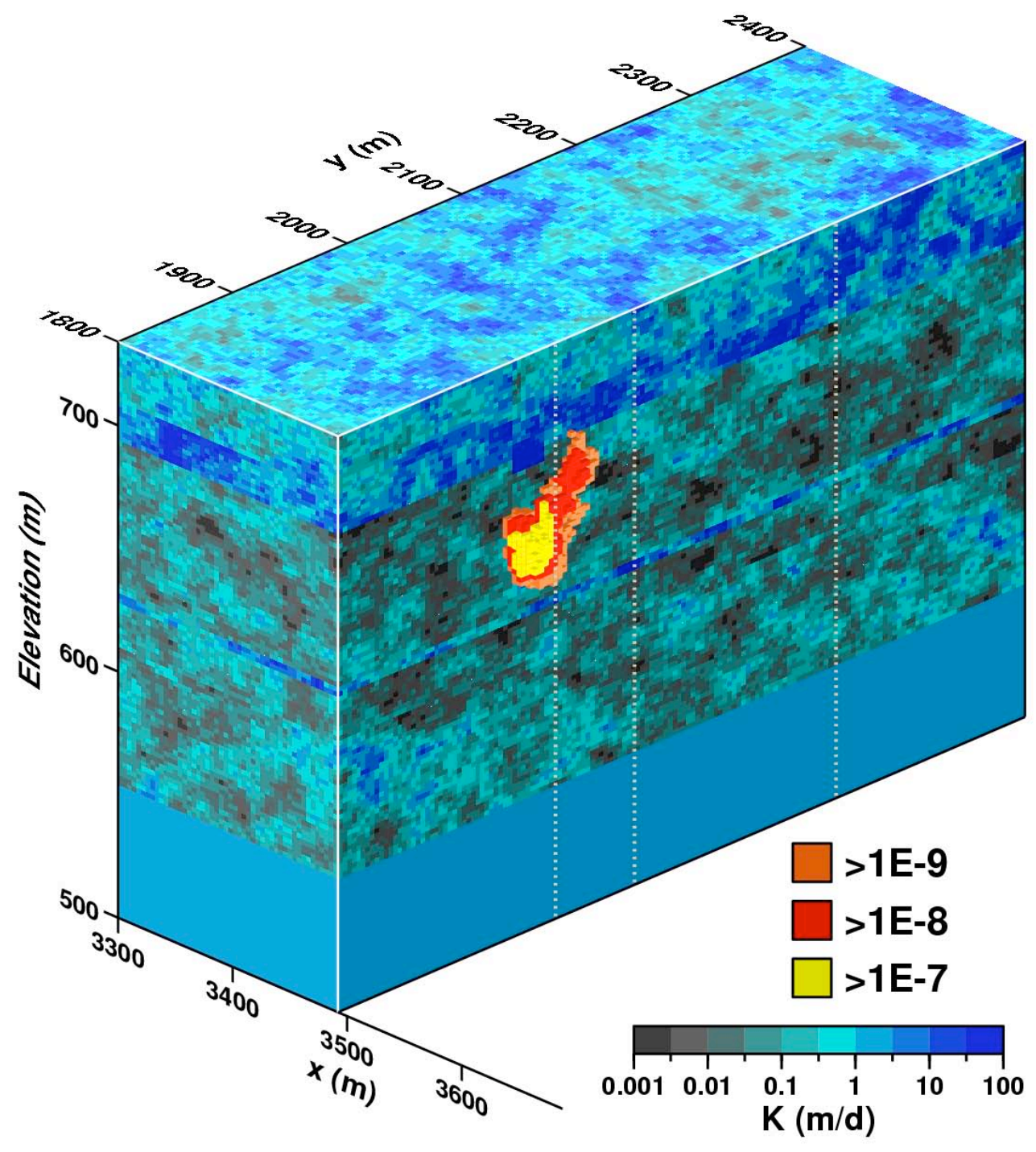

Figure 14. Tracer initially distributed in the exchange volume, realization 35 , at $t=$ 500 years. Aqueous concentrations in moles/L. Background hydraulic conductivity distribution as indicated. 

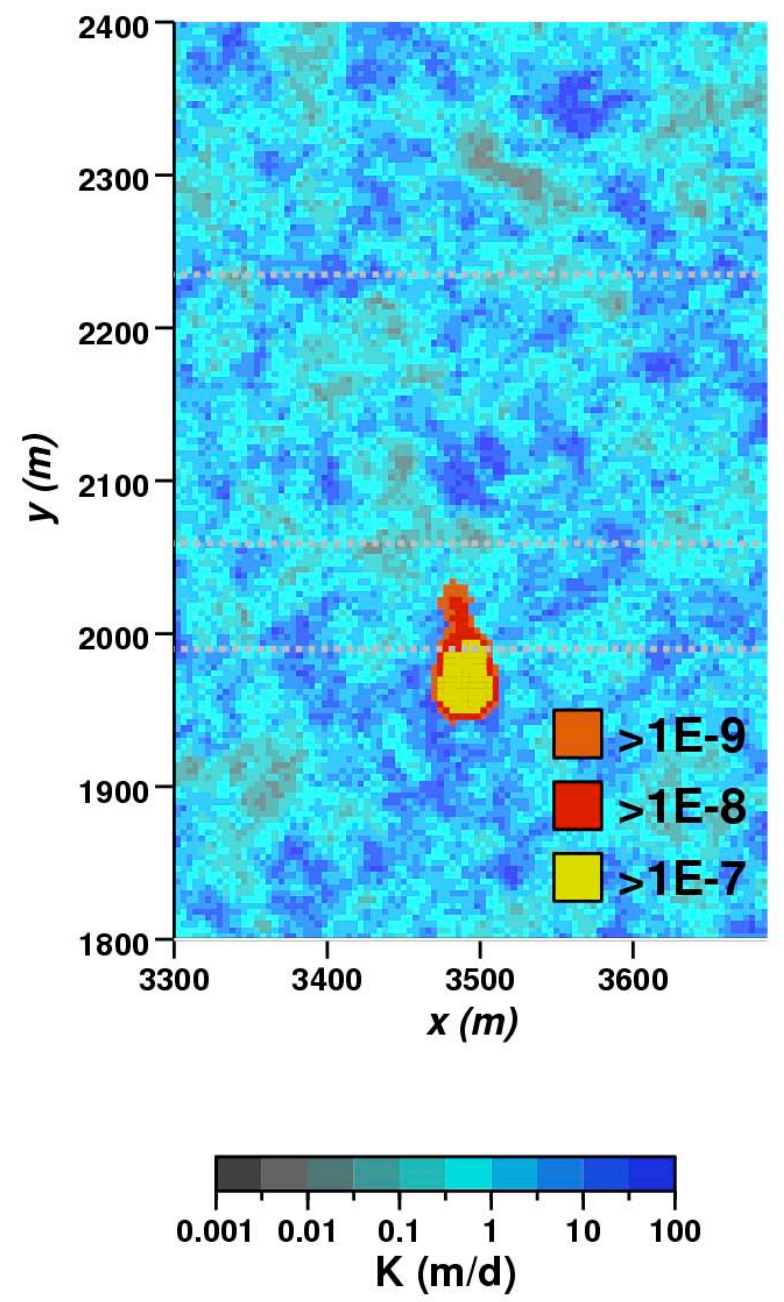

Figure 15. Uranium initially distributed in the exchange volume and glass, realization 5, at $\mathbf{t}=\mathbf{5 0 0}$ years. Aqueous concentrations in moles/L. Background hydraulic conductivity distribution at water table as indicated. 

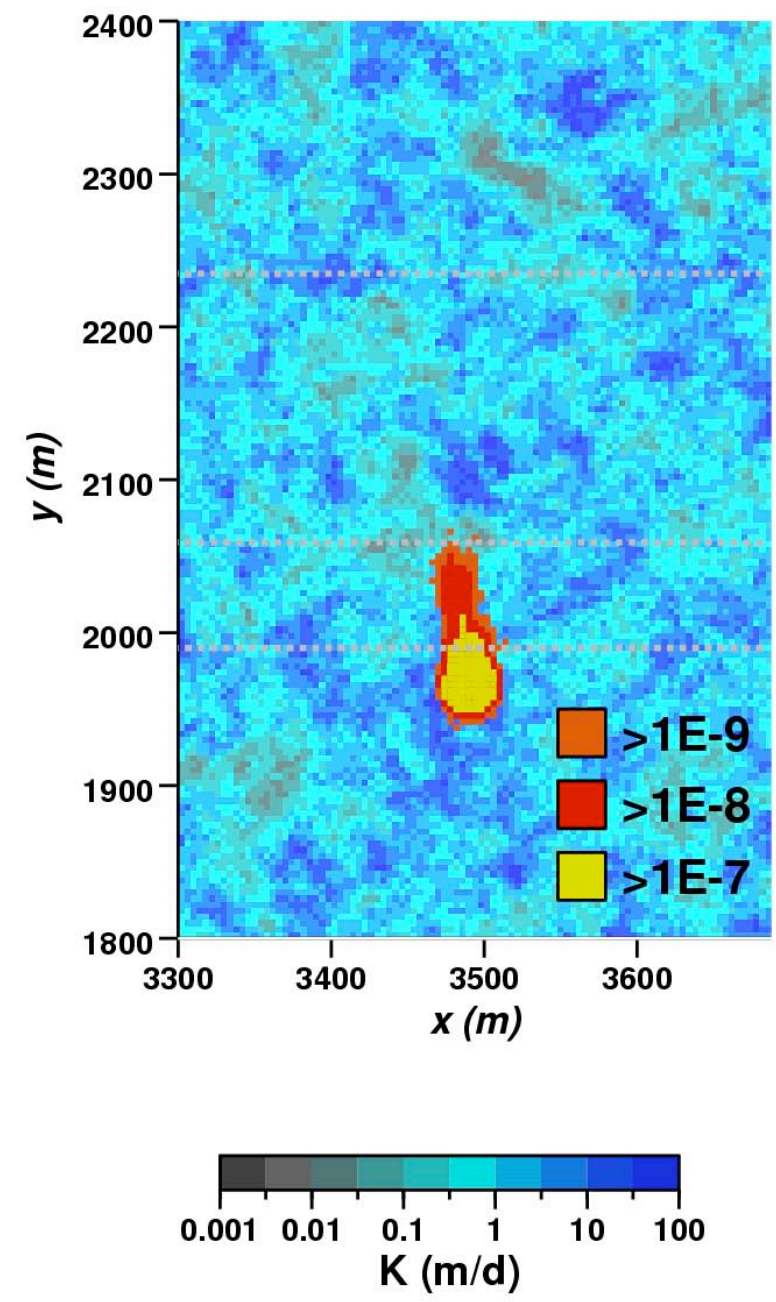

Figure 16. Uranium initially distributed in the exchange volume and glass, realization 5, at $t=1000$ years. Aqueous concentrations in moles/L. Background hydraulic conductivity distribution at water table as indicated. 


\section{References}

Aagaard, P., and H. C. Helgeson (1982), Thermodynamic and kinetic constraints on reaction rates among minerals and aqueous solutions, I. Theoretical considerations. American Journal of Science 282, 237-285.

Baxter, R. G. (1983), Description of Defense Waste Processing Facility Reference Form and Canister, Savannah River Plant, Savannah River, GA, Report no. DP-1606, rev. 1.

Bibler N. E. and C. M. Jantzen (1987), Materials interactions relating to long-term geologic disposal of nuclear waste glass, Materials Research Society Symposium Proceedings 84,47-66.

Bowen, S., D.L. Finnegan, J.L. Thompson, C.M. Miller, P. L. Baca, L.F. Olivas, C.G. Geoffrion, D.K. Smith, W. Goishi, B.K. Esser, J.W. Meadows, N. Namboodiri, J.F. Wild (2001), Nevada Test Site Radionuclide Inventory 1951-1992, LA-13859-MS, Los Alamos National Laboratory, Los Alamos, New Mexico.

Bourcier, W.L., S.A. Carroll, and B.L. Phillips (1994), Constraints on the affinity term for modeling long-term glass dissolution rates. Materials Research Society Symposium Proceedings, 333: 507-512.

Bourcier, W.L., S.K. Roberts, D.K. Smith, S.Hulsey, L.Newton, A.Sawvel, C.J. Bruton, C. Papelis, W. Um, C. Russell, and J. Chapman (2000), Determination of Reactive Surface Area of Melt Glass, UCRL-ID-145181, Lawrence Livermore National Laboratory, Livermore, California.

Carle, S. F., M. Zavarin, and G.A. Pawloski (2002), Geostatistical Analysis of Spatial Variability of Mineral Abundance and Kd in Frenchman Flat, NTS, Alluvium, UCRL-ID-150200, Lawrence Livermore National Laboratory, Livermore California.

Dagan, G. (1989), Flow and Transport in Porous Formations, Springer-Verlag, Berlin.

Grambow, B. (1987), Nuclear Waste Glass Dissolution: Mechanism, model and application, JSS Project, Swedish Nuclear Fuel and Waste Management Co., Report Number 87-02, $114 \mathrm{p}$.

Hoffman, D. C., R. Stone, W. W. Dudley, Jr. (1977), Radioactivity in the Underground Environment of the CAMBRIC Nuclear Explosion at the Nevada Test Site, Informal Report LA-6877-MS, Los Alamos National Laboratory, Los Alamos, New Mexico.

IAEA (International Atomic Energy Agency) (1998), The Radiological Situation at the Atolls of Mururoa and Fangataufa, Technical Report, Volume 3: Inventory of radionuclides underground at the atolls, Vienna, Austria, IAEA-MFTR-3.

Knauss, K.G., W.L. Bourcier, K.D. McKeegan, C.I. Marzbacher, S.N. Nguyen, F.J. Ryerson, D.K. Smith, H.C. Weed, and L. Newton (1990), Dissolution kinetics of a simple analogue nuclear waste glass as a function of $\mathrm{pH}$, time, and temperature, MRS Symposium Proceedings, 176: 371-381.

Mazer, J.J. (1987), Kinetics of glass dissolution as a function of temperature, glass composition, and solution pHs. Ph.D. thesis, Northwestern University. 
Pawloski, G. A., A. F. B. Tompson, and S. F. Carle, eds. (2001), Evaluation of the Hydrologic Source Term from Underground Nuclear Tests on Pahute Mesa at the Nevada Test Site: The CHESHIRE test, UCRL-ID-147023, Lawrence Livermore National Laboratory, Livermore, California.

Ramspott, L. D., and R. D. McArthur (1977), Results of the Exploratory Drill Hole Ue5n, Frenchman Flat, Nevada Test Site, UCID-17392, Lawrence Livermore National Laboratory, Livermore, California.

Stoller-Navarro (2004a), Integrated Analysis Report for Single- and Multiple-Well Aquifer Testing at Frenchman Flat Well Cluster RNM-2S, Nevada Test Site, Nevada, Revision No.: 0, September 2004.

Stoller-Navarro (2004b), Phase II Hydrologic Data for the Groundwater Flow and Contaminant Transport Model of Corrective Action Unit 98: Frenchman Flat, Nye County, Nevada, Revision No: 0, December, 2004.

Timmons, D. M., and L. E. Thompson (1996), Geochemical and petrographic studies and the relationships to durability and leach resistance of vitrified products from the in situ vitrification process, International Topical Meeting on Nuclear and Hazardous Waste Management.

Tompson, A. F. B., C. J. Bruton, and G. A. Pawloski, eds. (1999), Evaluation of the hydrologic source term from underground nuclear tests in Frenchman Flat at the Nevada Test Site: The CAMBRIC test, UCRL-ID-132300, Lawrence Livermore National Laboratory, Livermore, California.

USGS (2004), Aquifer Test - Analysis of multiple-well aquifer test RNM-2S, Frenchman Flat, Nevada, memorandum from M.T. Pavelko and K.J. Halford, U. S. Geological Survey, dated June 6, 2004.

Warren R. G., F. C. Benedict, Jr., T. P. Rose, D. K. Smith, S. J. Chipera, E. C. Kluk, and K. M. Raven (2002), Alluvial Layering and Distribution of Reactive Phases within Drill Holes ER5/4 and UE5n of Frenchman Flat, LA-UR-02-6206, Los Alamos National Laboratory, Los Alamos, New Mexico.

Zavarin, M., and C. J. Bruton (2004), A Non-Electrostatic Surface Complexation Approach to Modeling Radionuclide Migration at the Nevada Test Site: I. Iron Oxides and Calcite, UCRL-TR-208673, Lawrence Livermore National Laboratory, Livermore, California.

Zavarin, M., S.K. Roberts, B.E. Viani, G.A. Pawloski, and T.P. Rose (2004a), Nuclear Melt Glass Dissolution and Secondary Mineral Precipitation at 40 to $200{ }^{\circ} \mathrm{C}$, UCRLTR-204870, Lawrence Livermore National Laboratory, Livermore, California.

Zavarin, M., S.K. Roberts, P. Zhao, R.W. Williams, T.P. Rose, A. Rainer, and G.A. Pawloski. (2004b), High Temperature Studies of Glass Dissolution Rates Close to Saturation, UCRL-TR-204874, Lawrence Livermore National Laboratory, Livermore, California. 


\section{Appendix A: Physical medium properties and specifications used in the steady state flow model}

A brief description of each hydrofacies layer or altered zone used in the current steady state flow model is given in Table A1, while a close up image of these layers and zones in the vicinity of CAMBRIC (U-5e) is shown in Figure A1.

Table A1. Description of the hydrofacies layers and altered zones used in the current steady state flow model.

\begin{tabular}{|c|c|}
\hline $\begin{array}{l}\text { Layer or altered } \\
\text { zone }\end{array}$ & Description \\
\hline AL2a & Upper portion of Warren et al. (2002) alluvial layer 2 \\
\hline AL2b & Lower portion of Warren et al. (2002) alluvial layer 2 \\
\hline AL3 & Warren et al. (2002) alluvial layer 3 \\
\hline AL4 & Warren et al. (2002) alluvial layer 4 \\
\hline AL5 & Warren et al. (2002) alluvial layer 5 \\
\hline AL6 & Warren et al. (2002) alluvial layer 6 \\
\hline AL7 & Warren et al. (2002) alluvial layer 7 \\
\hline CAV & CAMBRIC cavity (excluding melt glass zone) \\
\hline CHM1 & Portion of CAMBRIC chimney associated with AL3 \\
\hline CHM2 & Portion of CAMBRIC chimney associated with AL2b \\
\hline CHM3 & Portion of CAMBRIC chimney associated with AL2a \\
\hline MG & CAMBRIC melt glass zone \\
\hline $\mathrm{CZ}$ & CAMBRIC compressed or "crush" zone surrounding cavity \\
\hline PIM & "Pimento" region representing the intersection of CAV and CHM1 \\
\hline GRAV & Thin gravel pack around pumping well RNM-2S \\
\hline
\end{tabular}

The altered zone hydrofacies associated with the CAMBRIC test include the melt glass (MG), cavity (CAV), chimney (CHM1,2,3), compressed or "crush" zone (CZ), and pimento region (PIM), as described below:

$>$ The cavity is assumed to be spherical volume of radius of $13.4 \mathrm{~m}$ centered at the CAMBRIC working point (294 m below ground surface) with a volume of $10,079 \mathrm{~m}^{3}$.

$>$ The melt glass (MG) hydrofacies is the lower $7.4 \mathrm{~m}$ portion of the cavity volume, more properly a spherical segment, occupying a volume of $1,881 \mathrm{~m}^{3}$. The top of the MG hydrofacies is $6 \mathrm{~m}$ below the CAMBRIC working point. As mentioned earlier, the MG hydrofacies contains a mixture of melt glass and in-fallen alluvium. 
The cavity (CAV) hydrofacies is that portion of the cavity volume that excludes (e.g., that lies above) the MG hydrofacies, occupying a volume of $8,198 \mathrm{~m}^{3}$.

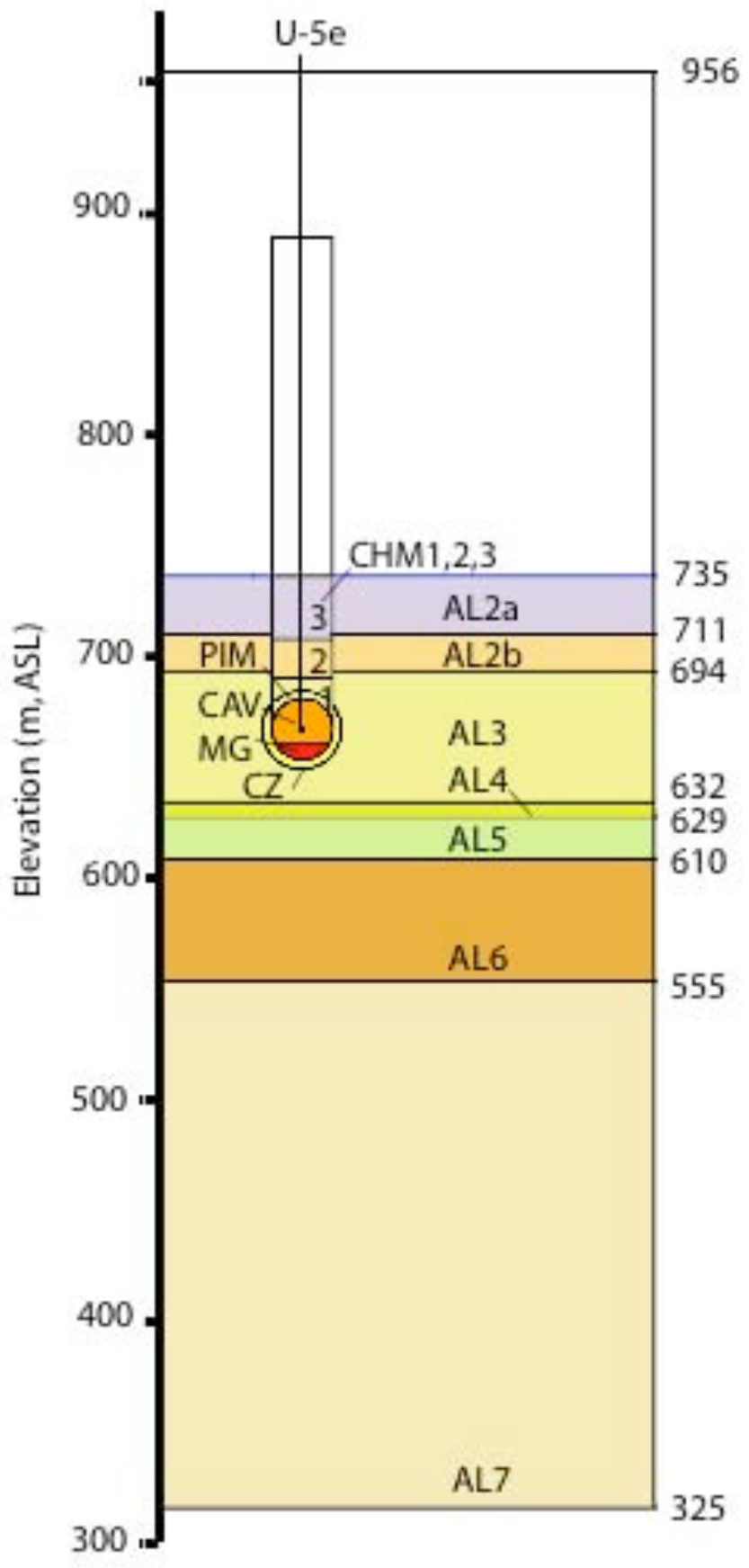

Figure A1: Close up image of the layer and altered zone hydrofacies distribution in the vicinity of CAMBrIC (U-5e), as used in the Steady State Flow model (see also Table A1). The water table and top of the model domain are located at $735 \mathrm{~m}$ (ASL); the ground surface is at $956 \mathrm{~m}$ (ASL), and the working point at $662 \mathrm{~m}$ (ASL). 
The chimney is assumed to be a vertical cylinder of radius of $13.4 \mathrm{~m}$ whose axis is centered on the CAMBRIC working point. The chimney extends from the top of the cavity proper to a point $221 \mathrm{~m}$ above the CAMBRIC working point. The chimney is subdivided into three hydrofacies (CHM3, CHM2, and CHM1) based on downdropped and bulked zones derived from three in-fallen layers (AL2a, AL2b, and AL3, respectively). CHM1 extends from the top of the cavity to $27 \mathrm{~m}$ above the CAMBRIC working point; CHM2 extends from $27 \mathrm{~m}$ to $46 \mathrm{~m}$ above the CAMBRIC working point, and CHM3 extends from $46 \mathrm{~m}$ to $73 \mathrm{~m}$ above the CAMBRIC working point.

$>$ The compressed zone hydrofacies (CZ) is assumed to be a partial spherical shell centered at the CAMBRIC working point, extending in the radial direction from the cavity boundary (inner surface) to an outer surface at $18.1 \mathrm{~m}$ radius. It is considered a partial shell because it excludes a portion that overlaps with the CHM1 hydrofacies. The volume of the $\mathrm{CZ}$ (partial shell) is $11,153 \mathrm{~m}^{3}$. The volume of the overlap, also called the pimento (PIM) region or upper compressed zone (UCZ), is $3,607 \mathrm{~m}^{3}$. The volume of the complete shell is $14,760 \mathrm{~m}^{3}$. The physical properties assigned to the PIM (or UCZ) are the same as CHM1, although the initial radionuclide inventories assigned to PIM and CHM1 differ.

> The complete spherical volume enclosed by the outer surface of the compressed and pimento zones, of radius $18.1 \mathrm{~m}$ and volume $24,838 \mathrm{~m}^{3}$, is referred to as the exchange volume (EV), into which the radiologic source term is distributed (see Appendix $\mathrm{C}$ ). The EV does not possess unique physical properties as associated with the various hydrofacies introduced above.

It should be noted that the volumes cited for each of the altered zone hydrofacies associated with the CAMBRIC test above are "geometrically exact". The discretized volumes, as realized in either the NUFT or Parflow models, will differ slightly. This will be discussed further in Appendix $\mathrm{C}$ as it pertains to the initialization of the radiologic source term.

Table A2 shows the porosity and top and bottom elevations of each alluvial layer (AL2a to AL7) and altered zone hydrofacies (CHMx, CAV, MG, CZ, PIM, and GRAV) used in the steady state (Parflow) flow model. Additional layers are used in the transient model. These layers and zones lie within the AA2 hydrostratigraphic unit in the greater Frenchman Flat HSU model. Typical permeability (k) and hydraulic conductivity (K) specifications used in these layers and zones are also shown, along with the geostatistical parameters used for the Gaussian model of spatial variability for ln K (if applicable). These were developed from the procedure outlined in Appendix B. Shaded rows correspond to units or zones not included in the current model. 
Table A2: Physical medium properties and specifications used in the source term flow models (gray areas are not directly included in the steady state Parflow model). Top and bottom of layers or zones are given with respect to elevation above sea level (ASL) or above working point (AWP). Horizontal and vertical permeabilities (k-h, k-v) as determined in the NUFT model, and their corresponding hydraulic conductivities (K-h, K-v) determined at $24^{\circ} \mathrm{C}$, should be considered their effective or up-scaled values. Geostatistical paramters used in Parflow model provided, generally determined as described as in Appendix $B$.

Notes:

(a) Geostatistical paramters not chosen according to Appendix B; $K_{G}$ set equal to $K$-h directly

(b) $\mathrm{CZ} \mathrm{K} \mathrm{K}_{\mathrm{G}}$ reduced from $\mathrm{K}-\mathrm{h}$ in additional calibration process (see section 2.2 )

(c) Spatially constant hydraulic conductivity used $\left(K_{G}=K-h\right)$

\begin{tabular}{|c|c|c|c|c|c|c|c|c|c|c|c|c|c|c|c|c|c|}
\hline \multirow{2}{*}{ UNIT (j) } & \multirow{2}{*}{ Porosity } & \multirow{2}{*}{$\begin{array}{c}\text { Top } \\
\text { (m, AWP) }\end{array}$} & \multirow{2}{*}{$\begin{array}{c}\text { Bottom } \\
\text { (m, AWP) }\end{array}$} & \multirow{2}{*}{$\begin{array}{c}\text { Top } \\
\text { (m, ASL) }\end{array}$} & \multirow{2}{*}{$\begin{array}{c}\text { Bottom } \\
\text { ( } m, \text { ASL) }\end{array}$} & \multicolumn{3}{|c|}{ NUFT } & \multicolumn{2}{|c|}{$\begin{array}{c}\text { Effective hydraulic } \\
\text { conductivity at } 24^{\circ} \mathrm{C}\end{array}$} & \multicolumn{6}{|c|}{ Parflow } & \multirow{2}{*}{ : } \\
\hline & & & & & & $\begin{array}{l}\text { k-h } \\
(\mathrm{m} 2)\end{array}$ & $\begin{array}{l}\text { k-v } \\
(\mathbf{m} 2)\end{array}$ & $\begin{array}{c}\text { Physical } \\
\text { anisotropy, } \\
\text { E }\end{array}$ & $\begin{array}{c}\mathbf{K}-\mathbf{h} \\
(\mathbf{m} / \mathbf{d})\end{array}$ & $\begin{array}{c}\text { K-v } \\
(\mathrm{m} / \mathrm{d})\end{array}$ & sigma-f & $\begin{array}{c}\text { lambda-v } \\
(\mathrm{m})\end{array}$ & $\begin{array}{c}\text { lambda-h } \\
(\mathrm{m})\end{array}$ & $\begin{array}{c}\text { Statistcial } \\
\text { anisotropy, } \\
\text { e }\end{array}$ & $\mathbf{L}$ & $\begin{array}{c}\text { KG } \\
(\mathbf{m} / \mathbf{d})\end{array}$ & \\
\hline$\overline{\mathrm{AL}}$ & 0.36 & & & & & $2.54 \mathrm{E}-13$ & $1.27 \mathrm{E}-13$ & 0.50 & $2.36 \mathrm{E}-01$ & \begin{tabular}{|c|}
$1.18 \mathrm{E}-01$ \\
\end{tabular} & 1.50 & 6.00 & 14.29 & 0.42 & 0.42 & \begin{tabular}{l||}
$1.43 \mathrm{E}-01$ \\
\end{tabular} & \\
\hline ALV & 0.36 & & & & & $2.54 \mathrm{E}-13$ & $1.27 \mathrm{E}-13$ & 0.50 & $2.36 \mathrm{E}-01$ & $1.18 \mathrm{E}-01$ & 1.50 & 6.00 & 14.29 & 0.42 & 0.42 & $\begin{array}{l}1.43 \mathrm{E}-01 \\
\end{array}$ & \\
\hline AL1v & 0.33 & 294 & 177 & 956 & 839 & $4.27 \mathrm{E}-12$ & $6.10 \mathrm{E}-13$ & 0.14 & $3.97 E+00$ & 5.67E-01 & 1.50 & 6.00 & 46.15 & 0.13 & 0.18 & $2.06 \mathrm{E}+00$ & \\
\hline$A L 2 v$ & 0.36 & 177 & 73 & 839 & 735 & $4.27 \mathrm{E}-12$ & $6.10 \mathrm{E}-13$ & 0.14 & $3.97 E+00$ & 5.67E-01 & 1.50 & 6.00 & 46.15 & 0.13 & 0.18 & $2.06 \mathrm{E}+00$ & \\
\hline AL2a & 0.36 & 73 & 49 & 735 & 711 & $4.21 \mathrm{E}-12$ & $2.11 \mathrm{E}-12$ & 0.50 & $3.91 \mathrm{E}+00$ & $1.96 \mathrm{E}+00$ & 1.50 & 6.00 & 14.29 & 0.42 & 0.42 & $2.37 \mathrm{E}+00$ & \\
\hline AL2b & 0.36 & 49 & 32 & 711 & 694 & $2.42 \mathrm{E}-11$ & $1.21 \mathrm{E}-11$ & 0.50 & $2.25 \mathrm{E}+01$ & $1.13 \mathrm{E}+01$ & 1.50 & 6.00 & 14.29 & 0.42 & 0.42 & $1.36 \mathrm{E}+01$ & \\
\hline AL3 & 0.32 & 32 & -30 & 694 & 632 & $2.50 \mathrm{E}-13$ & $1.25 \mathrm{E}-13$ & 0.50 & 2.32E-01 & $1.16 \mathrm{E}-01$ & 1.50 & 6.00 & 14.29 & 0.42 & 0.42 & $1.41 \mathrm{E}-01$ & \\
\hline AL4 & 0.32 & -30 & -33 & 632 & 629 & $1.61 \mathrm{E}-11$ & $8.05 \mathrm{E}-12$ & 0.50 & $1.50 \mathrm{E}+01$ & $7.50 \mathrm{E}+00$ & 1.50 & 6.00 & 14.29 & 0.42 & 0.42 & $9.09 \mathrm{E}+00$ & \\
\hline AL5 & 0.32 & -33 & -52 & 629 & 610 & $2.42 \mathrm{E}-13$ & $1.21 \mathrm{E}-13$ & 0.50 & 2.25E-01 & $1.13 \mathrm{E}-01$ & 1.50 & 6.00 & 14.29 & 0.42 & 0.42 & $1.36 \mathrm{E}-01$ & \\
\hline AL6 & 0.32 & -52 & -107 & 610 & 555 & 3.23E-13 & $1.62 \mathrm{E}-13$ & 0.50 & 3.00E-01 & 1.50E-01 & 1.50 & 6.00 & 14.29 & 0.42 & 0.42 & $1.82 \mathrm{E}-01$ & \\
\hline AL7 & 0.32 & -107 & -337 & 555 & 325 & $2.15 \mathrm{E}-12$ & $1.08 \mathrm{E}-12$ & 0.50 & $2.00 E+00$ & $1.00 \mathrm{E}+00$ & 1.50 & 6.00 & 14.29 & 0.42 & 0.42 & $1.21 \mathrm{E}+00$ & \\
\hline AL8 & 0.32 & -337 & -403 & 325 & 259 & $3.23 \mathrm{E}-13$ & $1.62 \mathrm{E}-13$ & 0.50 & $3.00 \mathrm{E}-01$ & $1.50 \mathrm{E}-01$ & 1.50 & 6.00 & 14.29 & 0.42 & 0.42 & $1.82 \mathrm{E}-01$ & \\
\hline AL9 & 0.3 & -403 & -606 & 259 & 56 & $3.22 \mathrm{E}-14$ & $1.61 \mathrm{E}-14$ & 0.50 & 3.00E-02 & $1.50 \mathrm{E}-02$ & $\begin{array}{l}1.50 \\
1.50\end{array}$ & $\begin{array}{l}0.00 \\
6.00\end{array}$ & $\begin{array}{l}14.29 \\
14.29\end{array}$ & $\begin{array}{l}0.42 \\
0.42\end{array}$ & $\begin{array}{l}0.42 \\
0.42\end{array}$ & $\begin{array}{l}1.02 \mathrm{E}-02 \\
1.82\end{array}$ & \\
\hline AL10 & 0.3 & -606 & -706 & 56 & -44 & $3.22 \mathrm{E}-12$ & $1.61 \mathrm{E}-12$ & 0.50 & $3.00 \mathrm{E}+00$ & $1.50 \mathrm{E}+00$ & 1.50 & 6.00 & 14.29 & 0.42 & 0.42 & $1.82 \mathrm{E}+00$ & \\
\hline CHM3 & 0.36 & 73 & 46 & 735 & 708 & $4.21 \mathrm{E}-12$ & $2.11 \mathrm{E}-12$ & 0.50 & $3.91 E+00$ & $1.96 \mathrm{E}+00$ & 1.50 & 6.00 & 14.29 & 0.42 & 0.42 & $2.37 \mathrm{E}+00$ & \\
\hline CHM2 & 0.36 & 46 & 27 & 708 & 689 & $2.42 \mathrm{E}-11$ & $1.21 \mathrm{E}-11$ & 0.50 & $2.25 \mathrm{E}+01$ & $1.13 \mathrm{E}+01$ & 1.50 & 6.00 & 14.29 & 0.42 & 0.42 & $1.36 \mathrm{E}+01$ & \\
\hline CHM1 & 0.36 & 27 & 13 & 689 & 675 & $2.50 \mathrm{E}-13$ & $1.25 \mathrm{E}-13$ & 0.50 & 2.32E-01 & $1.16 \mathrm{E}-01$ & 1.50 & 6.00 & 14.29 & 0.42 & 0.42 & $1.41 \mathrm{E}-01$ & \\
\hline PIM & 0.36 & 18 & 0 & 680 & 662 & $2.50 \mathrm{E}-13$ & 2.50E-13 & 1.00 & $2.32 \mathrm{E}-02$ & $2.32 \mathrm{E}-02$ & 1.00 & 6.00 & 6.00 & 1.00 & & $2.20 \mathrm{E}-01$ & $a$ \\
\hline CAV & 0.32 & 13 & -6 & 675 & 656 & $2.37 \mathrm{E}-13$ & $2.37 \mathrm{E}-13$ & 1.00 & 2. $20 \mathrm{E}-01$ & $2.20 \mathrm{E}-01$ & 1.00 & 6.00 & 6.00 & 1.00 & & $2.20 \mathrm{E}-01$ & $a$ \\
\hline MG & 0.29 & -6 & -13 & 656 & 649 & $1.61 \mathrm{E}-13$ & $1.61 \mathrm{E}-13$ & 1.00 & $1.50 \mathrm{E}-01$ & $1.50 \mathrm{E}-01$ & 1.00 & 6.00 & 6.00 & 1.00 & & $1.50 \mathrm{E}-01$ & $a$ \\
\hline CZ (NUFT) & 0.27 & 18 & -18 & 680 & 644 & $1.08 \mathrm{E}-14$ & $1.08 \mathrm{E}-14$ & 1.00 & $1.00 \mathrm{E}-02$ & $1.00 \mathrm{E}-02$ & & & & & & & \\
\hline $\begin{array}{c}\mathrm{CZ} \\
\text { (Parflow) }\end{array}$ & 0.27 & 18 & -18 & 680 & 644 & & & 1.00 & $1.00 \mathrm{E}-02$ & $1.00 \mathrm{E}-02$ & 1.50 & 6.00 & 14.29 & 0.42 & & $1.67 \mathrm{E}-03$ & $a, b$ \\
\hline $\begin{array}{l}\text { GRAV } \\
\text { (NUFT) }\end{array}$ & 0.5 & & & & & $3.35 \mathrm{E}-09$ & $3.35 \mathrm{E}-09$ & 1.00 & $3.11 E+03$ & $3.11 \mathrm{E}+03$ & & & & & & & \\
\hline $\begin{array}{c}\text { GRAV } \\
\text { (Parflow) }\end{array}$ & 0.5 & & & & & & & 1.00 & $3.00 \mathrm{E}+01$ & $3.00 \mathrm{E}+01$ & & & & & & $3.00 \mathrm{E}+01$ & c \\
\hline ATM & 0.99 & & & & & $1.00 \mathrm{E}-09$ & $1.00 \mathrm{E}-09$ & 1.00 & $9.29 E+02$ & $9.29 E+02$ & & & & & & & \\
\hline
\end{tabular}




\section{Appendix B: Stochastic properties used in the Parflow calculations}

The transient CAMBRIC hydrologic source term (HST) simulations will be carried out using both the NUFT and Parflow flow models, coupled with a combination of streamline and particlebased transport models.

The NUFT model is primarily used to study early ( 0 to $10 \mathrm{y})$ flow behavior under the effects of residual test heat, and is calibrated to the ER-5-4 multi-well aquifer test (MWAT), conducted in 2003 under ambient (contemporary) hydraulic conditions. The NUFT model has been developed and calibrated in a zoned (primarily layered) alluvium configuration, with constant, effective-scale hydraulic medium properties (permeability) for each zone or layer.

The Parflow model is primarily used to study later time (10-1000y) isothermal flow behavior in the same zoned alluvium configuration, except that the hydraulic medium properties (hydraulic conductivity) in the extended alluvium layers and the altered zones surrounding the working point are specified at a much finer spatial resolution in terms of spatially correlated Gaussian random fields. This is similar to the approach used in the previous CAMBRIC HST calculations (Tompson et al., 1999).

Because the permeabilities used in the NUFT application have been calibrated to the MWAT and form the basis for the first 10 years of the HST simulation, we specified the stochastic conductivity distributions in Parflow such that the effective (scaled-up) conductivities associated with each distribution in each in each layer or zone match their counterparts in NUFT, which are essentially effective properties in the first place. The procedure for doing this is outlined below, although it has only been applied to the extended, unaltered alluvium layers.

\section{B.1 NUFT specification}

The NUFT results were developed in terms of anisotropic permeabilites, $\mathbf{k}_{\mathrm{j}}\left(\mathrm{m}^{2}\right)$ specified in each zone or layer $\mathrm{j}$. Each zone or layer is considered horizontally isotropic and vertically anisotropic such that only horizontal and vertical permeability components, $k_{h, j}$ and $k_{v, j}$, are considered. The ratio of these two components defines the anisotropy ratio:

$$
E_{j}=\frac{k_{v, j}}{k_{h, j}}=\frac{K_{v, j}^{N}}{K_{h, j}^{N}}
$$

The calibrated permeability components used in NUFT can be converted into corresponding "calibrated" hydraulic conductivity components, $K_{h, j}^{N}$ and $K_{v, j}^{N}(\mathrm{~m} / \mathrm{s}$ or m/d) as a function of 
temperature, T. As shown, the ratio of these components will be the same as in (B1). These components can also be considered effective scale hydraulic conductivities.

\section{B.2 Parflow specification}

The Parflow results were developed in terms of stationary randomly distributed scalar-valued hydraulic conductivity distributions specified at a fine scale of resolution within each zone or layer $\mathrm{j}$. The statistical characteristics of these random distributions are based on a Gaussian random field model. Specifically, for layer $\mathrm{j}$, we have

$$
\begin{aligned}
& K_{j}(\mathbf{x})=K_{G j} e^{f_{j}(\mathbf{x})} \\
& \left.E\left[f_{j}(\mathbf{x}) f_{j}(\mathbf{x}+\mathbf{r})\right]=\sigma_{f j}^{2} e^{\left\{-\left(\left(r_{h} / \lambda_{h j}\right)^{2}+\left(r_{v} / \lambda_{v j}\right)^{2}\right)^{1 / 2}\right.}\right\}
\end{aligned}
$$

where $K_{G j}$ is the geometric mean conductivity (m/s or m/d), $\sigma_{f j}^{2}$ is the $\ln K$ variance (dimensionless), and $\lambda_{h, j}$ and $\lambda_{v, j}$ are the horizontal and vertical correlation scales (m) of the distribution in layer $\mathrm{j}$, respectively. In (B2), $E[\bullet]$ denotes the stochastic mean operator.

Corresponding to each statistical conductivity distribution is an effective, large-scale hydraulic conductivity, $\hat{\mathbf{K}}_{j}(\mathrm{~m} / \mathrm{s}$ or $\mathrm{m} / \mathrm{d})$ whose magnitude is dependent on the statistical properties of the underlying distribution. Even though the small-scale conductivities are scalarvalued, the effective conductivity may be tensorial or anisotropic in nature, as a function of anisotropy in the spatial correlation model (B3).

In the particular form shown in (B3), the correlation structure is isotropic in the horizontal $\left(\lambda_{h, j}\right)$ and anisotropic in the vertical $\left(\lambda_{v, j}\right)$ according to the ratio

$$
e_{j}=\frac{\lambda_{v, j}}{\lambda_{h, j}}
$$

Closed form estimates of the effective horizontal and vertical conductivities corresponding to the distribution in (B2, B3) are given in equations 3.4.17 and 3.4.18 of Dagan (1989), namely

$$
\begin{aligned}
& \frac{\hat{K}_{h j}}{K_{G j}}=1+\frac{\sigma_{f j}^{2}}{2}\left(1-L_{j}\right) \\
& \frac{\hat{K}_{v j}}{K_{G j}}=1+\frac{\sigma_{f j}^{2}}{2}\left(-1+2 L_{j}\right)
\end{aligned}
$$


where

$$
L_{j}=\frac{e_{j}^{2}}{1-e_{j}^{2}}\left[-1+\frac{1}{e_{j} \sqrt{1-e_{j}^{2}}} \tan ^{-1} \sqrt{\frac{1}{e_{j}^{2}}-1}\right]
$$

In the Parflow model, we specify the distributions in (B2) and (B3) for each layer in such a way that the effective values in (B5) and (B6) match their counterparts used in NUFT, while honoring or approximating some of the statistical parameters used in the previous CAMBRIC HST simulations. Note that anisotropy in the horizontal correlation structure used in the previous simulations will not be possible now. As we know the effective values in (B5) and (B6) a priori, the geostatistical layer parameters were developed using the following approach:

1. Identify plausible values for $\sigma_{f, j}^{2}$ and $\lambda_{v, j}$ for each layer. These are probably the easier parameters to estimate from available data, as described in the previous HST report.

Specifically, we specify $\sigma_{f, j}=1.5$ and $\lambda_{v, j}=6 \mathrm{~m}$ in all Parflow layers, as used in Table 20 of Tompson et al., (1999).

2. Require that the anisotropy, $E_{j}$, identified in the NUFT model be reproduced by the ratio of effective horizontal and vertical conductivities in (B5) and (B6). This leads to

$$
E_{j}=\frac{\hat{K}_{v, j}}{\hat{K}_{h, j}}=\frac{1+\sigma_{f j}^{2}\left(-1+2 L_{j}\right) / 2}{1+\sigma_{f j}^{2}\left(1-L_{j}\right) / 2}
$$

which means that

$$
L_{j}=\frac{1+E_{j}}{2+E_{j}}-\frac{2-2 E_{j}}{\left(2+E_{j}\right) \sigma_{f}^{2}}
$$

3. Iteratively identify a level of correlation anisotropy, $e_{j}$, in (B4) that produces the same value of $L_{j}$ above. Since we have specified the vertical correlation scale, $\lambda_{v, j}$, we can now calculate the horizontal value, $\lambda_{h, j}$, from (B4).

4. Since we must have $\hat{K}_{h, j}=K_{h, j}^{N}$ and $\hat{K}_{v, j}=K_{v, j}^{N}$, evaluate $K_{G}$ from (B5) or (B6) using the assumed value of $\sigma_{f, j}^{2}$ and the same value of $L_{j}$ above.

Calculated results for the NUFT zones and layers used in the calibration NUFT and steady state Parflow models are shown in Table A2. The temperature used for the permeability to conductivity conversion was $24^{\circ} \mathrm{C}$. 


\section{Appendix C: Radionuclide inventory data used in the steady state source term model}

Radionuclide inventory data used in the steady state source term model for CAMBRIC were derived from the total Frenchman Flat CAU inventory tabulated in Bowen et al. (2001). The Bowen et al. data were first averaged by the number of tests conducted in Frenchman Flat (10) and then decay corrected specifically to CAMBRIC $\mathrm{t}_{0}$, as described previously. The results are given in Table $\mathrm{C} 1$.

The percentage or fractional distribution of the radionuclides among the glass, rubble, gas, and water phases, as derived from IAEA (1998), are also provided in Table C1. In this specification, (a) certain isotopes appear (e.g., ${ }^{150} \mathrm{Eu}$ ) as analogs to others specified in the IAEA report; (b) glass fractions for all $\mathrm{Pu}$ and Am isotopes were reduced from $98 \%$ to $95 \%$ as a measure of conservatism (as was done by Pawloski et al., 2001, for the CHESHIRE HST), and (c) the fractional distributions of Sr and Cs shown differ from those used in Tompson et al. (1999), which reflect CAMBRIC-specific partitioning estimates made by Hoffman et al. (1977).

In the simulations, the glass fraction of each radionuclide inventory was partitioned into the solid nuclear melt glass volume fraction within the MG hydrofacies. The rubble, gas, and water fractions were combined and distributed within in the aqueous phase inside of the $18.1 \mathrm{~m}$ radius exchange volume (EV) centered on the CAMBRIC working point. To preserve the inventory masses represented in the model, the volume fraction of glass and total pore volume within the MG and EV regions were developed by considering the total discretized model volumes associated with these regions, as opposed to the absolute volumes summarized in Appendix A. These volumes are summarized in Table C2.

Table C1. Radionuclide inventories and partition fractions used the Steady State CAMBRIC source term simulations.

\begin{tabular}{ccccccc}
\hline & & & \multicolumn{4}{c}{ Partitioning, percent } \\
\cline { 6 - 8 } $\mathrm{RN}$ & $\begin{array}{c}\text { Half Life } \\
(\mathrm{yr})\end{array}$ & $\begin{array}{c}\text { Total } \\
\text { moles }\end{array}$ & glass & rubble & gas & water \\
\hline${ }^{3} \mathrm{H}$ & $1.23 \mathrm{E}+01$ & $2.81 \mathrm{E}+00$ & 0 & 0 & 2 & 98 \\
${ }^{14} \mathrm{C}$ & $5.73 \mathrm{E}+03$ & $1.07 \mathrm{E}-01$ & 0 & 10 & 80 & 10 \\
${ }^{36} \mathrm{Cl}$ & $3.01 \mathrm{E}+05$ & $7.50 \mathrm{E}-01$ & 50 & 40 & 0 & 10 \\
${ }^{39} \mathrm{Ar}$ & $2.69 \mathrm{E}+02$ & $4.98 \mathrm{E}-04$ & 0 & 10 & 80 & 10 \\
${ }^{41} \mathrm{Ca}$ & $1.03 \mathrm{E}+05$ & $1.89 \mathrm{E}+00$ & 70 & 30 & 0 & 0 \\
${ }^{59} \mathrm{Ni}$ & $7.51 \mathrm{E}+04$ & $3.47 \mathrm{E}-02$ & 95 & 5 & 0 & 0 \\
${ }^{63} \mathrm{Ni}$ & $1.00 \mathrm{E}+02$ & $5.68 \mathrm{E}-03$ & 95 & 5 & 0 & 0 \\
${ }^{85} \mathrm{Kr}$ & $1.07 \mathrm{E}+01$ & $2.26 \mathrm{E}-03$ & 0 & 10 & 80 & 10 \\
${ }^{90} \mathrm{Sr}$ & $2.91 \mathrm{E}+01$ & $2.90 \mathrm{E}-02$ & 40 & 60 & 0 & 0
\end{tabular}




\begin{tabular}{|c|c|c|c|c|c|c|}
\hline${ }^{93} \mathrm{Zr}$ & $1.50 \mathrm{E}+06$ & $4.69 \mathrm{E}-02$ & 95 & 5 & 0 & 0 \\
\hline${ }^{94} \mathrm{Nb}$ & $2.03 E+04$ & $3.90 \mathrm{E}-03$ & 95 & 5 & 0 & 0 \\
\hline${ }^{99} \mathrm{Tc}$ & $2.13 \mathrm{E}+05$ & $6.96 \mathrm{E}-02$ & 80 & 20 & 0 & 0 \\
\hline${ }^{107} \mathrm{Pd}$ & $6.50 \mathrm{E}+06$ & $3.55 \mathrm{E}-02$ & 70 & 30 & 0 & 0 \\
\hline${ }^{121} \mathrm{Sn}$ & $5.50 \mathrm{E}+01$ & $3.58 \mathrm{E}-04$ & 60 & 40 & 0 & 0 \\
\hline${ }^{126} \mathrm{Sn}$ & $1.00 \mathrm{E}+05$ & $5.73 \mathrm{E}-03$ & 70 & 30 & 0 & 0 \\
\hline${ }^{129} \mathrm{I}$ & $1.57 \mathrm{E}+07$ & $1.99 \mathrm{E}-02$ & 50 & 40 & 0 & 10 \\
\hline${ }^{135} \mathrm{Cs}$ & $2.30 \mathrm{E}+06$ & 8.76E-02 & 20 & 80 & 0 & 0 \\
\hline${ }^{137} \mathrm{Cs}$ & $3.02 \mathrm{E}+01$ & 7.96E-02 & 20 & 80 & 0 & 0 \\
\hline${ }^{151} \mathrm{Sm}$ & $9.00 \mathrm{E}+01$ & $9.17 \mathrm{E}-03$ & 95 & 5 & 0 & 0 \\
\hline${ }^{150} \mathrm{Eu}$ & $3.60 \mathrm{E}+01$ & $1.68 \mathrm{E}-07$ & 95 & 5 & 0 & 0 \\
\hline${ }^{152} \mathrm{Eu}$ & $1.35 \mathrm{E}+01$ & $1.17 \mathrm{E}-02$ & 95 & 5 & 0 & 0 \\
\hline${ }^{154} \mathrm{Eu}$ & $8.59 \mathrm{E}+00$ & $5.73 \mathrm{E}-03$ & 95 & 5 & 0 & 0 \\
\hline${ }^{166} \mathrm{Ho}$ & $1.20 \mathrm{E}+03$ & $6.90 \mathrm{E}-04$ & 95 & 5 & 0 & 0 \\
\hline${ }^{232} \mathrm{U}$ & $6.89 \mathrm{E}+01$ & $2.63 \mathrm{E}-07$ & 90 & 10 & 0 & 0 \\
\hline${ }^{233} \mathrm{U}$ & $1.59 \mathrm{E}+05$ & $5.94 \mathrm{E}-05$ & 90 & 10 & 0 & 0 \\
\hline${ }^{234} \mathrm{U}$ & $2.46 \mathrm{E}+05$ & $2.97 \mathrm{E}-02$ & 90 & 10 & 0 & 0 \\
\hline${ }^{235} \mathrm{U}$ & $7.04 \mathrm{E}+08$ & $1.69 \mathrm{E}+00$ & 90 & 10 & 0 & 0 \\
\hline${ }^{236} \mathrm{U}$ & $2.34 \mathrm{E}+07$ & $1.96 \mathrm{E}-02$ & 90 & 10 & 0 & 0 \\
\hline${ }^{238} \mathrm{U}$ & $4.47 \mathrm{E}+09$ & $1.19 \mathrm{E}+02$ & 90 & 10 & 0 & 0 \\
\hline${ }^{237} \mathrm{~Np}$ & $2.14 \mathrm{E}+06$ & $6.37 \mathrm{E}-03$ & 95 & 5 & 0 & 0 \\
\hline${ }^{238} \mathrm{Pu}$ & $8.77 \mathrm{E}+01$ & $9.84 \mathrm{E}-03$ & 95 & 5 & 0 & 0 \\
\hline${ }^{239} \mathrm{Pu}$ & $2.41 \mathrm{E}+04$ & $9.55 \mathrm{E}+00$ & 95 & 5 & 0 & 0 \\
\hline${ }^{240} \mathrm{Pu}$ & $6.56 \mathrm{E}+03$ & $6.42 \mathrm{E}-01$ & 95 & 5 & 0 & 0 \\
\hline${ }^{241} \mathrm{Pu}$ & $1.44 \mathrm{E}+01$ & $6.63 \mathrm{E}-02$ & 95 & 5 & 0 & 0 \\
\hline${ }^{242} \mathrm{Pu}$ & $3.75 \mathrm{E}+05$ & $3.02 \mathrm{E}-03$ & 95 & 5 & 0 & 0 \\
\hline${ }^{241} \mathrm{Am}$ & $4.33 \mathrm{E}+02$ & $1.42 \mathrm{E}-02$ & 95 & 5 & 0 & 0 \\
\hline
\end{tabular}


Table C2. Volumes and porosities of zones used for initial radionuclide distribution. Some zones are considered hydrofacies with unique physical properties.

\begin{tabular}{|c|c|c|c|c|}
\hline Zone or Hydrofacies $^{\mathrm{a}}$ & $\begin{array}{c}\text { Idealized bulk } \\
\text { volume }^{\mathrm{b}}\left(\mathrm{m}^{3}\right)\end{array}$ & $\begin{array}{c}\text { Parflow bulk } \\
\text { volume }\left(\mathrm{m}^{3}\right)\end{array}$ & $\begin{array}{c}\text { NUFT bulk } \\
\text { volume }\left(\mathrm{m}^{3}\right)\end{array}$ & Porosity \\
\hline Melt glass (MG),d & 1,881 & 2,336 & 2,048 & 0.29 \\
\hline Cavity (CAV) & 8,198 & 7,744 & 8,576 & 0.32 \\
\hline Compressed (CZ) & 11,153 & 10,560 & 10,624 & 0.27 \\
\hline Upper Compressed (UCZ) & 3,607 & 3,360 & 3,648 & 0.36 \\
\hline
\end{tabular}

${ }^{a}$ The union of these four volumes comprises the exchange volume (EV) inside of which the entire glass and aqueous portions of the RST are distributed.

${ }^{\mathrm{b}}$ As reported in Appendix A.

${ }^{c}$ Because of discretization differences, the MG volume used in the NUFT model, from which the temperature history for the melt glass release function was derived, is slightly different than the MG volume in the Parflow model.

${ }^{\mathrm{d}}$ The melt glass will comprise $210 \mathrm{~m}^{3}$ of the MG zone while the remaining volume is taken up by in fallen alluvium and porosity. The melt glass volume fraction is determined by dividing $210 \mathrm{~m}^{3}$ by the appropriate MG zone volume; for the Parflow model, it results in a volume fraction of 0.0899 . 
To reduce the computational effort, radionuclides listed in Table $\mathrm{C} 1$ were simplified to a series of 13 of radionuclide classes which could be used to reconstruct the transport behavior of all RST radionuclides as a post-process (Table C3). The classes are similar in number, but not identical to those included in the unclassified CHESHIRE model. Specifically, the number of tracer classes was reduced owing to a simplification of the disturbed zone conceptual model; yet an additional Ni radionuclide class was added because of newly available sorption data (Ni was previously treated as a tracer analog). Several sorbing radionuclides are still treated as tracers $(\mathrm{Nb}, \mathrm{Pd}$, and $\mathrm{Sn}$ ) because sorption data are not available. Each radionuclide class concentration was based on the inventories listed in Table $\mathrm{C} 1$. For the two tracer classes, an inventory of $1 \mathrm{~mol}$ was used.

Table C3. Initial concentrations of 13 radionuclide classes in the aqueous phase and nuclear melt glass, as based upon the Bowen et al. (2001) inventory and the pore volumes in the discretized NUFT volumes in Table C2. Italicized radionuclides are treated as tracers primarily because sorption data are not available.

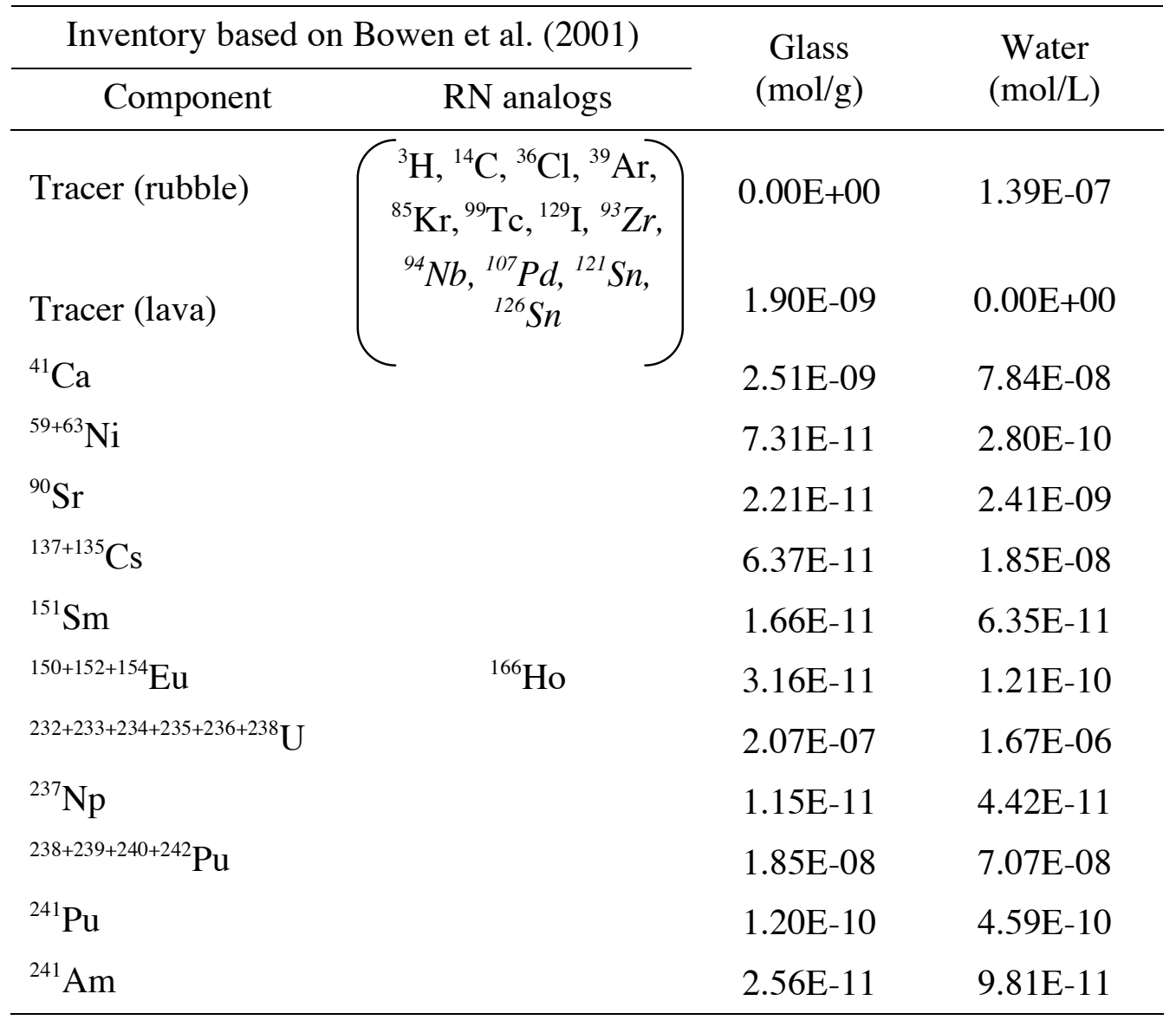




\section{Appendix D: The Glass Model}

Glasses are amorphous, thermodynamically unstable materials that tend to transform with time into more stable crystalline phases. The rate of this transformation provides a limit to the release rates of radioactive elements contained within the melt glass.

When water first contacts an alkali aluminosilicate glass such as a rhyolitic melt glass, an ion exchange process takes place that quickly depletes alkalis from the outermost few nanometers of glass surface. With time, this outer alkali-depleted hydrous surface layer thickens. For high silica glasses such as rhyolites, the hydration layer can continue to thicken over time further slowing the release rates of species from the glass. This process also restricts further water contact along narrow fractures where the hydration swelling reduces fracture permeability.

Some of the elements released from the melt glass may be incorporated into alteration phases and some may remain in solution and may be carried away in the fluid. For a silicate glass such as that generated from tuffaceous alluvium and tuffs at the NTS, reaction with groundwater will cause the formation of mainly clay and zeolite minerals. Zeolite precipitation is generally restricted to temperatures above ambient. Alteration minerals can affect the release rates of radionuclides from the melt glass through ion exchange, sorption, and precipitation reactions involving both major elements and radionuclides.

Alkali aluminosilicate glasses, such as rhyolitic glass, typically show a V-shaped $\mathrm{pH}$ dependence to their dissolution rates that has a minimum at near-neutral $\mathrm{pH}$. Figure $\mathrm{D} 1 \mathrm{presents}$ far-from-saturation dissolution rate data where the dissolution rates are not reduced by saturation effects (Mazer, 1987). These rates are therefore the maximum values at which the glass will dissolve at the given $\mathrm{pH}$ (excepting any catalytic effects such as might occur in the presence of strong complexing agents). The rate data show a progressive increase in durability (decrease in dissolution rate) as the silica content of the glass increases. For example, rhyolitic glass dissolves more slowly than basaltic glass.

Glasses exhibit a saturation effect similar to that of crystalline solids. In closed system experiments, the dissolution rate slows as species build up in solution. The dissolution rate under near-saturation conditions can be several orders of magnitude slower than the rate measured far from saturation. For silicate glasses, the saturation effect is due mainly to dissolved silica. Most other aqueous species have less effect, particularly in neutral to alkaline $\mathrm{pH}$ solutions. The saturation effect, which slows the reaction rate, is likely to be important for slowly flowing groundwater interacting with the melt glass. Slow groundwater flow rates relative to glass-water reaction rates favor a buildup of silica concentrations in solution. Furthermore, since the ambient groundwater at NTS has relatively high silica concentrations due to the dissolution of native volcanic rocks containing glass and cristobalite, initial glass dissolution rates in contact with native waters will also be affected by saturation effects. 


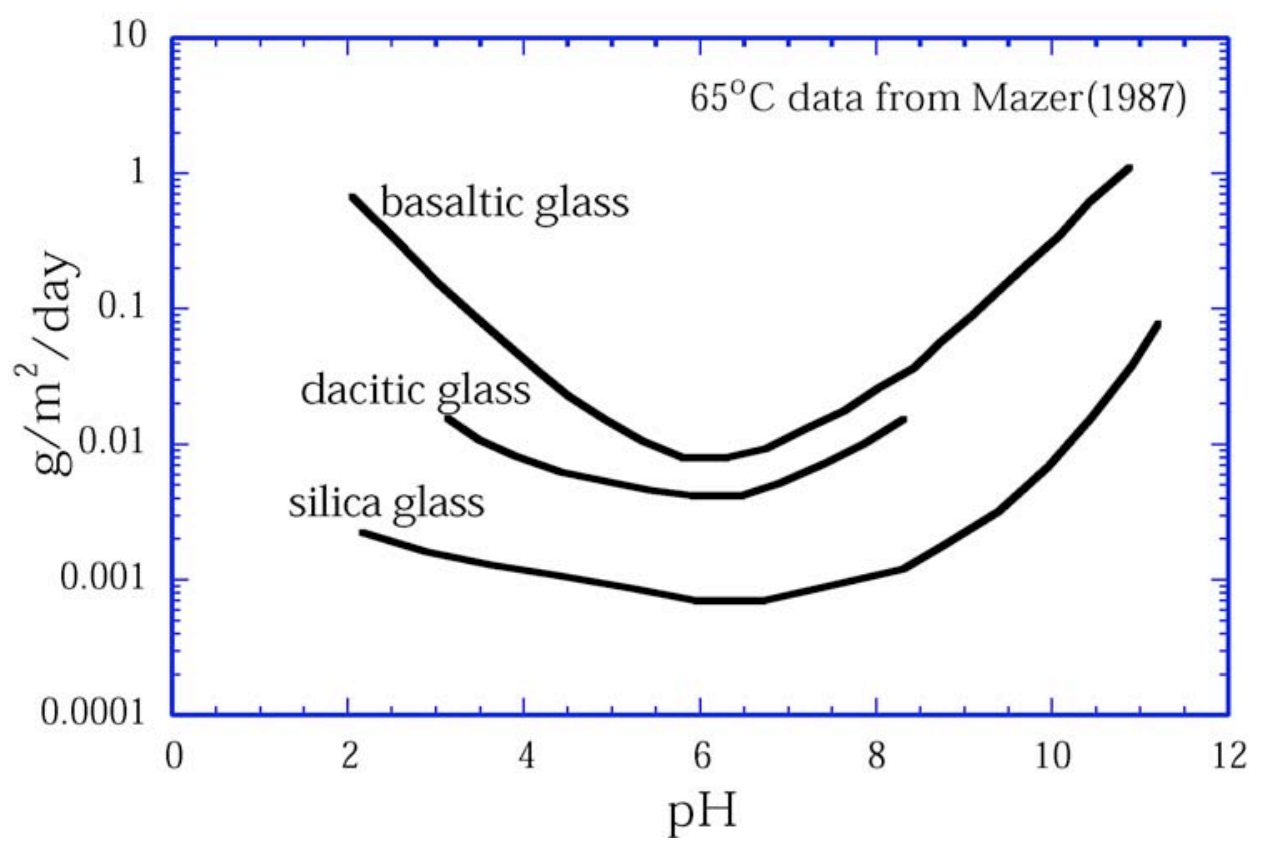

Figure D1. Dissolution rates for synthetic volcanic glasses measured at $65^{\circ} \mathrm{C}$ by Mazer (1987). These rates are for test conditions far from saturation with respect to the glass.

\section{D.1 Rate equation.}

The processes controlling the rate of glass dissolution described above are accounted for in a rate equation as follows:

$$
r=k_{0} \times e^{\frac{E_{a}}{R}\left(\frac{T-T_{0}}{T_{0} T}\right)} \times A_{s} \times \prod_{i} a_{i}^{n_{i}} \times\left(1-\left(\frac{Q}{K}\right)^{1 / \sigma}\right)^{v}+A_{s} k_{f}
$$

where $r$ is the rate of glass dissolution (mol-glass/g-glass/sec) at a specified temperature $T, A_{s}$ is the reactive surface area of the glass $\left(\mathrm{m}^{2} / \mathrm{g}\right), k_{0}$ is the rate coefficient $\left(\mathrm{mol} / \mathrm{m}^{2} / \mathrm{s}\right)$ for glass dissolution at a specified temperature $T_{o}$ (typically $25^{\circ} \mathrm{C}$ ), $E_{a}$ is the activation energy, $R$ is the gas constant, $\Pi a_{i}^{n i}$ is the product function of catalytic or inhibitive species $\left(\mathrm{H}^{+}\right.$and $\mathrm{OH}^{-}$in our model), $Q$ and $K$ are the activity product and solubility product for the glass dissolution reaction (Aagaard and Helgeson, 1982), $\sigma$ and $v$ are coefficients commonly used to fit the saturation effect, and $k_{f}$ is a term sometimes used to account for the relatively slow rate of glass dissolution close to saturation where the saturation term $(1-Q / K)$ alone is inadequate. In the following sections, we report on the values used for each of these parameters.

\section{D.1.1 Glass surface area, $A_{s}$}

One of the most critical parameters necessary for predicting radionuclide release rates from melt glass is the reactive surface area of the melt glass. This term is important because the 
reaction rate of the glass is proportional to the reactive surface area. ${ }^{1}$ Estimating the reactive surface area for melt glass is complicated by the high degree of heterogeneity of the melt glass zone. Photos taken of exploratory post-test drifts show that the melt glass zone is a breccia of rhyolite blocks (introduced during cavity collapse) that are incorporated into melt glass that is variably cracked and vesiculated (full of gas bubbles and having a texture similar to pumice). The relative proportions of massive to fractured and vesicular glass are unknown, and their distributions in space are probably chaotic.

The reactive surface area of glass is initially formed from several processes. Groundwater and other volatiles present in the subsurface at the time of the test and incorporated in the melt will tend to exsolve as the melt solidifies. This will result in vesicular zones of high porosity and comparatively high effective surface areas. However, it is not known whether these vesicular zones also have high permeability and allow flowing groundwater to contact most of the surface area, which is a measure of reactive surface area. Also, when glasses cool from the outside, thermal gradients normal to the cooling surface produce differential thermal contraction that causes cracking. Even slowly cooled meter-sized glass masses end up as composites of fist-sized glass pieces along with finer material in a three-dimensional mosaic of cracks (Baxter, 1983). A similar cracking process probably affects massive melt glass as it cools.

In the long term, reactions between the melt glass and water will give rise to hydrous alteration products. These reactions generally have a positive molar volume change and will therefore have a tendency to decrease the permeability in the zones that contain the hydrous phases. This results in an overall decrease in the fluid-accessible reactive surface area of glass. This effect has been observed in leaching studies of glasses from in situ vitrification sites (Timmons and Thompson, 1996). The above issues are difficult to address without detailed field examination and laboratory studies of melt glasses.

To provide a better estimate for reactive surface area, measurements of reactive surface areas of intact natural analog rhyolite glass cores were made (Bourcier et al., 2000). Analog samples of pumice, breccias, massive glass, and mixtures of all three textures were collected. These samples were then cored and the cores used in flow-through dissolution tests. The reactive surface area was determined by measuring the amounts of species dissolved by the fluid during passage through and reaction with the glass. Because surface area-normalized glass dissolution rate constants are known from previous work under these conditions, the integrated reactive surface area for the sample was computed from the amounts of dissolved glass constituents in the outlet fluid. The values for reactive surface area of these rhyolite samples ranged from about 0.001 to $0.0065 \mathrm{~m}^{2} / \mathrm{g}$. BET-measured surface areas of these same samples ranged from 0.019 to $0.4 \mathrm{~m}^{2} / \mathrm{g}$, between one and two orders-of-magnitude greater than measured reactive surface areas. This difference between surface area measured by BET and surface area measured from observed

\footnotetext{
${ }^{1}$ Note that the reactive surface area of glass refers to the surface area of glass alone, and not the surface areas of secondary precipitates on the glass (e.g, clays). Surface areas of crushed glass measured using BET may include the contributions of these alteration minerals that have much higher surface areas than glass. Only the surface area of glass is included in the rate. It is the dissolution of glass that releases radionuclides. Each alteration mineral is represented by its own rate equation and sorption characteristics, when appropriate.
} 
dissolution rates has been commonly observed. As a result, the reactive surface area of nuclear melt glass recommended by Bourcier et al. (2000) was between 0.001 and $0.01 \mathrm{~m}^{2} / \mathrm{g}$.

Based on observations of melt glass samples, it is believed that the natural analog samples represent the high porosity vesiculated zones of the nuclear melt glasses. However, the nuclear melt glasses are heterogeneous and also contain zones of massive glass. The reactive surface area of the massive glass is likely to be very low; it could not be measured in laboratory experiments because flow could not be established (massive glass was not permeable). Water will contact only the fractured surfaces of the massive glass. The reactive surface areas of fractured manmade glass cylinders reported by Baxter (1983) are on the order of $0.00005 \mathrm{~m}^{2} / \mathrm{g}$, which is much lower than our measured reactive surface areas for vesicular and brecciated natural glass samples. Baxter's measurements were made on glass logs $2 \mathrm{ft}$ wide and $10 \mathrm{ft}$ long. The logs fracture during cooling due to thermal gradients and dissolution along these fractures dominated the reactive surface area test.

A bulk value for reactive surface area of $0.001 \mathrm{~m}^{2} / \mathrm{g}$ was chosen for the steady state CAMBRIC model to account for the contribution of massive glass zones to reactive surface area, and to provide for the likelihood that hydrous phases will precipitate and reduce permeability. This value is identical to that used in the unclassified CHESHIRE HST simulations. The $0.001 \mathrm{~m}^{2} / \mathrm{g}$ value lies on the low end of the range of reported data for the analog samples. However, given the vessiculated nature of the analog glasses, this value is considered a fairly conservative estimate of the reactive surface area of the entire melt glass zone (that is, it does not underestimate surface area). In the lower limit, the surface area report by Baxter (1983) may be used while, at the upper limit, a value of $0.4 \mathrm{~m}^{2} / \mathrm{g}$ may be suitable. In the model, the surface area of glass was allowed to decrease linearly with the amount of glass dissolved.

\section{D.1.2 Rate coefficient $k$, product terms $a_{i}^{n i}$, and activation energy $E_{a}$}

Because the melt glass composition is similar to that for natural rhyolitic glasses, results of previous dissolution studies of natural silicate glasses (i.e. Mazer, 1987) were used to estimate the glass dissolution rate of the CAMBRIC melt glass. The effects of small amounts of contaminants, including radioactive ones with their associated radiation fields, have been shown to have negligible effects on glass dissolution rates (Bibler and Jantzen, 1987).

For the CAMBRIC melt glass, the dacite $\left(63.24 \% \mathrm{SiO}_{2}\right)$ dissolution data in Figure D1 were used to regress the value of the rate coefficient for glass dissolution (dacite $\mathrm{SiO}_{2}$ concentration is similar to that of the CAMBRIC alluvium). First, the $65{ }^{\circ} \mathrm{C}$ data for dacite glass were fit to a polynomial. Three rate constants, in combination with the product function (where $\mathrm{a}_{\mathrm{i}}$ is the activity of $\mathrm{H}^{+}$or $\mathrm{OH}^{-}$and $n_{i}$ is the fitted exponent), were fit to this polynomial (Figure D2). Specifically, the V-shaped polynomial fit to the glass dissolution rate was modeled by using the sum of three linear rates: a $\mathrm{pOH}$-dependent rate at low $\mathrm{pHs}$, a $\mathrm{pH}$-independent rate at intermediate $\mathrm{pH}$, and a $\mathrm{pH}$-dependent rate at high $\mathrm{pHs}$ (see fit in Figure 2). The combination of these linear rates accounts for the $\mathrm{pH}$ effect on the dissolution rate. 


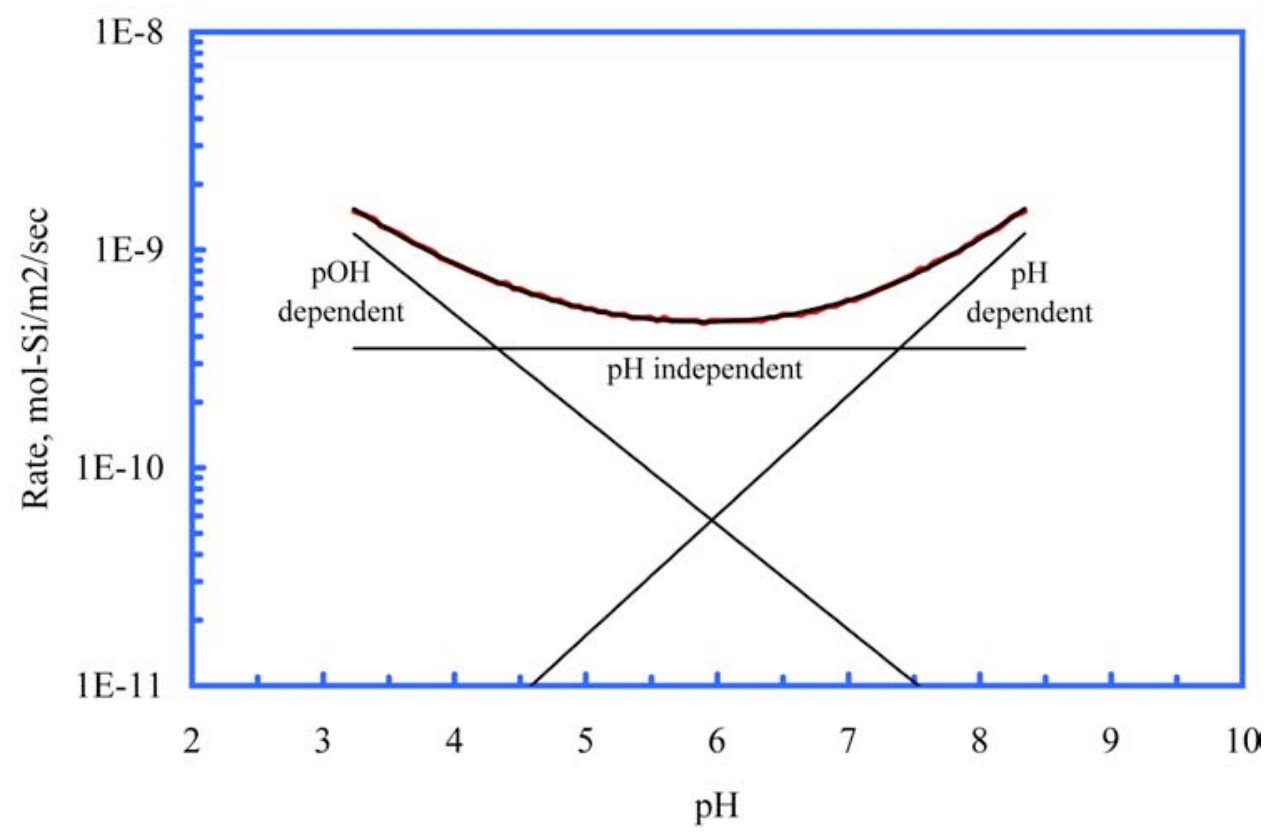

Figure D2. Fit (thick black line) to $65^{\circ} \mathrm{C}$ dacite dissolution data of Mazer (1987) (thick red line). The $\mathrm{pH}$-dependent rate is fit using a sum of three rates: a pOH-dependent rate, a pH-independent rate, and a pH-dependent rate (thin black lines). 1 mol of glass defined as 100 grams.

As suggested earlier, the durability (or the rate that glass will dissolve) is greatly affected by the silica content of the glass (Figure D1). To account for the effect of glass composition on dissolution rates, it was estimated, based on the data shown in Figure D1, that the dissolution rate (in $\mathrm{mol} \mathrm{Si} / \mathrm{m}^{2} / \mathrm{sec}$ ) decreases by $0.03 \log$ units for each $1 \%$ increase in $\mathrm{SiO}_{2}$ content. Thus, to arrive at a dissolution rate constant and $\mathrm{pH}$ dependence of glass dissolution for a glass with $65.1 \% \mathrm{SiO}_{2}$, rate constants were adjusted by $-0.056 \mathrm{log}$ units (in $\mathrm{mol} \mathrm{Si} / \mathrm{m}^{2} / \mathrm{sec}$ ).

The rate of glass dissolution is strongly dependent on temperature. The temperature dependence is controlled by the activation energy $E_{a}$. In the unclassified CHESHIRE HST model, it was conservatively assumed that the activation energy for glass (and several secondary minerals) was $20 \mathrm{kcal} / \mathrm{mol}$. Recent glass dissolution experiments suggest that the activation energy is closer to $12-15 \mathrm{kcal} / \mathrm{mol}$ (Zavarin et al., 2004b). This reduction in activation energy dramatically reduces the glass dissolution rate at high temperatures (a $>2$-order-of-magnitude decrease in dissolution rate at $150{ }^{\circ} \mathrm{C}$ ). The range of plausible activation energy is from 10 to 20 $\mathrm{kcal} / \mathrm{mol}$.

In general, the standard state in our thermodynamic database is reported at $25^{\circ} \mathrm{C}$. Thus, rate constants need to be determined at $25^{\circ} \mathrm{C}$. To determine the melt glass dissolution rate constants in their standard state, we must adjust the rate constants determined at $65^{\circ} \mathrm{C}$ by the temperature- 
dependent term. The melt glass dissolution standard state $\left(25^{\circ} \mathrm{C}\right)$ rate constants used in the CAMBRIC model are listed in Table D1. The values used in the CAMBRIC model differ from the unclassified CHESHIRE HST model. This difference is affected by three factors: adjustment of parameters from $65^{\circ} \mathrm{C}$ to $25^{\circ} \mathrm{C}$ was accomplished here (1) using an activation energy of 15 $\mathrm{kcal} / \mathrm{mol}$, (2) accounting for the changing water dissociation constant $(\mathrm{Kw})$ as a function of temperature and (3) using a $\mathrm{SiO}_{2}$ concentration consistent with XRF measurements of Frenchman Flat alluvium. The uncertainty associated with the parameters in Table D1 is difficult to assess. However, uncertainties in these parameters are likely to be lower than the range of uncertainty reported for the reactive surface area of the glass. Thus, the uncertainty associated with these parameters can likely be neglected.

Table D1. CAMBriC melt glass dissolution rate constants at standard state $\left(25^{\circ} \mathrm{C}\right)$. $\left[\mathrm{H}^{+}\right]$and $\left[\mathrm{OH}^{-}\right]$refer to the activity of these species. In low ionic strength solutions, the activity is similar to the concentration of these species in solution.

\begin{tabular}{cc}
\hline Species & Rate $\left(\text { mol-glass } / \mathrm{m}^{2}-\mathrm{sec}\right)^{*}$ \\
\hline $\mathrm{H}^{+}(\mathrm{pH}$ dependent $)$ & $1.75 \mathrm{E}-9 \times\left[\mathrm{H}^{+}\right]^{0.48}$ \\
$\mathrm{OH}^{-}(\mathrm{pOH}$ dependent $)$ & $1.60 \mathrm{E}-8 \times\left[\mathrm{OH}^{-}\right]^{0.55}$ \\
$\mathrm{pH}$ independent & $1.44 \mathrm{E}-11$ \\
\hline
\end{tabular}

* 1 mol glass is defined as 100 grams of glass.

Figure D3 illustrates the effect of both $\mathrm{pH}$ and temperature on the far-from-saturation dissolution rates of the CAMBRIC melt glass. The rates are calculated using an activation energy of $15 \mathrm{kcal} / \mathrm{mol}$. Note that the $\mathrm{V}$-shaped curves shift to the left with increasing temperature. This shift results from the change in the water dissociation as a function of temperature. For example, at $25^{\circ} \mathrm{C}$, the $\mathrm{Kw}$ of water is known to be $10^{-14}$. However, it is $\sim 10^{-15}$ at $\mathrm{O}^{\circ} \mathrm{C}$ and $\sim 10^{-13}$ at $60{ }^{\circ} \mathrm{C}$. This forces the curve to shift to the left. This was been observed in borosilicate glass dissolution experiments of Knauss et al. (1990) and is likely to occur in the case of nuclear melt glass dissolution as well. 


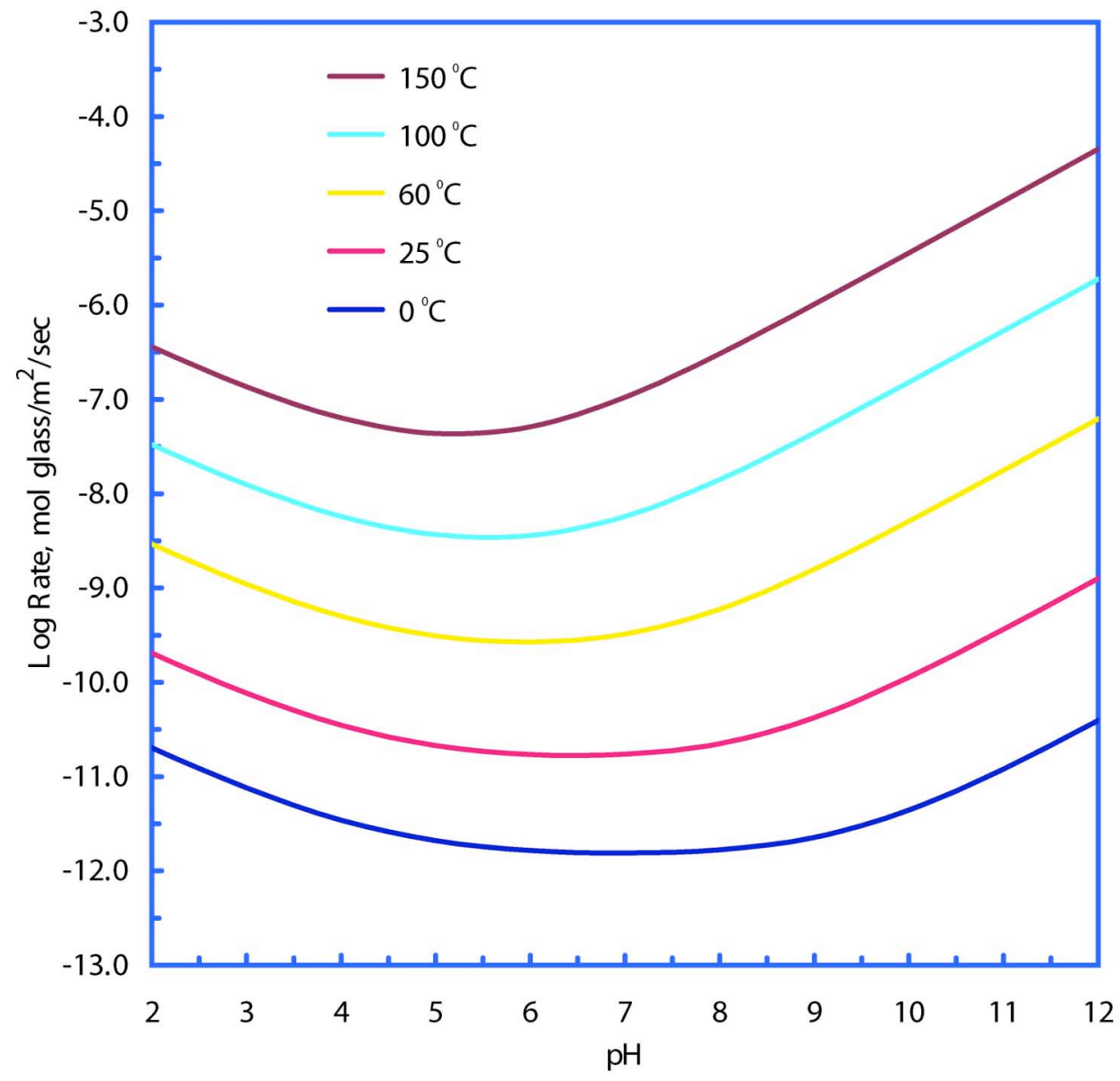

Figure D3. Far-from-saturation, surface-area-normalized dissolution rates for CAMBRIC glass as a function of temperature and $\mathrm{pH}$.

\section{D.1.3 The saturation term $\left(1-(Q / K)^{1 / \sigma}\right)^{v}$}

As mentioned earlier, the rate of glass dissolution slows as the solution approaches saturation with respect to the glass. Previous studies have shown that the primary cause of the rate decrease is the increasing concentration of dissolved silica (Grambow, 1987). Although other species may have some effect, our glass dissolution model is limited to the effect of silica because of the lack of more detailed information. This implies that for the saturation term $(1-Q / K)$ in the rate equation, the value of $Q$ is simply the concentration of dissolved $\mathrm{SiO}_{2}(\mathrm{aq})$ and $K$ is the silica concentration in solution at glass "saturation" for a particular glass composition.

The equilibrium constant $(K)$ for glasses is usually determined experimentally by measuring the silica concentration in solution under conditions when the dissolution rate of the glass slows to near zero in static (closed system) glass dissolution experiments. For silica-rich glasses such as rhyolites, values of $K$ usually lie between the values of $K$ for the silica polymorphs cristobalite and amorphous silica (Grambow, 1987). Because of the lack of available experimental data on saturation effects for melt glasses, the conservative assumption is made that $K$ is defined by 
amorphous silica. The larger the value of $K$, the larger the value of the saturation term becomes, which increases the calculated dissolution rate.

Recent glass dissolution experiments close to saturation (Zavarin et al., 2004a, b) suggest that the $\sigma$ coefficient may be as high as 100 , which leads to greatly reduced glass dissolution rates even under relatively unsaturated conditions. Values as high as 10 were previously reported (Bourcier et al., 1994). However, sufficient evidence was not available to confidently apply an exponent to the saturation term in the steady state model, particularly since this might significantly reduce the overall rate of glass dissolution. The results of Zavarin et al. (2004a, b) were only used to adjust the activation energy of reaction, as described in the previous section. However, from the standpoint of parameter uncertainty and based on these experimental data, it is reasonable to suggest a range of $\sigma$ from 1 to 100 .

\section{D.1.4 The close-to-saturation rate $\boldsymbol{k}_{\boldsymbol{f}}$}

Glasses exhibit a saturation effect similar to that of crystalline solids where the dissolution rate slows as species build up in solution. However, due to the unstable nature of glasses, dissolution is expected to continue even when solutions are at saturation with amorphous silica. The close-to-saturation rate accounts for this slow rate. Typically, this rate is several orders of magnitude slower than the dissolution rate far from saturation.

In the CAMBRIC steady state model, silica concentrations in solution were not allowed to build up to levels high enough to make the close-to-saturation rate significant. The simulations were prevented from reaching high aqueous silica concentrations for two reasons: (1) silica aqueous concentrations in Frenchman Flat are typically found close to equilibrium with $\beta$ cristobalite (below saturation with respect to amorphous silica), and (2) we chose to estimate melt glass dissolution more conservatively due to the lack of field observations suggesting high silica buildup in solution. Thus, the close-to-saturation rate of glass dissolution could be ignored

in our model. The saturation term $k_{f}$ may become more important in future simulations when our understanding of the precipitation rates of secondary minerals and evolution of groundwater composition in contact with melt glasses improves.

\section{D.2. Implementation of glass dissolution model.}

The glass dissolution model described in the previous section is being incorporated into both the transient and steady state models using the GIMRT streamline and particle codes. In the GIMRT model, the glass dissolution model can be implemented directly, using the glass dissolution rate equation and parameters described in the previous section. The particle code, however, does not explicitly provide for the complex chemical interactions such as $\mathrm{pH}$ and secondary mineral precipitation that control glass dissolution rates. Chemistry effects have to be anticipated and hardwired into this glass model. Thus, the major differences between the glass model used in GIMRT and the glass model in the particle code are that 
$>$ The $\mathrm{pH}$ and glass activity product $Q$ are allowed to vary in GIMRT.

$>$ GIMRT allows alteration minerals to precipitate and sequester elements released from glass. The precipitation of alteration minerals changes the fluid chemistry, including $\mathrm{pH}$ and $Q$, which affects the glass dissolution rate.

A temperature-dependent model is employed in the steady state model, even though the flow simulations are based upon isothermal conditions. Supplementary information regarding the implementation of the glass dissolution model in the GIMRT model will be described in a future document. Below, we describe the implementation of the glass dissolution model in the steady state particle model simulations.

\section{D.2.1 Particle model details.}

A simplified glass dissolution model is required for the particle code. As mentioned earlier, a temperature dependent model was used, based upon a simulated temperature history derived from the transient flow model. The rate of glass dissolution was developed assuming that:

$>$ The $\mathrm{SiO}_{2}$ (aq) activity in solution is controlled by the solubility of $\beta$-cristobalite at all temperatures. This controls the saturation state of the solution with respect to glass.

$>$ The $\mathrm{pH}$ of the solution is not affected by secondary mineral precipitates but is affected by temperature.

$>$ The $\mathrm{pH}$-dependent glass dissolution rate constants are identical to those developed for the GIMRT code.

$>$ An activation energy of $15 \mathrm{kcal} / \mathrm{mol}$ controls the temperature dependence of the glass dissolution rate.

This glass model is significantly different from the model used in Pawloski et al. (2001). In those simulations, the glass dissolution rate was based on a rate constant calculated at $\mathrm{pH} 8.3$ and at $25^{\circ} \mathrm{C}$ (pH 8.4 is used here to reflect ambient solution conditions). In the CAMBRIC model, the glass dissolution rate was adjusted to a $\mathrm{SiO}_{2}$ content of $65.1 \%$ instead of $78.6 \%$ to reflect the difference in silica content of the surrounding alluvium. Also, in the unclassified CHESHIRE HST, the saturation state of the solution with respect to the glass $(1-Q / K)$ was constant and based on equilibrium with $\alpha$-cristobalite at $25^{\circ} \mathrm{C}(Q)$ and the solubility of amorphous silica at $25^{\circ} \mathrm{C}$ $(K)$, resulting in a constant $1-Q / K$ of 0.48 . In the CAMBRIC model, the saturation state was defined by $\beta$-cristobalite and amorphous silica solubilities as a function of temperature. Finally, the temperature dependence of glass dissolution was a function of an activation energy of 20 $\mathrm{kcal} / \mathrm{mol}$ in the CHESHIRE model while $15 \mathrm{kcal} / \mathrm{mol}$ is used in the CAMBRIC steady state model. In addition, the CAMBRIC steady-state model allows the $\mathrm{pH}$ to vary as a function of temperature as a result of water dissociation. The improvements made to the particle glass dissolution model result in a glass model that more closely resembles the full complexity of the GIMRT model. Nevertheless, the critical effect of secondary mineral precipitation and subsequent solution 
chemistry changes on glass dissolution cannot be accounted for in the steady-state particle model.

To determine the glass dissolution rate for the particle model, the following procedure was applied. First, the rate coefficient $k$ and product terms $a_{j}^{i}$ were based on the parameters in Table $\mathrm{D} 1$. The $\mathrm{pH}$ and $\mathrm{pOH}$ terms were determined by assuming that the initial solution $\mathrm{pH}$ at $25^{\circ} \mathrm{C}$ is 8.4 and that deviations from $\mathrm{pH} 8.4$ as a function of temperature are constrained by the $\mathrm{Kw}$ of water and charge balance. Specifically, the $\log _{10} \mathrm{Kw}$ value of water as a function of temperature was fit to the following polynomial based on $\mathrm{Kw}$ data from the EQ3/6 database:

$$
\begin{aligned}
& -\log \left(\mathrm{K}_{\mathrm{w}}\right)= \\
& \quad 6.1485 \times 10^{-10} \mathrm{~T}^{4}-4.9425 \times 10^{-7} \mathrm{~T}^{3}+1.9154 \times 10^{-4} \mathrm{~T}^{2}-4.1691 \times 10^{-2} \mathrm{~T}+14.935
\end{aligned}
$$

where $\mathrm{T}$ is in degrees Celsius.

Using this function for $\mathrm{K}_{\mathrm{w}}$ and knowing that the charge imbalance between $\mathrm{H}^{+}$and $\mathrm{OH}^{-}$at 25 ${ }^{\circ} \mathrm{C}$ and $\mathrm{pH} 8.4$ is $2.48 \times 10^{-6} \mathrm{~mol} / \mathrm{L}$, the $\mathrm{pH}$ and $\mathrm{pOH}$ change as a function of temperature was predicted by the following equations:

$$
p H(T)=-\log \left(\frac{-2.48 \times 10^{-6}+\left(\left(2.48 \times 10^{-6}\right)^{2}+\left(4 K_{w}(T)\right)\right)^{1 / 2}}{2}\right)
$$

and

(D4) $\quad p O H(T)=-\log \left(K_{w}(T)\right)-p H(T)$

These values can be combined with the information of Table D1 to determine the glass dissolution rate far from saturation at a particular temperature. To determine the saturation term as a function of temperature, the solubility of $\beta$-cristobalite and amorphous silica as a function of temperature were incorporated into the $1-Q / K$ term. By fitting the solubility of these two minerals to a polynomial, the saturation term as a function of temperature is predicted by the following:

$$
1-\frac{Q(T)}{K(T)}=4.1559 \times 10^{-11} T^{4}-5.8913 \times 10^{-8} T^{3}+2.1665 \times 10^{-5} T^{2}
$$


where $\mathrm{T}$ is in degrees Celsius.

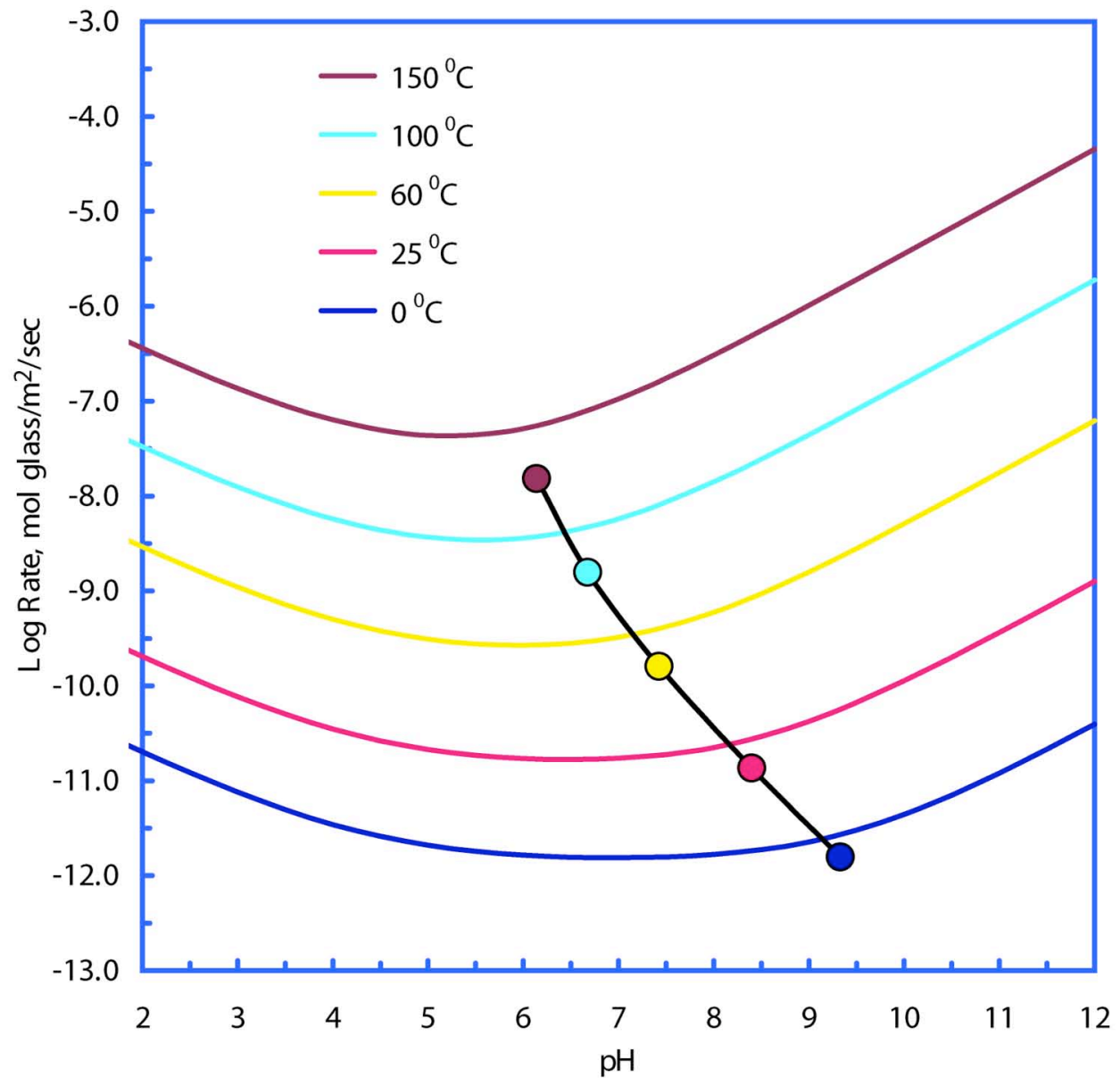

Figure D4. Far-from-saturation, surface-area-normalized dissolution rates for CAMBRIC glass as a function of temperature and $\mathrm{pH}$ (curves). Circle data points reflect the incremental change in $\mathrm{pH}$ and glass dissolution rates as a function of temperature, as incorporated in the particle model (assuming saturation with respect to $\beta$-cristobalite).

Finally, we include the activation energy of $15 \mathrm{kcal} / \mathrm{mol}$ in the temperature-dependent term. By combining the above equations and the rate constant data in Table D1, we arrive at the equation that controls glass dissolution rates in the particle code. ${ }^{2}$ In Figure D4, the resulting rate of glass dissolution as a function of temperature (data points) is compared with the far-from saturation rates (curves). In the particle code, the change in $\mathrm{pH}$ as a function of temperature is hardwired. In the GIMRT code, $\mathrm{pH}$ can be allowed to vary as a result of secondary mineral precipitation or other geochemical reactions. Similarly, the $\mathrm{SiO}_{2}(\mathrm{aq})$ activity in solution may also

\footnotetext{
${ }^{2}$ Note that the reactive surface area of glass is $0.001 \mathrm{~m}^{2} / \mathrm{g}$ in both GIMRT and particle models.
} 
vary depending on solution conditions and affect glass dissolution rates. Simply put, while the glass dissolution model in the particle model is obliged to follow the path that connects the data points in Figure D4, the GIMRT code allows the glass dissolution rate to vary, in principle, over the entire 2D space of Figure D4.

The temperature history of the glass zone, as derived from the transient flow model, and the corresponding glass dissolution rate are shown as a function of time in Figure D5. Two specific results are shown, one based upon an initial temperature of $170{ }^{\circ} \mathrm{C}$ (used here), and the other on an initial temperature of $120{ }^{\circ} \mathrm{C}$. The $170{ }^{\circ} \mathrm{C}$ result is based upon an initial temperature just below the boiling point of water when the water pressure is hydrostatic - that is, when saturated conditions exist from the melt glass to the ambient water table elevation. The $120{ }^{\circ} \mathrm{C}$ result is based upon an initial temperature just below the boiling point of water when the water pressure is below hydrostatic - that is, when saturated conditions exist from the melt glass to a point well below the ambient water table elevation, as may occur if the resaturation process is slow (possibly at other tests in Frenchman Flat).

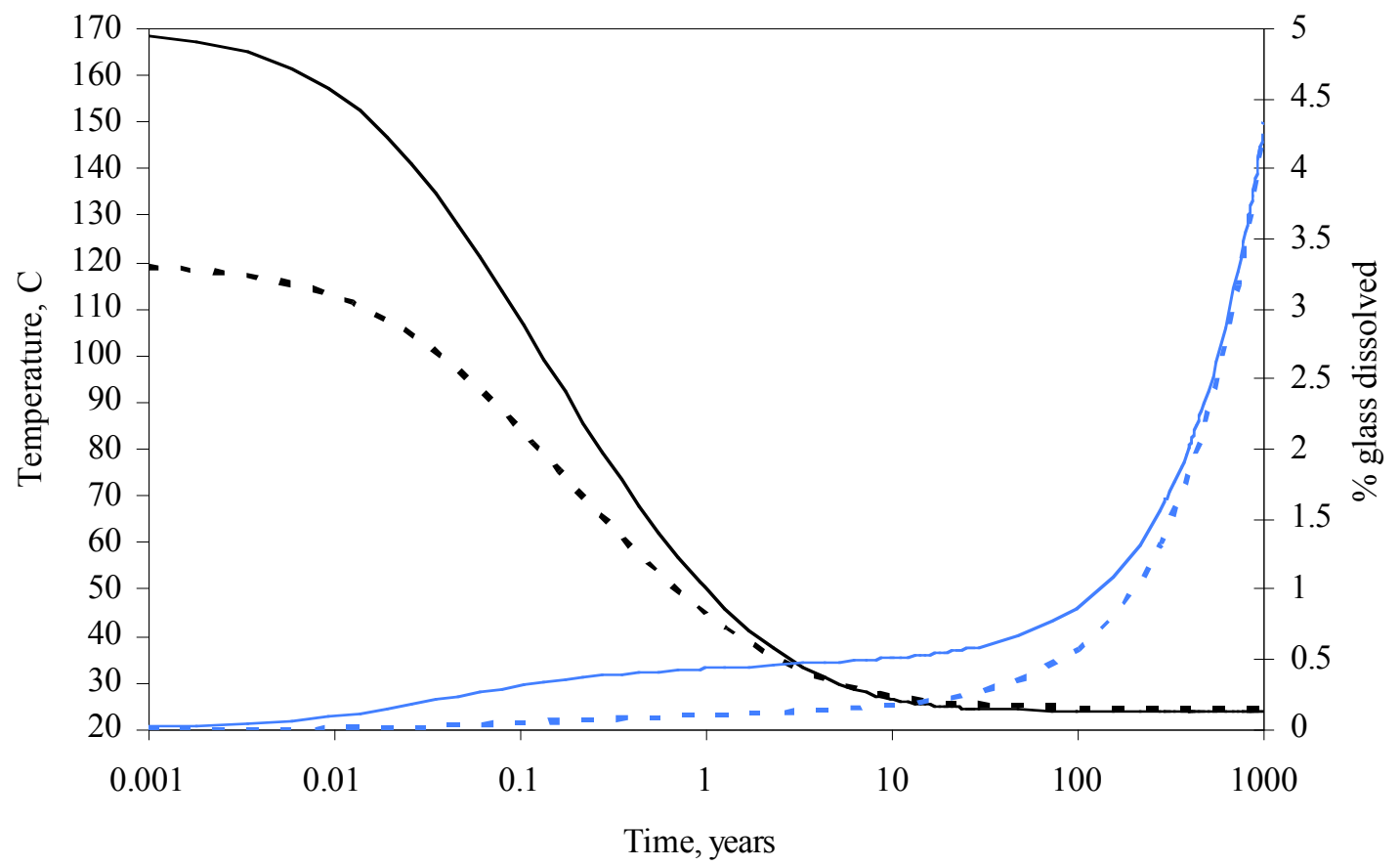

Figure D5. Mean glass zone temperature and percent glass dissolved as a function of time for the steady-state particle model. These are based upon two NUFT simulations of melt glass zone temperature history, one initialized at $\mathrm{T}=170{ }^{\circ} \mathrm{C}$ (used in the current particle model) and the other at $\mathrm{T}=120^{\circ} \mathrm{C}$ (not used here).

In either case, the initial temperature is an approximation because the glass is cooling from much hotter temperatures. The issue is really what the temperature is when saturated conditions develop in the glass zone, and different in-filling scenarios can result in different re-saturation 
histories. In this sense, the $170{ }^{\circ} \mathrm{C}$ result is the more conservative of the two. In the current model, the dissolution rates produced by either temperature profile are much higher than those expected under ambient conditions. However the spread between the $170{ }^{\circ} \mathrm{C}$ and $120^{\circ} \mathrm{C}$ results does not produce significantly different rate histories, as the dissimilarity in total glass dissolved differs by less than $0.5 \%$ after 1000 years. A separate table of these data is available. 


\section{Appendix E: The Radionuclide Retardation Model}

The radionuclide retardation model was based on the surface complexation/ion exchange modeling approach used in the unclassified CHESHIRE simulations. However, some changes to the mineral properties and additional reactions developed since the unclassified CHESHIRE model have been included in the CAMBRIC steady state model. In particular, mineral reactive surface areas for calcite and iron oxide have been reduced significantly based on recent flow-through experiments (Zavarin and Bruton, 2004). Also, the reaction of Ni radionuclides with mineral surfaces was added to our model. Details regarding the aqueous speciation constants, surface complexation constants, ion exchange constants, and mineral surface areas/cation exchange capacities will be reported in a future transient CAMBRIC modeling report. These data can be made available in spreadsheet form upon request.

The Kd values for each alluvial layer included in the steady state model were calculated based on the water chemistry near the CAMBRIC test and the detailed mineralogic analysis of alluvium from ER-5-4 reported by Warren et al. (2002). The average and standard deviation $\log _{10} \mathrm{Kd}$ (e.g., $<\mathrm{Z}>$ and $\sigma_{\mathrm{Z}}$ where $\mathrm{Z}=\log _{10} \mathrm{Kd}$ ) for each radionuclide class and each alluvial layer were determined from the geometric mean of $\mathrm{Kd}$ values calculated from all of the alluvium XRD measurements reported by Warren et al. (2002) for ER-5-4. Because XRD data were not available for layer 1 from ER-5-4, mineralogy measurements from UE-5n were used. The water chemistry used to derive radionuclide-mineral Kd values is listed in Table E1. This water chemistry was based on an average water chemistry measured in wells RNM-1, RNM-2S, and UE-5n and reported in the Phase II Frenchman Flat transport parameters data documentation package draft report. For the purpose of calculating Kds, the $\mathrm{O}_{2}(\mathrm{~g})$ fugacity was set to $10^{-20}$ bars; this ensured that the $\mathrm{Pu}$ oxidation states that dominate in the aqueous phase are $\mathrm{Pu}(\mathrm{IV})$ and $\mathrm{Pu}(\mathrm{V})$. All other radionuclides remain in their oxidized form under these conditions. Radionuclide Kds are reported in Table E2. 
Table E1. Simulated groundwater composition based on measurements near CAMBRIC.

\begin{tabular}{|c|c|c|c|c|c|c|c|c|c|c|c|c|}
\hline $\mathrm{pH}$ & $\begin{array}{c}\text { Alkalinity as } \\
\mathrm{HCO}_{3} \\
(\mathrm{mg} / \mathrm{l})\end{array}$ & $\underset{(\mathrm{mg} / \mathrm{l})}{\mathrm{Ca}}$ & $\begin{array}{c}\mathrm{Cl} \\
(\mathrm{mg} / \mathrm{l})\end{array}$ & $\underset{(\mathrm{mg} / \mathrm{l})}{\mathrm{K}}$ & $\begin{array}{c}\mathrm{Mg} \\
(\mathrm{mg} / \mathrm{l})\end{array}$ & $\begin{array}{c}\mathrm{Na} \\
(\mathrm{mg} / \mathrm{l})\end{array}$ & $\begin{array}{c}\mathrm{SO} 4 \\
(\mathrm{mg} / \mathrm{l})\end{array}$ & $\begin{array}{c}\mathrm{F} \\
(\mathrm{mg} / \mathrm{l})\end{array}$ & $\begin{array}{c}\mathrm{SiO}_{2} \\
(\mathrm{mg} / \mathrm{l})\end{array}$ & $\underset{(\mathrm{mg} / \mathrm{l})}{\mathrm{Sr}}$ & $\begin{array}{l}\mathrm{Cs} \\
\text { (ug/l) }\end{array}$ & $\begin{array}{c}\mathrm{U} \\
\text { (ug/l) }\end{array}$ \\
\hline 8.37 & $1.67 \mathrm{E}+2$ & $1.35 \mathrm{E}+1$ & $1.45 \mathrm{E}+1$ & $8.37 \mathrm{E}+0$ & $4.03 \mathrm{E}+0$ & $6.67 \mathrm{E}+1$ & $3.40 \mathrm{E}+1$ & $5.70 \mathrm{E}-1$ & $7.01 \mathrm{E}+1$ & $9.20 \mathrm{E}-2$ & $2.50 \mathrm{E}-2$ & $3.75 \mathrm{E}+0$ \\
\hline
\end{tabular}

Table E2. Mean and standard deviation $\log _{10} \mathrm{Kd}$ values for specific radionuclides in each alluvial layer or hydrofacies. Gray zones are not included in the current steady state Parflow model.

\begin{tabular}{|c|c|c|c|c|c|c|c|c|c|c|}
\hline & \multicolumn{10}{|c|}{$\log _{10} \mathrm{Kd}(\mathrm{mL} / \mathrm{g})$} \\
\hline & \multicolumn{10}{|c|}{ Layer AL1 } \\
\hline \multirow{2}{*}{$\begin{array}{l}\text { Average } \\
\text { SD }\end{array}$} & 2.0 & 4.1 & 1.8 & 2.7 & 3.6 & 3.0 & 3.4 & 0.6 & 0.3 & 1.9 \\
\hline & 0.1 & 0.3 & 0.1 & 0.3 & 0.1 & 0.0 & 0.1 & 0.2 & 0.4 & 0.1 \\
\hline & \multicolumn{10}{|c|}{ Layer AL2a, b; Chimney zones CHM2, 3} \\
\hline \multirow{3}{*}{$\begin{array}{l}\text { Average } \\
\text { SD }\end{array}$} & 2.2 & 3.8 & 1.9 & 3.1 & 3.9 & 3.2 & 3.5 & 0.6 & 0.2 & 2.0 \\
\hline & 0.1 & 0.2 & 0.1 & 0.1 & 0.1 & 0.1 & 0.2 & 0.1 & 0.1 & 0.1 \\
\hline & \multicolumn{10}{|c|}{ Layer AL3, Chimney zone CHM1 } \\
\hline Average & 2.8 & 4.1 & 2.5 & 3.0 & 3.8 & 3.1 & 3.3 & 0.4 & 0.1 & 1.9 \\
\hline \multirow[t]{2}{*}{ SD } & 0.2 & 0.1 & 0.2 & 0.1 & 0.1 & 0.1 & 0.2 & 0.1 & 0.2 & 0.1 \\
\hline & \multicolumn{10}{|c|}{ Melt Glass zone, MG } \\
\hline Average & 2.7 & 4.0 & 2.5 & 3.0 & 3.7 & 3.0 & 3.2 & 0.4 & 0.1 & 1.9 \\
\hline \multirow[t]{2}{*}{ SD } & 0.2 & 0.1 & 0.2 & 0.1 & 0.1 & 0.1 & 0.2 & 0.1 & 0.2 & 0.1 \\
\hline & \multicolumn{10}{|c|}{ Layer AL4 } \\
\hline Average & 2.7 & 4.1 & 2.5 & 3.1 & 3.9 & 3.1 & 3.3 & 0.5 & 0.2 & 2.0 \\
\hline \multirow[t]{2}{*}{ SD } & 0.1 & 0.3 & 0.1 & 0.2 & 0.2 & 0.2 & 0.3 & 0.3 & 0.2 & 0.2 \\
\hline & \multicolumn{10}{|c|}{ Layer AL5 } \\
\hline Average & 2.6 & 4.2 & 2.4 & 3.0 & 3.8 & 3.1 & 3.3 & 0.5 & 0.1 & 1.9 \\
\hline \multirow[t]{2}{*}{ SD } & 0.1 & 0.1 & 0.2 & 0.3 & 0.3 & 0.3 & 0.3 & 0.2 & 0.2 & 0.2 \\
\hline & \multicolumn{10}{|c|}{ Layer AL6 } \\
\hline Average & 2.1 & 4.0 & 1.8 & 3.1 & 3.9 & 3.2 & 3.4 & 0.5 & 0.2 & 2.0 \\
\hline \multirow[t]{2}{*}{ SD } & 0.1 & 0.1 & 0.1 & 0.1 & 0.1 & 0.1 & 0.1 & 0.1 & 0.1 & 0.1 \\
\hline & \multicolumn{10}{|c|}{ Layer AL7 } \\
\hline Average & 2.1 & 4.0 & 1.8 & 3.1 & 3.9 & 3.2 & 3.5 & 0.6 & 0.3 & 2.1 \\
\hline SD & 0.1 & 0.1 & 0.1 & 0.1 & 0.1 & 0.1 & 0.2 & 0.1 & 0.1 & 0.1 \\
\hline
\end{tabular}




\begin{tabular}{|c|c|c|c|c|c|c|c|c|c|c|}
\hline \multirow{3}{*}{$\begin{array}{l}\text { Average } \\
\text { SD }\end{array}$} & \multicolumn{10}{|c|}{ Layer AL8 } \\
\hline & 2.1 & 3.9 & 1.8 & 3.4 & 4.1 & 3.4 & 3.6 & 0.7 & 0.4 & 2.2 \\
\hline & 0.1 & 0.2 & 0.0 & 0.1 & 0.1 & 0.1 & 0.1 & 0.1 & 0.1 & 0.1 \\
\hline & \multicolumn{10}{|c|}{ Layer AL9 } \\
\hline Average & 2.3 & 3.9 & 1.9 & 3.5 & 4.3 & 3.6 & 3.9 & 1.0 & 0.5 & 2.4 \\
\hline \multirow[t]{2}{*}{ SD } & 0.3 & 0.2 & 0.3 & 0.2 & 0.2 & 0.2 & 0.3 & 0.3 & 0.2 & 0.2 \\
\hline & \multicolumn{10}{|c|}{ Layer AL10 } \\
\hline Average & 1.9 & 4.0 & 1.5 & 3.2 & 4.0 & 3.3 & 3.6 & 0.7 & 0.3 & 2.1 \\
\hline \multirow[t]{2}{*}{ SD } & 0.2 & 0.1 & 0.1 & 0.2 & 0.2 & 0.1 & 0.1 & 0.1 & 0.1 & 0.1 \\
\hline & \multicolumn{10}{|c|}{ Layer AL11 } \\
\hline \multirow[t]{2}{*}{ Average } & 2.6 & 4.0 & 2.3 & 3.1 & 3.9 & 3.2 & 3.5 & 0.6 & 0.2 & 2.0 \\
\hline & \multicolumn{10}{|c|}{ Layer AL12 } \\
\hline Average & 1.9 & 3.7 & 1.5 & 3.2 & 4.0 & 3.2 & 3.5 & 0.6 & 0.3 & 2.1 \\
\hline SD & 0.1 & 0.3 & 0.1 & 0.1 & 0.1 & 0.1 & 0.1 & 0.1 & 0.1 & 0.1 \\
\hline
\end{tabular}

